University of Tennessee Health Science Center UTHSC Digital Commons

\title{
Assessment of the Zoonotic Potential of a Novel Bovine Influenza Virus
}

\author{
Laura Evelyn Eckard \\ University of Tennessee Health Science Center
}

Follow this and additional works at: https://dc.uthsc.edu/dissertations

Part of the Animal Diseases Commons, Public Health Commons, Virus Diseases Commons, and the Viruses Commons

\section{Recommended Citation}

Eckard, Laura Evelyn, "Assessment of the Zoonotic Potential of a Novel Bovine Influenza Virus" (2016). Theses and Dissertations (ETD). Paper 388. http://dx.doi.org/10.21007/etd.cghs.2016.0405. 


\title{
Assessment of the Zoonotic Potential of a Novel Bovine Influenza Virus
}

\begin{abstract}
A novel orthomyxovirus was recently identified from pigs, with subsequent work suggesting the natural reservoir being bovine populations. The virus had genome characteristics most similar to influenza $\mathrm{C}$ viruses (ICV) but, due to the extent of sequence divergence, was proposed as a new genus, influenza D virus (IDV). Current literature on IDV has largely focused on the agricultural significance of the virus and provided evidence for the agricultural impact via observation of widespread prevalence and pathology in laboratory infected cattle. However, only one study, which identified $1.3 \%$ seroprevalence in a small cohort, has addressed the zoonotic potential of IDV to date, despite evidence that the virus can infect multiple mammalian species. Regardless of zoonotic potential, it is clear that IDV have distinct host ranges from ICV but the molecular markers responsible are not known. In this dissertation we assessed the zoonotic potential of D/swine/Oklahoma/1334/2011 (D/OK), a representative IDV, and conducted studies to investigate receptor binding specificity, temperature sensitivity of replication kinetics, and $\mathrm{pH}$ of inactivation, all factors known to affect influenza A virus (IAV) host range.
\end{abstract}

In order to better address zoonotic potential of D/OK we independently verified the high seroprevalence of $\mathrm{D} / \mathrm{OK}$ in cattle in the US and found evidence of D/OK circulation in this animal population since at least 2003. We also identified $1 \%$ seroprevalence in a cohort of older humans who lived in a rural community with likely exposure to cattle. This seropositivity rate was not, however, elevated compared to earlier studies in populations with low exposure to cattle suggesting that the responses measured were not specific. Further analysis of the seropositive sera indeed found that the IDV seroreactivity was most likely due to cross-reactivity of antibodies induced after prior ICV infection. Despite our inability to identify strong serologic support for zoonotic IDV infection, we did show that D/OK was able to replicate and transmit by direct contact in ferrets and that it replicated robustly in differentiated human respiratory cells, both of which are consistent with an ability to replicate in humans for IAV.

We next explored possible mechanisms for the differences in host range of IDV, which has multiple host species, and ICV, which infects primarily humans. Characterization of the HEF proteins of D/OK and a representative ICV demonstrated that D/OK exhibits altered receptor binding specificity and replicates at higher temperatures than ICV although it does bind receptors present in the human respiratory tract. Using virus-like particles with mutant hemagglutinin-esterase fusion (HEF) proteins, we found that the differences in receptor binding of D/OK were at least partially attributable to residues F143, W201, and F256 that line the putative receptor binding pocket. Surprisingly, we also found that, unlike other orthomyxoviruses, the replication of $\mathrm{D} / \mathrm{OK}$ was not affected by prior incubation at low $\mathrm{pH}$, raising the possibility that its replication might be $\mathrm{pH}$ independent.

Reassortment of orthomyxoviruses is a known mechanism of pandemic emergence of IAV and an informal proxy for genus distinction with viruses from distinct genera considered unable to successfully reassort. Contradictory to published data using conventional approaches we found that, using reverse genetics to force reassortment, D/OK genes could complement each of the corresponding genes from ICV and viable reassortants were produced. It is unclear, however, the biologic impact of these reassortments. The answer to this and other aspects of our work will require a resolution to the current US Governments pause on gain-of-function research. This observation does, however, bring into question the validity of classification of a new influenza genus despite IDV exhibiting the phylogenetic and antigenic divergence used to distinguish a novel genus.

Together the evidence described in this study show that D/OK is widespread in cattle and has characteristics consistent with a zoonotic potential, although we were unable to find convincing evidence for such transmission in a small cohort of humans. We did find that D/OK has many features such as host 
range, receptor usage, sensitivity to $\mathrm{pH}$, and optimal replication that are distinct from ICV and, we propose, supports its classification as a new genus with the orthomyxovirus family. Continued surveillance and investigation of host species barriers is necessary to further address the public health risk presented by this novel virus.

\section{Document Type}

Dissertation

Degree Name

Doctor of Philosophy (PhD)

\section{Program}

Biomedical Sciences

\section{Research Advisor}

Richard Webby, PhD

\section{Keywords}

bovine, emerging, influenza, $\mathrm{pH}$ inactivation, reassortment, zoonotic

\section{Subject Categories}

Animal Diseases | Diseases | Medicine and Health Sciences | Organisms | Public Health | Virus Diseases | Viruses 


\title{
Assessment of the Zoonotic Potential of a Novel Bovine Influenza Virus
}

\author{
A Dissertation \\ Presented for \\ The Graduate Studies Council \\ The University of Tennessee \\ Health Science Center
}

In Partial Fulfillment Of the Requirements for the Degree

Doctor of Philosophy

From The University of Tennessee

By

Laura Evelyn Eckard

May 2016 
Copyright (C) 2016 by Laura Evelyn Eckard. All rights reserved. 


\section{DEDICATION}

I would like to dedicate this dissertation to my parents who are my heroes and inspiration. Also, to my husband and best friend; the whole is greater than the sum of its parts. 


\section{ACKNOWLEDGEMENTS}

I would like to acknowledge Evelyn Stigger-Rosser, Jeri-Carol Crumpton, Adam Rubrum, Jennifer DeBeauchamp-Newman, Ashley Webb, and Trushar Jeevan for their technical support and advice. Stephanie Sonnberg, Atanaska Marinova-Petrova, SookSan Wong, Mark Zanin, Zeynep Kocer, Gazi Kayali, Sun-Wu Yoon, Min-Suk Song, Jeremy Jones, Mariette Ducatez, and Bryan Kaplan for their advice, discussions, and general guidance.

I thank the Webby lab as a whole for contributing to a friendly and supportive environment to work. I appreciate every member of the lab and am proud to call you all friends.

I thank the faculty members of my committee, Drs. Robert Webster, Stacey Schultz-Cherry, Michael Whitt, and Vicki Baselski, for your guidance as I pursued my doctoral degree. I sincerely appreciate the time which you invested in my education and the opportunity to learn from scientists whom I regard with so much respect.

Last, I thank my mentor Dr. Richard Webby for the opportunity to work in your lab and for your mentorship. I learned not only how to think scientifically but how to act as a leader. I have no doubt that the lessons learned in my doctoral education will benefit me for the rest of my career. 


\begin{abstract}
A novel orthomyxovirus was recently identified from pigs, with subsequent work suggesting the natural reservoir being bovine populations. The virus had genome characteristics most similar to influenza $\mathrm{C}$ viruses (ICV) but, due to the extent of sequence divergence, was proposed as a new genus, influenza D virus (IDV). Current literature on IDV has largely focused on the agricultural significance of the virus and provided evidence for the agricultural impact via observation of widespread prevalence and pathology in laboratory infected cattle. However, only one study, which identified $1.3 \%$ seroprevalence in a small cohort, has addressed the zoonotic potential of IDV to date, despite evidence that the virus can infect multiple mammalian species. Regardless of zoonotic potential, it is clear that IDV have distinct host ranges from ICV but the molecular markers responsible are not known. In this dissertation we assessed the zoonotic potential of D/swine/Oklahoma/1334/2011 (D/OK), a representative IDV, and conducted studies to investigate receptor binding specificity, temperature sensitivity of replication kinetics, and $\mathrm{pH}$ of inactivation, all factors known to affect influenza A virus (IAV) host range.
\end{abstract}

In order to better address zoonotic potential of $\mathrm{D} / \mathrm{OK}$ we independently verified the high seroprevalence of D/OK in cattle in the US and found evidence of D/OK circulation in this animal population since at least 2003. We also identified $1 \%$ seroprevalence in a cohort of older humans who lived in a rural community with likely exposure to cattle. This seropositivity rate was not, however, elevated compared to earlier studies in populations with low exposure to cattle suggesting that the responses measured were not specific. Further analysis of the seropositive sera indeed found that the IDV seroreactivity was most likely due to cross-reactivity of antibodies induced after prior ICV infection. Despite our inability to identify strong serologic support for zoonotic IDV infection, we did show that D/OK was able to replicate and transmit by direct contact in ferrets and that it replicated robustly in differentiated human respiratory cells, both of which are consistent with an ability to replicate in humans for IAV.

We next explored possible mechanisms for the differences in host range of IDV, which has multiple host species, and ICV, which infects primarily humans. Characterization of the HEF proteins of D/OK and a representative ICV demonstrated that $\mathrm{D} / \mathrm{OK}$ exhibits altered receptor binding specificity and replicates at higher temperatures than ICV although it does bind receptors present in the human respiratory tract. Using virus-like particles with mutant hemagglutinin-esterase fusion (HEF) proteins, we found that the differences in receptor binding of D/OK were at least partially attributable to residues F143, W201, and F256 that line the putative receptor binding pocket. Surprisingly, we also found that, unlike other orthomyxoviruses, the replication of $\mathrm{D} / \mathrm{OK}$ was not affected by prior incubation at low $\mathrm{pH}$, raising the possibility that its replication might be $\mathrm{pH}$ independent.

Reassortment of orthomyxoviruses is a known mechanism of pandemic emergence of IAV and an informal proxy for genus distinction with viruses from distinct 
genera considered unable to successfully reassort. Contradictory to published data using conventional approaches we found that, using reverse genetics to force reassortment, $\mathrm{D} / \mathrm{OK}$ genes could complement each of the corresponding genes from ICV and viable reassortants were produced. It is unclear, however, the biologic impact of these reassortments. The answer to this and other aspects of our work will require a resolution to the current US Governments pause on gain-of-function research. This observation does, however, bring into question the validity of classification of a new influenza genus despite IDV exhibiting the phylogenetic and antigenic divergence used to distinguish a novel genus.

Together the evidence described in this study show that $\mathrm{D} / \mathrm{OK}$ is widespread in cattle and has characteristics consistent with a zoonotic potential, although we were unable to find convincing evidence for such transmission in a small cohort of humans. We did find that $\mathrm{D} / \mathrm{OK}$ has many features such as host range, receptor usage, sensitivity to $\mathrm{pH}$, and optimal replication that are distinct from ICV and, we propose, supports its classification as a new genus with the orthomyxovirus family. Continued surveillance and investigation of host species barriers is necessary to further address the public health risk presented by this novel virus. 


\section{TABLE OF CONTENTS}

CHAPTER 1. INTRODUCTION ...................................................................................1

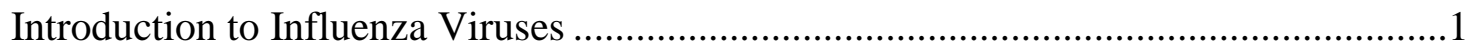

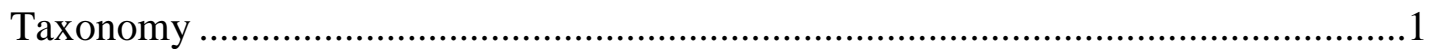

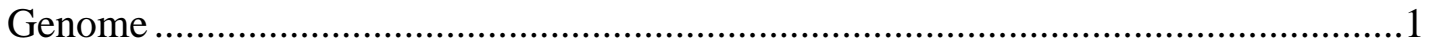

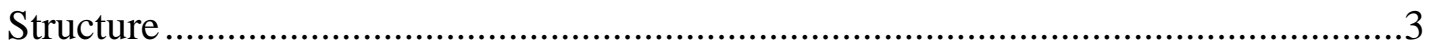

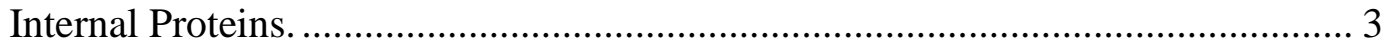

Structural Proteins and Surface Glycoproteins................................................ 5

Influenza Virus Reassortment .................................................................

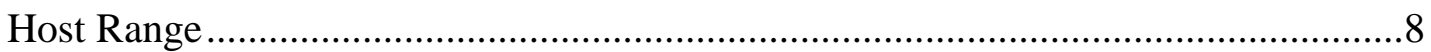

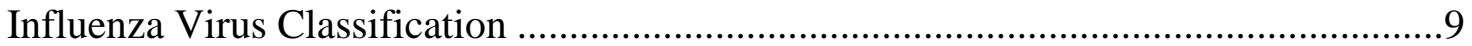

Classification Based on Antigenicity and Sequence Homology ................................9

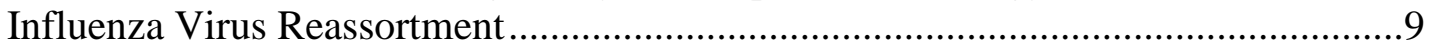

Identification of a Novel Influenza Virus ............................................................. 10

Genetic and Antigenic Characterization ............................................................ 10

The Case for Classification of Bovine Influenza as a New Genus ............................10

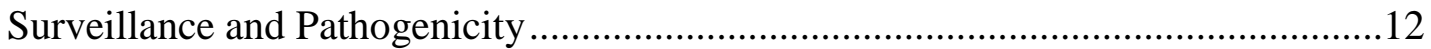

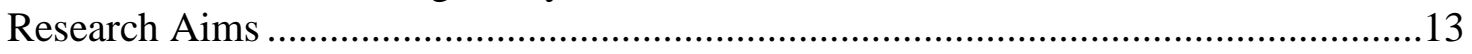

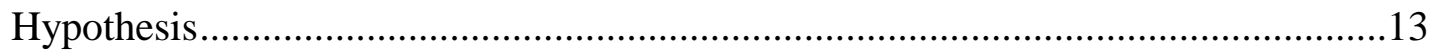

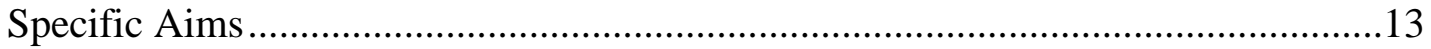

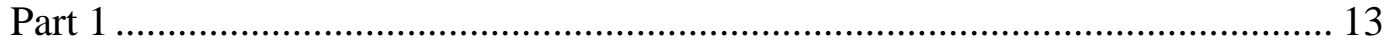

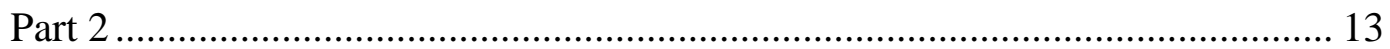

\section{CHAPTER 2. SEROLOGICAL SURVEILLANCE OF D/OK AND}

ASSESSMENT OF ZOONOTIC AND REASSORTMENT POTENTIAL...............14

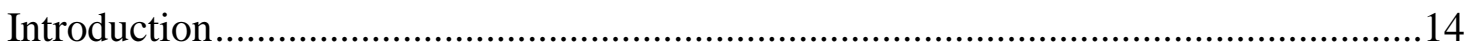

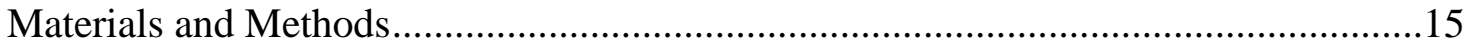

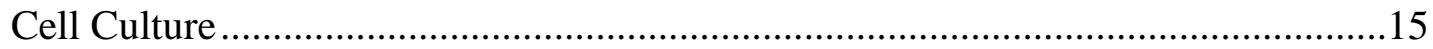

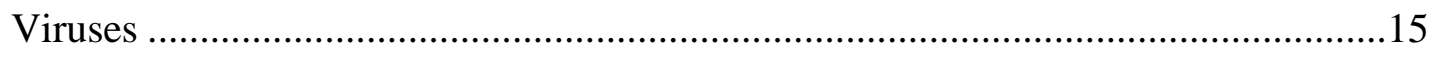

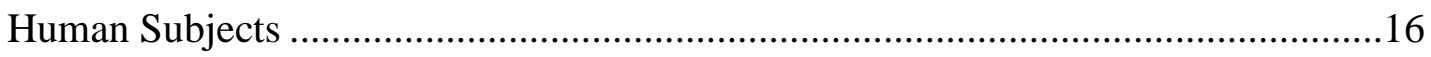

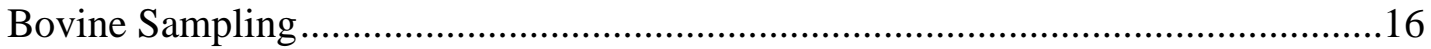

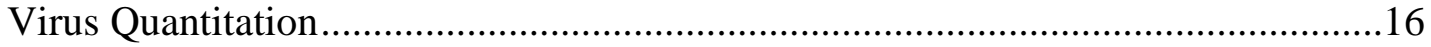

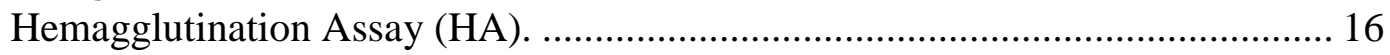

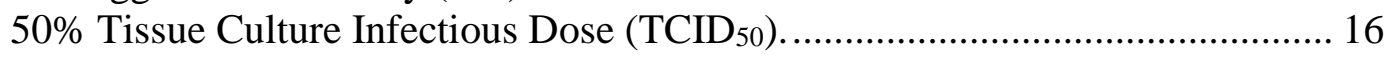

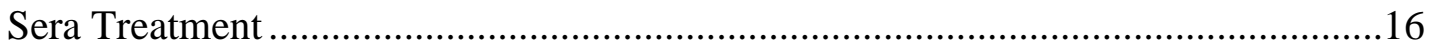

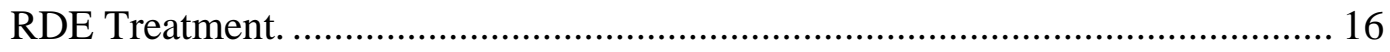

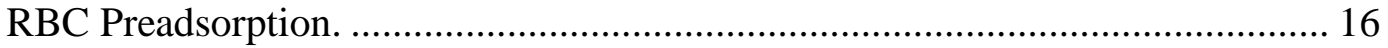

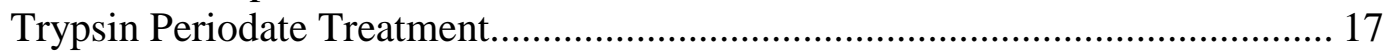

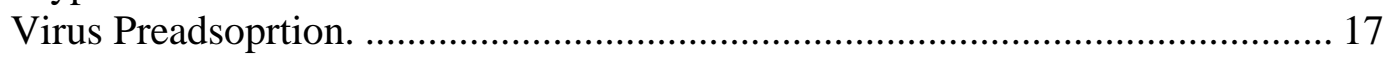

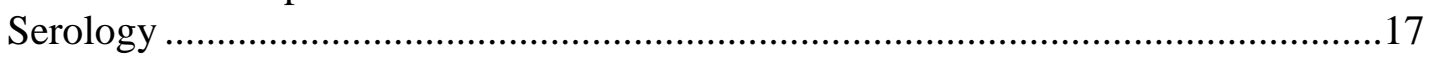

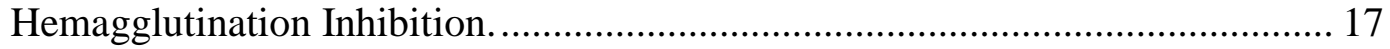

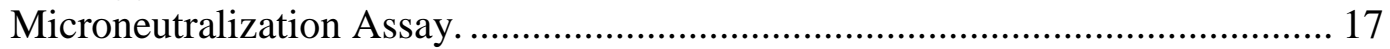

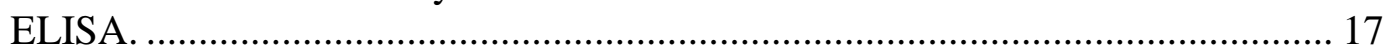

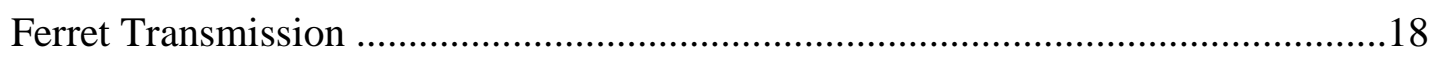


Normal Human Bronchial Epithelial Replication Kinetics........................................18

Reverse Genetics Plasmid Construction .............................................................18

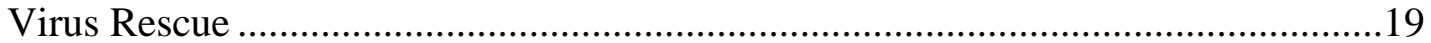

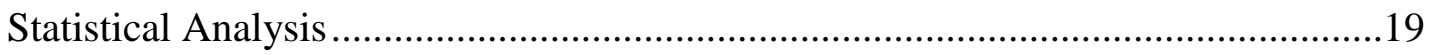

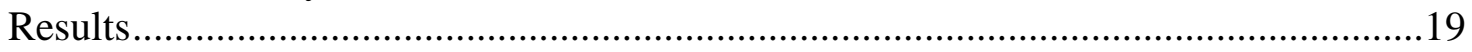

Serology of Historic Bovine Samples ................................................................19

Geographic Distribution of IDV Seroprevalence .....................................................22

D/OK Serological Surveillance in Likely Highly Exposed Individuals .....................20

Influenza C/D Virus Replication Kinetics in NHBE Cells ........................................24

Influenza C/D Virus Transmission in Ferrets ....................................................28

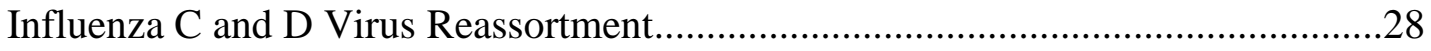

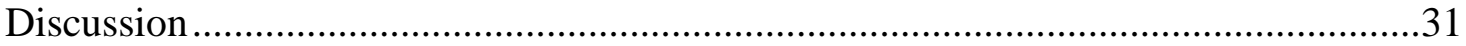

\section{CHAPTER 3. RECEPTOR TROPISM AND ESTERASE STABILITY OF IDV}

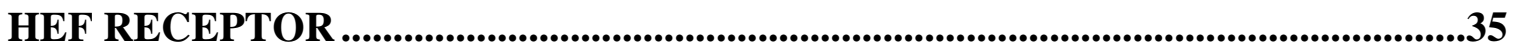

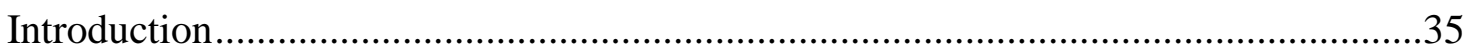

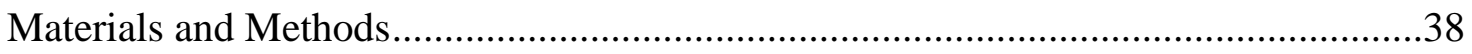

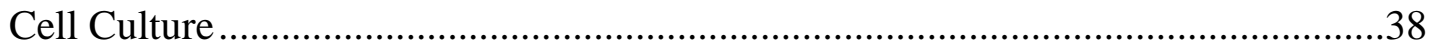

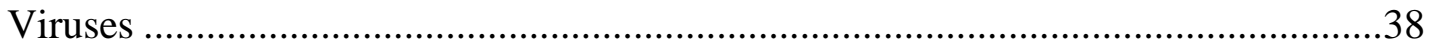

Virus Quantitation: Hemagglutination Assay ……………………...........................38

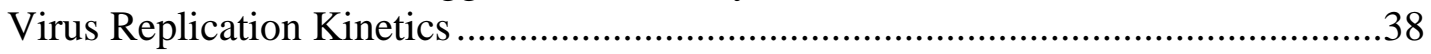

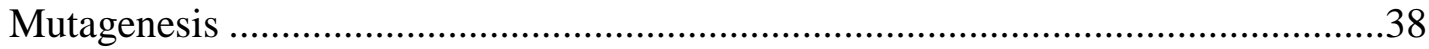

Viral-like Particle Expression .............................................................................39

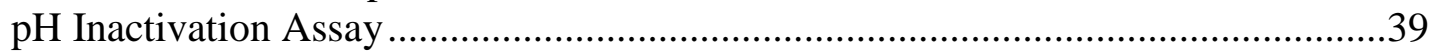

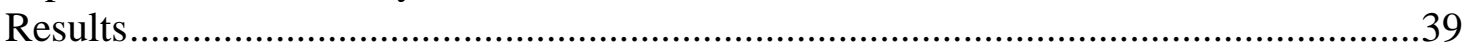

D/OK Receptor Tropism.................................................................................39

Hemagglutination Specificity Assay.................................................................... 39

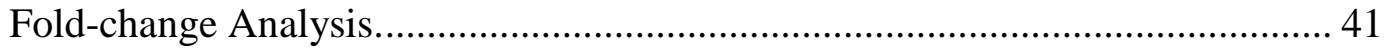

Use of VLP Instead of Virus................................................................................ 41

Optimization of Hemagglutination Assay. ............................................................. 41

HEF Mutant Strategy. ................................................................................. 43

Expression and Quantitation of Mutant HEF VLP............................................... 43

Effect of Receptor Mutations on Hemagglutination Specificity............................. 43

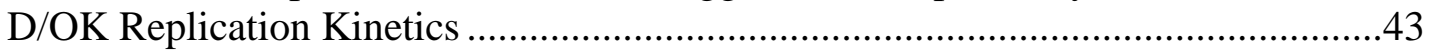

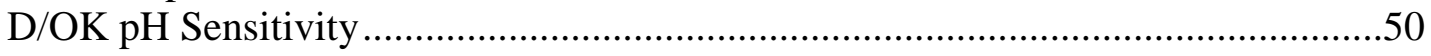

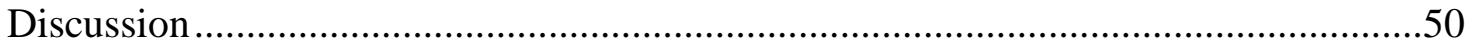

\section{CHAPTER 4. CONCLUSIONS AND FUTURE DIRECTIONS ...................................53}

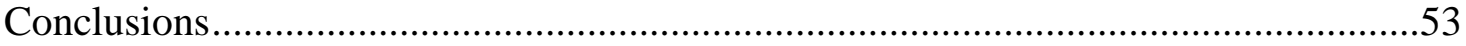

Bovine Influenza Viruses Should Be Classified as IDV ..........................................53

D/OK Is Widespread in Cattle with at Least Ten Years of Exposure Evident in the United States Population .....................................................................................54

D/OK Possesses Characteristics Generally Attributed to Zoonotic Potential and Can Reassort with ICV ..................................................................................5

D/OK May Possess Altered Host Restrictions from ICV ………...............................56

Continued IDV Assessment and Surveillance for Public Safety .................................58 


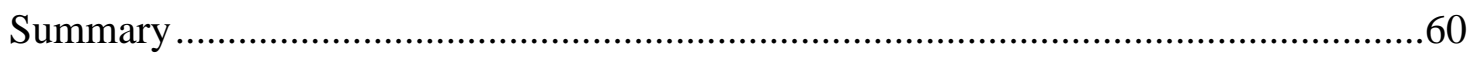

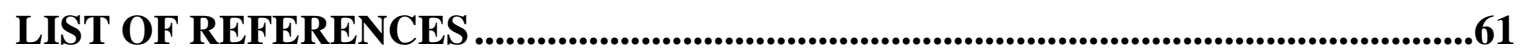

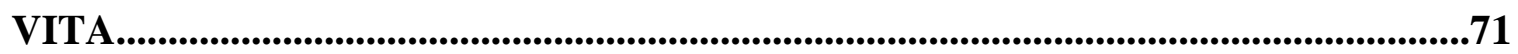




\section{LIST OF TABLES}

Table 2-1. Total bovine sera collected prior to 2003 by state...................................22

Table 2-2. Seroprevalence of IDV, per state, collected after 2003 .............................22

Table 2-3. The number of sera from individuals likely exposed to cattle which were tested for IDV antibodies by HI is listed by season.

Table 2-4. There is no statistical correlation between D/OK and C/Victoria antibody titers as assessed by HI, ELISA, or MN

Table 2-5. There is no statistical correlation between $\mathrm{HI}$ and $\mathrm{MN}$ titers for $\mathrm{D} / \mathrm{OK}$ or C/Victoria.

Table 2-6. C/Victoria cRBC pre-adsorption of eight D/OK HI-positive sera removed previous D/OK $\mathrm{HI}$ antibody titers but $\mathrm{A} /$ Brisbane $\mathrm{HI}$ antibody titers were only reduced by 2 -fold in another set of eight sera.

Table 2-7. HI cross-reactivity is not observed between IDV and ICV with polyclonal ferret sera as assessed by HI but is cross-reactive as assessed by $\mathrm{MN}$ and ELISA.

Table 2-8. ICV but not D/OK inoculated ferrets seroconverted. 30

Table 2-9. Average HA titer of rescued wild type and reassortant reverse genetics virus.

Table 3-1. IDV hemagglutination specificity differs from ICV. .40

Table 3-2. D/OK exhibits preference for horse RBC agglutination...........................42

Table 3-3. D/OK VLP do not exhibit the same HA specificity as D/OK virus. ............42

Table 3-4. Strategy of receptor binding mutations...............................................46

Table 3-5. Mutant receptor binding VLPs alter HA specificity of D/OK as compared to WT VLP and WT virus.

Table 3-6. Mutant receptor binding VLPs alter HA specificity of C/JJ as compared to WT VLP and WT virus. 


\section{LIST OF FIGURES}

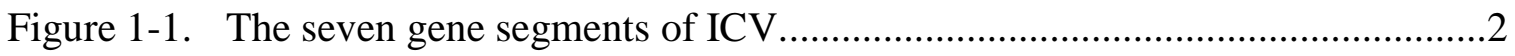

Figure 1-2. Comparison of IAV, IBC, and ICV structure .......................................

Figure 1-3. Similar overall structure of IAV HA and ICV HEF. ...............................

Figure 1-4. The phylogenetic relationship of C/OK with human ICV ........................11

Figure 2-1. D/OK-reactive antibodies as assessed by $\mathrm{HI}$ are undetected in bovine

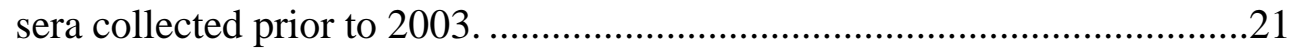

Figure 2-2. $\mathrm{D} / \mathrm{OK} \mathrm{MN}$ titers statistically correlate to $\mathrm{HI}$ titers in bovine sera. ...............21

Figure 2-3. D/OK HI titers of bovine sera using RDE treated sera are not significantly different than RDE + RBC preadsorption treated sera...........22

Figure 2-4. D/OK HI titers of bovine sera using RDE treated sera are not significantly different than trypsin periodate treated sera.

Figure 2-5. There is no statistical correlation between HI D/OK- and C/Victoriareactive antibodies from individuals from a rural farm community. 25

Figure 2-6. There is no statistical correlation of ELISA titers between D/OK- and $\mathrm{C} /$ Victoria-reactive antibodies of individuals which were D/OK HI positive.

Figure 2-7. There is no statistical correlation of MN titers between D/OK- and $\mathrm{C} /$ Victoria-reactive antibodies of individuals which were D/OK HI positive.

Figure 2-8. D/OK replicates to higher titers than human ICV in normal human bronchial epithelial cells.

Figure 2-9. $\mathrm{D} / \mathrm{OK}$ and $\mathrm{C} / \mathrm{K}$ owloon are shed by inoculated ferrets but only D/OK is shed by direct contact ferrets.

Figure 3-1. The non-homologous amino acid residues proposed to affect receptor binding specificity of D/OK HEF reside in the receptor binding and esterase domains.

Figure 3-2. Altered ligand orientation in the D/OK receptor binding site as predicted by computer modeling may contribute to altered receptor specificity.

Figure 3-3. Double and triple receptor binding mutants have increased effect on HA specificity compared to single mutants. 
Figure 3-4. D/OK replication replicates to highest titers in ST cells at $37^{\circ} \mathrm{C} \ldots \ldots \ldots \ldots \ldots . . . . .49$

Figure 3-5. D/OK infectivity is not affected by $\mathrm{pH}$ inactivation.................................51 


\section{LIST OF ABBREVIATIONS}

$\begin{array}{ll}\text { A/Brisbane } & \text { A/Brisbane/59/2007 } \\ \text { A/TN/09 } & \text { A/Tennessee/1-560/2009 } \\ \text { BPL } & \text { } \text {-Propiolactone } \\ \text { BSA } & \text { Bovine serum albumin } \\ \text { C/AA } & \text { C/Ann Arbor/1950 } \\ \text { C/JHB } & \text { C/Johannesburg/1/1966 } \\ \text { C/Kowloon } & \text { C/Kowloon/V09-2204956/2009 } \\ \text { C/OK } & \text { C/swine/Oklahoma/1334/2011 } \\ \text { C/Victoria } & \text { C/Victoria/1/2011 } \\ \text { CAT } & \text { Chloramphenicol acetyl transferase } \\ \text { cRBC } & \text { Chicken red blood cell } \\ \text { D/OK } & \text { D/swine/Oklahoma/1334/2011 } \\ \text { DMEM } & \text { Dulbecco modified Eagle's medium } \\ \text { EDTA } & \text { Ethylenediaminetetraacetic acid } \\ \text { EIA } & \text { Enzyme immunoassay } \\ \text { FBS } & \text { Fetal bovine serum } \\ \text { GMT } & \text { Geometric mean titer } \\ \text { HA } & \text { Hemagglutination assay } \\ \text { HEF } & \text { Hemagglutinin-esterase fusion protein } \\ \text { HI } & \text { Hemagglutination inhibition assay } \\ \text { HIU } & \text { Hemagglutination inhibition units } \\ \text { HRT-18G } & \text { Human rectal tumor-18G cells } \\ & \end{array}$




$\begin{array}{ll}\text { IAV } & \text { Influenza A virus } \\ \text { IBV } & \text { Influenza B virus } \\ \text { ICV } & \text { Influenza C virus } \\ \text { IDV } & \text { Influenza D virus } \\ \text { IFN } & \text { Interferon } \\ \text { M } & \text { Matrix protein } \\ \text { MDCK } & \text { Madin-Darby canine kidney cells } \\ \text { MEM } & \text { Minimum essential medium } \\ \text { MN } & \text { Microneutralization assay } \\ \text { moi } & \text { multiplicity of infection } \\ \text { NA } & \text { Neuraminidase } \\ \text { NHBE } & \text { Normal human bronchial epithelial cells } \\ \text { NK } & \text { Not known } \\ \text { NP } & \text { Nucleoprotein } \\ \text { NS } & \text { Nonstructural protein } \\ \text { P3 } & \text { Polymerase 3 } \\ \text { PA } & \text { Polymerase acidic } \\ \text { PB1 } & \text { Polymerase basic 1 } \\ \text { PB2 } & \text { Polymerase basic 2 } \\ \text { PBS } & \text { Phosphate buffered saline } \\ \text { RBST } & \text { Phosphate buffered saline with Tween } \\ \text { Red blood cell } \\ \text { Receptor destroying enzyme } \\ \text { ID }\end{array}$




$\begin{array}{ll}\text { rg-C/JJ } & \text { Reverse genetics C/JJ/1950 } \\ \text { rg-D/OK } & \text { Reverse genetics D/swine/Oklahoma/1334/2011 } \\ \text { RIA } & \text { Radio immunoassay } \\ \text { RIG-I } & \text { Retinoic-inducible gene I } \\ \text { ST } & \text { Swine testicle cells } \\ \text { TCID50 } & \text { 50\% tissue culture infectious dose } \\ \text { TPCK } & \text { L-1-(tosyl-amido-2-phenyl)ethyl chloromethyl ketone } \\ \text { VLP } & \text { Viral-like particle } \\ \text { vRNA } & \text { Viral RNA } \\ \text { vRNP } & \text { Viral ribonucleoprotein } \\ \text { WT } & \text { Wild-type } \\ \text { WT-rg } & \text { Wild-type reverse genetics } \\ \text { 293T } & \text { Human embryonic kidney 293T cells }\end{array}$




\title{
CHAPTER 1. INTRODUCTION
}

\author{
Introduction to Influenza Viruses
}

\section{Taxonomy}

Influenza viruses are included in the Orthomyxoviridae family and divided into three genera, Influenzavirus A, Influenzavirus $B$, and Influenzavirus $C$. Other genera in this family include Isavirus and Thogotovirus $(1,2)$. Influenza A viruses (IAV) can be further classified by serotype according to the two surface glycoproteins (hemagglutinin and neuraminidase) expressed. There are 18 hemagglutinin (HA) and 11 neuraminidase (NA) serotypes of IAV $(3,4)$. There is only 1 serotype for influenza $\mathrm{B}$ viruses (IBV) with two evolutionary lineages, the B/Victoria/2/87-like and $\mathrm{B} /$ Yamagata/16/88-like lineages (5). The single serotype of influenza $\mathrm{C}$ viruses (ICV) has six evolutionary lineages: C/Taylor/1233/47-like, C/Yamagata/26/81-like, C/Kanagawa/1/76-like, C/Aichi/1/81-like, C/Sao Paulo/378/82-like, and C/Mississippi/80-like lineages (6-8).

\section{Genome}

Influenza viruses are characterized by a segmented genome comprised of negative-sense, single-stranded, RNA $(1,2)$. The influenza genome is composed of 7 or 8 RNA segments which encode the template for at least 9 proteins, depending on the genus $(1,9,10)$. All influenza genera comprise the following 6 gene segments in decreasing order of gene size: the polymerase basic 2 (PB2), polymerase basic 1 (PB1), polymerase acidic or polymerase $3(\mathrm{PA} / 3)$, nucleoprotein $(\mathrm{NP})$, matrix $(\mathrm{M})$, and nonstructural (NS). In addition to the six commonly shared gene segments, IAV and IBV contain 2 segments corresponding to expression of two surface glycoproteins, HA and NA, for a total of 8 gene segments. ICV contain 7 total segments expressing only one surface glycoprotein, hemagglutinin-esterase fusion (HEF) (Figure 1-1).

Each viral RNA (vRNA) segment is comprised of a gene flanked by noncoding regions of ribonucleotides on the 3' and 5' ends of each segment, which are essential for packaging of a complete genome (11). These noncoding sequences are highly conserved and specific to each genus (9). Specific differences in the sequence and length of the noncoding region have been identified between each genus with the shortest noncoding nucleotide length found on IAV gene segments (12). The length of the noncoding region appears to regulate viral protein translation in a genus specific manner (13). Furthermore, the noncoding regions exhibit partial complementarity in sequence leading to formation of secondary panhandle structures (9). Evidence exists to support the role of these secondary structures and overall length of the noncoding region in type specificity through formation of viral ribonucleoprotein (vRNP), initiation of replication/transcription, and viral packaging $(14,15)$. 


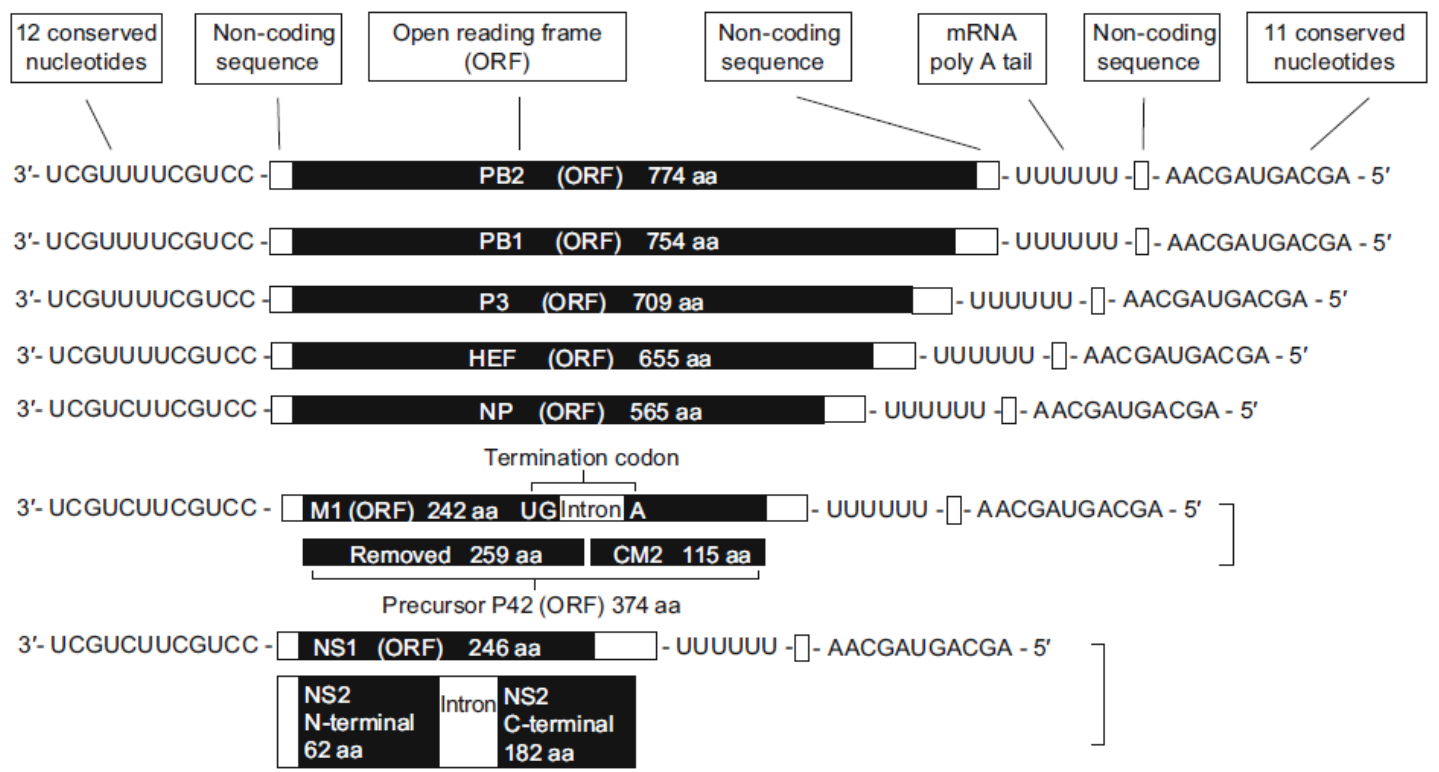

Figure 1-1. The seven gene segments of ICV.

Reprinted with permission and under the terms of the Creative Commons Attribution 4.0 International License. http://creativecommons.org/licenses/by/4.0/ Wang M, Veit M. Hemagglutinin-esterase-fusion (HEF) protein of influenza C virus. Protein Cell. 2016;7(1):28-45. Available from: "http://dx.doi.org/10.1007/s13238-015-0193-x 


\section{Structure}

Each influenza virus RNA segment is associated in a complex with the viral polymerase proteins and nucleoprotein which is referred to as the vRNP complex (1). The vRNP is packaged in a capsid composed of matrix 1 proteins (M1). The assembled capsid is further enveloped which includes an integral membrane protein, matrix 2 (M2), which functions as a proton channel, and glycoproteins which protrude from the viral envelope to facilitate efficient binding to, entry into, and budding of progeny virions from the host cell (Figure 1-2).

Internal Proteins. The proteins which comprise the vRNP include three polymerase proteins, $\mathrm{PB} 1, \mathrm{~PB} 2$, and $\mathrm{PA} / 3$, and the NP. PB1, PB2, and PA/3 are encoded by vRNA segments 2,1 , and 3 , respectively, and collectively form the viral polymerase complex which is responsible for replication and transcription of vRNA. Conserved nucleotide sequences in polymerase vRNA segments and amino acid motifs of the corresponding polymerase polypeptides suggest homologous function of each of the three polymerase subunits in IAV, IBV, and ICV (16).

The PB1 polymerase subunit serves as the structural basis for the polymerase complex through association with the $\mathrm{PA} / 3$ subunit at its $\mathrm{N}$-terminus and the $\mathrm{PB} 2$ subunit at its $\mathrm{C}$-terminus $(17,18)$. Once assembled, the polymerase complex is recruited by NP to form the vRNP. The PB1 subunit then associates with vRNA terminal ends and initiates the process of vRNA replication and transcription. The PB1 subunit contains a polymerase active site responsible for vRNA elongation during this process.

The PB2 polymerase subunit contains a PB1interaction domain for association at the PB1 C-terminus, a nuclear localization signal, and a cap-binding domain $(17,18)$. This subunit undergoes a conformational change induced by association of the PB1 protein with vRNA allowing it to recognize and bind the 5'cap on host premRNA which will then lead to "cap snatching" activity of the third polymerase subunit.

The third polymerase protein expressed by IAV and IBV is called the PA protein due to the protein's acidic pKa, 5.2 (16). The analogous protein expressed by ICV exhibits a neutral $\mathrm{pKa}, 7.2$, and is thus referred to as $\mathrm{P} 3$. The PA/3 polypeptide sequence encodes a PB1interaction domain for association with the $\mathrm{N}$-terminus of the PB1 polypeptide and an endonuclease domain $(17,18)$. The endonuclease activity of this subunit results in the "cap snatching" function of the polymerase after host premRNA 5' caps are bound by the PB2 subunit. The 5'cap is then used by the polymerase complex to initiate transcription of viral mRNA.

The three polymerase proteins comprise the complete polymerase complex which requires an additional protein, NP, to associate with vRNA. The NP protein promotes assembly of vRNP and, consequently, vRNA replication/transcription by association with the 3 ' and 5' noncoding regions of vRNA and recruitment of the 

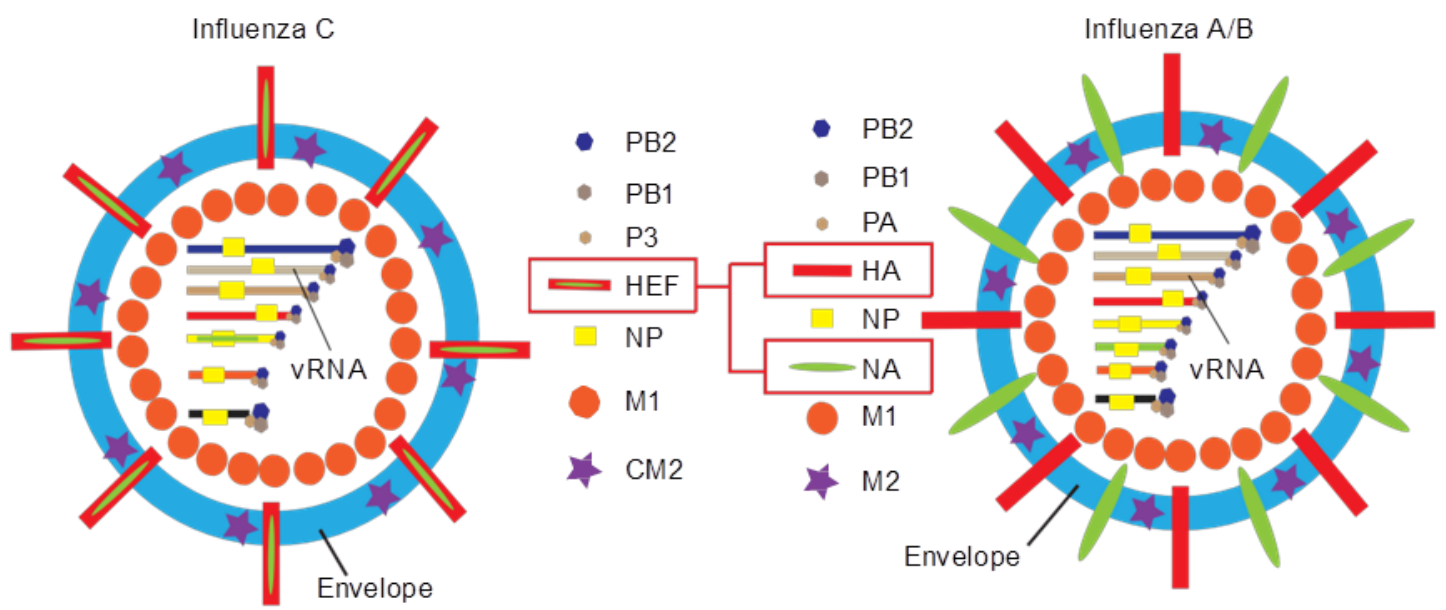

Figure 1-2. Comparison of IAV, IBC, and ICV structure.

Proteins with homologous function are represented by the same symbol.

Reprinted with permission and under the terms of the Creative Commons Attribution 4.0 International License. http://creativecommons.org/licenses/by/4.0/ Wang M, Veit M. Hemagglutinin-esterase-fusion (HEF) protein of influenza $\mathrm{C}$ virus. Protein Cell. 2016;7(1):28-45. Available from: "http://dx.doi.org/10.1007/s13238-015-0193-x 
polymerase proteins to the complex $(1,13)$. Studies of transcription/replication competence using a chloramphenicol acetyltransferase (CAT) reporter gene flanked by viral noncoding nucleotides reveal that interaction of NP and the polymerase complex is highly specific and contributes to type specificity $(12,19)$. Homologous interaction between NP and the polymerase complex is required for efficient transcription/replication of vRNA; however, the NP protein can exhibit some promiscuity of vRNA interaction, depending on the genus (19). The NP-polymerase complex of IAV is the most promiscuous, able to initiate replication/transcription of IAV, IBV and ICV RNA. The IBV polymerase complex is the most specific, able to efficiently replicate/transcribe only IBV RNA. Last, the ICV polymerase complexes efficiently utilize IBV and ICV but not IAV RNA.

The last of the internal proteins are the NS proteins, NS1 and NS2. The primary function of the NS1 protein in all three genera is to inhibit anti-viral interferon (IFN) signaling $(20,21)$. NS1 negatively regulates IFN signaling via two mechanisms: RNAdependent and RNA-independent mechanisms. The RNA-independent mechanism involves NS1 inhibition of retinoic acid-inducible gene I (RIG-I), the upstream activator of the IFN-beta promoter. NS1 c-terminal end binds RIG-I and inhibits downstream activation of the IFN-beta promoter in response to RIG-I recognition of double stranded RNA and 5'-triphosphate RNA. ICV NS1 has a unique function in this pathway from that of IAV or IBV NS1 because the n-terminal region also binds RIG-I but has a stimulatory affect, activating the downstream IFN-beta promoter (21). The purpose of this mechanism is not well understood. In the RNA-dependent pathway of all three genera, NS1 inhibits RIG-I via RNA-binding activity which allows NS1 to sequester the RNA away from RIG-I binding. The NS1 protein is not incorporated into the virion during packaging of any of the three genera (2). NS1 exhibits another type specific function in ICV; the NS1 protein up-regulates splicing of M and NS premRNA whereas the NS1 of IAV has an inhibitory action (22). The importance of this function is proposed to be in the viral replication cycle. NS1 is translated from a colinear RNA transcript whereas pre-mRNA splicing leads to creation of the NS2 transcript. In vivo quantitation of NS1 and NS2 protein levels reveal that both proteins reach maximum levels approximately 24 hours post-infection but that NS1 protein levels begin to wane earlier than NS2 levels, about 36 hours post-infection as opposed to 48 hours. Increased levels of NS1 have been proposed to contribute a positive feedback loops increasing splicing of mRNA, including NS mRNA resulting in reduced transcription of NS1 but increased production of NS2 transcripts. The NS2 polypeptide contains a nuclear export sequence and associates with the vRNP to assemble, transport to the cell cytoplasm, and virion assembly, as evidenced by its incorporation into the virion (23).

Structural Proteins and Surface Glycoproteins. The vRNP is packaged in a protective viral capsid that is composed of M1 proteins. The capsid becomes enveloped during the process of viral budding. The viral membrane contains M2 transmembrane ion channels and surface glycoproteins which are anchored to the viral membrane via a transmembrane domain and interact with M1 via the cytosolic tail. 
The M1 and M2 proteins are encoded on the approximately $1.2 \mathrm{~Kb}$, colinear viral gene segment 7 (2). IAV and IBV translate the M1 protein from unspliced mRNA. ICV uses a different coding strategy for M1, which is translated from spliced mRNA. Spliced mRNA is the primary species produced from M gene mRNA in ICV infected cells due to the proposed role of ICV NS1 in mRNA splicing upregulation $(24,25)$. The nascent mRNA has a splice site in the open reading frame which, when spliced, introduces a stop codon leading to translation of the M1 polypeptide. The M2 protein is transcribed from unspliced mRNA (26). After translation, the M2 protein undergoes glycosylation, followed by peptide cleavage to produce the final integral membrane protein.

The functions of both matrix proteins are analogous in IAV, IBV, and ICV $(2,24)$. The M1 protein is the most abundant viral protein and the primary component of the viral capsid, providing structural rigidity to and determining the morphology of the virion. It is also important in the budding process. The M2 protein is an ion channel which promotes capsid uncoating after host cell infection and budding of progeny virions. After the virion has fused with the host cell membrane and endocytosed into the host cell, the M2 ion channel allows influx of ions from the maturing endosome into the virion, causing uncoating of the viral capsid and release of the vRNA into the host cell cytoplasm. The M2 protein is also involved in incorporation of vRNPs into the budding virions and exhibits $\mathrm{pH}$ modulating activity to prevent acid inactivation of the HA during endosomal transport for some IAV and IBV $(2,27)$.

Finally, the viral surface glycoproteins are transmembrane proteins present in the viral membrane which covers the viral capsid (Figure 1-3). For IAV and IBV, the viral glycoproteins are the HA and NA whereas ICV express a single glycoprotein called the HEF. The HA of IAV and IBV facilitates host cell receptor recognition and binding and fusion of the viral and host cell membranes during infection. Neuraminic acid is the host cell receptor recognized by IAV and IBV HA proteins. The NA surface glycoprotein possesses receptor destroying enzyme function to cleave the sialic acid receptor on the host cell and enable virion budding. The HEF of ICV possesses unique properties from that of IAV and IBV receptors. Distinct from the sialidase function of the NA protein, the HEF protein possesses acetylesterase activity recognizing a 9-O acetylated sialic acid residue on the host cell membrane, as opposed to neuraminic acids in the case of the HA (10,28-31). Once bound to the host cell receptor, the virus is endocytosed and the HEF facilitates fusion between the viral envelope and host cell membrane, via a hydrophobic fusion peptide in the protein stalk, achieving entry into the cell cytoplasm. The final function of the HEF protein enables proper budding of progeny virions from the host cell. The esterase moiety cleaves the 9-O linked acetyl group from the cell receptor leaving a naked sialic acid residue on the host cell surface allowing release of progeny virions and prevention of host cell re-infection. 


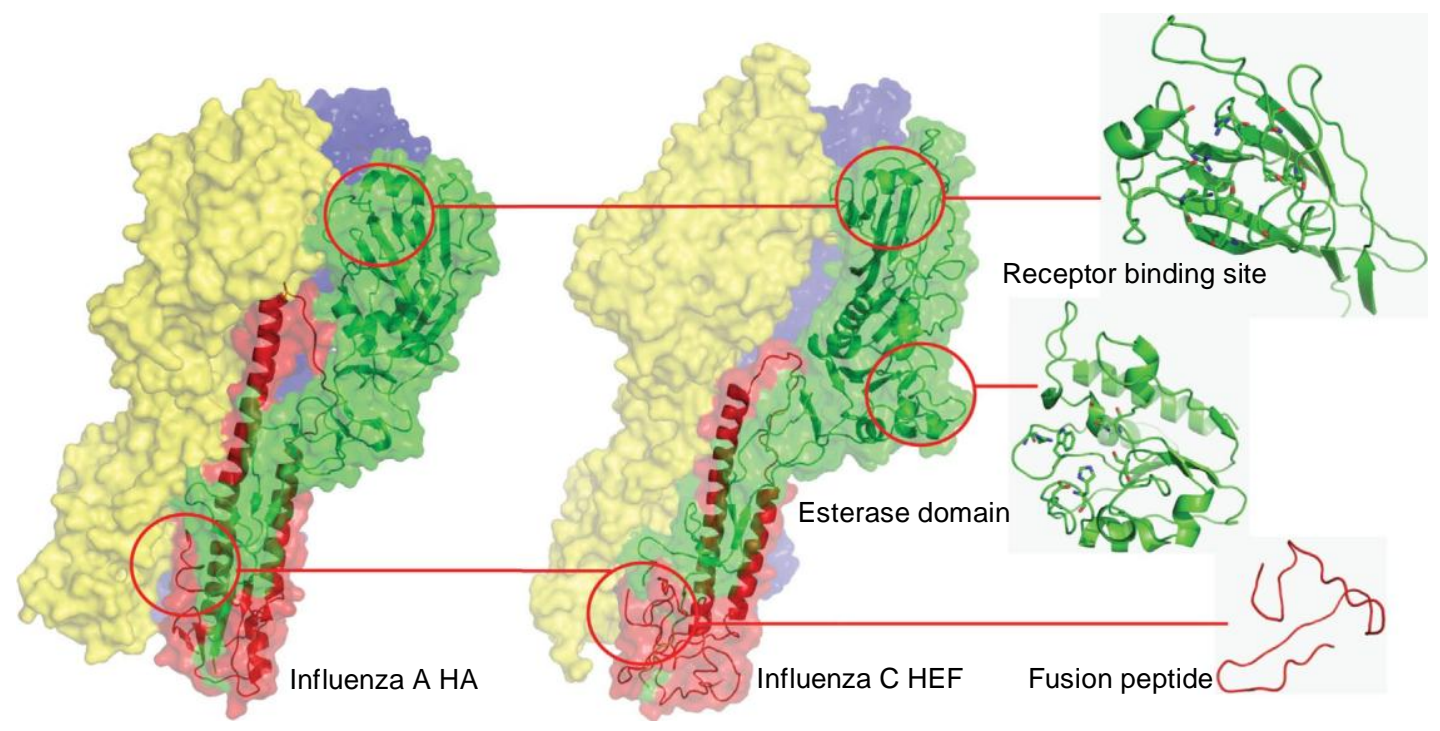

Figure 1-3. Similar overall structure of IAV HA and ICV HEF.

Reprinted with permission and under the terms of the Creative Commons Attribution 4.0 International License. http://creativecommons.org/licenses/by/4.0/ Wang M, Veit M. Hemagglutinin-esterase-fusion (HEF) protein of influenza C virus. Protein Cell. 2016;7(1):28-45. Available from: "http://dx.doi.org/10.1007/s13238-015-0193-x 


\section{Influenza Virus Reassortment}

The segmented structure of the influenza genome necessitates proper packaging of all gene segments for production of a fully infectious virion. Packaging of each gene segment is dependent upon recognition of the 3 'and 5' noncoding region of RNA by NP for formation of vRNP complexes and assembly into the virion (19). This system of genome packaging allows for reassortment of compatible viruses during coinfection of the same host cell (32). However, compatibility of the 3' and 5' noncoding regions of each gene segment between the co-infecting virus strains are required for genome packaging and reassortment $(11,15)$.

\section{Host Range}

Viruses in the genera IAV, IBV, and ICV have various host ranges but all genera include viruses that can infect humans. IAV circulate in a wide range of avian and mammalian hosts in addition to humans which includes waterfowl, terrestrial birds, swine, horse, dog, and seals (2). Furthermore, wild waterfowl are the natural reservoir for all subtypes of IAV and are thought to be the source of IAV in other animal species, making IAV the only influenza genus with an animal host reservoir. Yearly migration patterns of wild waterfowl maintain species transmission of IAV to other avian and mammalian hosts. With its large animal reservoir, distinct animal IAV can reassort with those IAV that are already human-adapted. Although the phenotype of their novel progeny is currently unpredictable, zoonotic transmission, in the case of the 1918 pandemic, and reassortment of animal influenza A viruses with distinct human-adapted influenza A viruses has yielded pandemic viral progeny in the cases of the 1957, 1968, and 2009 pandemics. IBV and ICV, on the other hand, circulate only in humans with occasional reverse zoonosis transmission of IBV to seals and ICV to pigs $(33,34)$. However, those IBV and ICV isolated from animals were of human lineage and represent sporadic reverse zoonosis, not a distinct lineage maintained in an animal host reservoir. Both genera, as a consequence of their single host reservoir in humans, have not produced pandemic reassortant progeny as observed over the past 100 years.

In humans, IAV and IBV cause seasonal outbreaks associated with mild to severe upper respiratory disease. ICV is also endemic in the human population but primarily causes mild disease in children. An estimated $60 \%$ of children are exposed to ICV by 4 years of age (35). Further, ICV is widespread in the United States where $96 \%$ of adults, 20-30 years of age, possess antibody titers against ICV (36). ICV, due to the mild presentation of their associated disease in children, are not included in clinical diagnostics of patients with influenza-like symptoms (37). This lack of investigation exists despite the high prevalence of infection by ICV in humans, as identified by a limited number serological surveys conducted, and 30\% of ICV infected infants requiring hospitalization (38). Moreover, $72 \%$ of hospitalized children exhibit more severe respiratory symptoms with high risk of complications such as influenza associated pneumonia (38-40). This evidence may suggest that ICV infection in 
children is more severe than previously reported and argues the merits of more thorough surveillance of ICV.

\section{Influenza Virus Classification}

\section{Classification Based on Antigenicity and Sequence Homology}

Taxonomic classification of influenza viruses is based, in part, upon antigenic differences of the internal proteins, M1 and NP. Although some variation of antigenic sites has been identified in the M1 and NP of IAV through analysis with monoclonal antibody panels, the two internal proteins are largely considered to be antigenically stable (41). Similar analysis of the ICV M1 and NP proteins failed to identify antigenic differences with a monoclonal antibody panel in either protein from numerous ICV isolated over a 40 year period. The internal M1 and NP proteins of ICV are considered to be more antigenically stable than IAV or IBV proteins (42).

A more recent approach to taxonomic classification has focused on gene sequencing of the M, NP, and the most conserved protein, PB1 (16). The amino acid sequence of the PB1 protein is highly conserved within genera with $90 \%$ or higher homology between IAVs. However, there is much less conservation between viruses of different genera. For example, the amino acid sequence of ICV PB1 proteins exhibit only $40 \%$ homology with IAV and IBV PB1 proteins. Furthermore, the polypeptide sequences of the M1 and NP proteins share $>85 \%$ intragenic homology but less, $\sim 30 \%$, intergenic homology (43).

IAV are further classified by subtype, which is determined by the viral surface glycoproteins expressed by each strain. The multiple animal hosts of IAV in combination with evolutionary pressure applied by host immune systems have led to evolution of multiple subtypes of the surface glycoproteins. The HA and NA exhibit approximately $49 \%$ and $50 \%$ homology between IAV subtypes, respectively (44). IBV and ICV lack multiple host species and do not exhibit multiple subtypes. The homology between the single IBV HA and NA and IAV HA and NA subtypes share $25 \%$ and $30 \%$ identity, respectively.

\section{Influenza Virus Reassortment}

Reassortment compatibility is determined, in part, by the length of and the secondary structure formed by the terminal noncoding regions of influenza RNA segments. These noncoding regions are highly conserved on the 3' and 5' terminal ends of each RNA segment and reassortment occurs frequently between strains of compatible type. Reassortment between influenza virus strains of different genera has not been observed in nature. 


\section{Identification of a Novel Influenza Virus}

\section{Genetic and Antigenic Characterization}

In 2011, Newport Laboratories (a livestock diagnostic laboratory in Worthington, MN) isolated a virus from a clinically sick pig in Oklahoma (43). A novel influenza $\mathrm{C}$-like virus was identified based upon phylogenetic and functional analysis and was designated C/swine/Oklahoma/1334/2011 (C/OK). The novel virus genome shared only $50 \%$ identity with previously described ICV although C/OK contains 7 RNA segments, all of which align with the RNA segments of human ICV (Figure 1-4). Additionally, the HEF protein demonstrated esterase function but not neuraminidase activity. C/OK was found to be antigenically distinct from human ICV by hemagglutination inhibition and agarose gel immunodiffusion assay $(43,45)$. Further, efforts to assess reassortment of $\mathrm{C} / \mathrm{OK}$ with human-adapted ICV failed to identify reassortant progeny after in vitro co-infection between the two viruses.

The finding that $\mathrm{C} / \mathrm{OK}$ was phylogenetically and antigenically distinct from human ICV evoked suggestions that it may represent a novel ICV subtype or a new genus $(43,45)$.

\section{The Case for Classification of Bovine Influenza as a New Genus}

$\mathrm{C} / \mathrm{OK}$ was classified as an ICV upon initial evaluation based upon presence of seven RNA segments which aligned most closely to ICV genes in phylogenetic analysis, including the HEF gene, and detection of esterase but not neuraminidase activity (43). However, overall sequence similarity of the C/OK genome was only $50 \%$ to that of human ICV. Furthermore, the HEF polypeptide of C/OK exhibited similar sequence identity to the HEF of human ICV as the HA of IAV subtypes. This evidence suggested that antigenic characterization of $\mathrm{C} / \mathrm{OK}$ should be conducted to evaluate $\mathrm{C} / \mathrm{OK}$ for classification as a novel ICV subtype or new genus.

The antigenic relationship of C/OK to IAV, IBV, and ICV was addressed by hemagglutination inhibition and agarose gel immunodiffusion assay using polyclonal ferret antibodies generated against viruses of each genus. Two human ICV strains were included in the analysis and, although antigenically distinct from IAV and IBV, were antigenically indistinct from each other. Conversely, $\mathrm{C} / \mathrm{OK}$ was antigenically distinct from all IAV, IBV, and ICV strains tested by these assays. C/OK antigenicity was not assessed in the context of taxonomic classification, by anti-M1 or anti-NP monoclonal antibodies, however, sequence analysis of C/OK M1, and NP proteins does predict antigenic distinctions.

The nucleotide sequences of the M and NP genes were used to predict the amino acid sequence of the translated polypeptides, based upon homologous ICV protein sequences. The $\mathrm{M}$ gene, due to unpredictability of post-translational splicing sites in the M gene polypeptide, the nascent polypeptide sequence, called p42, was 

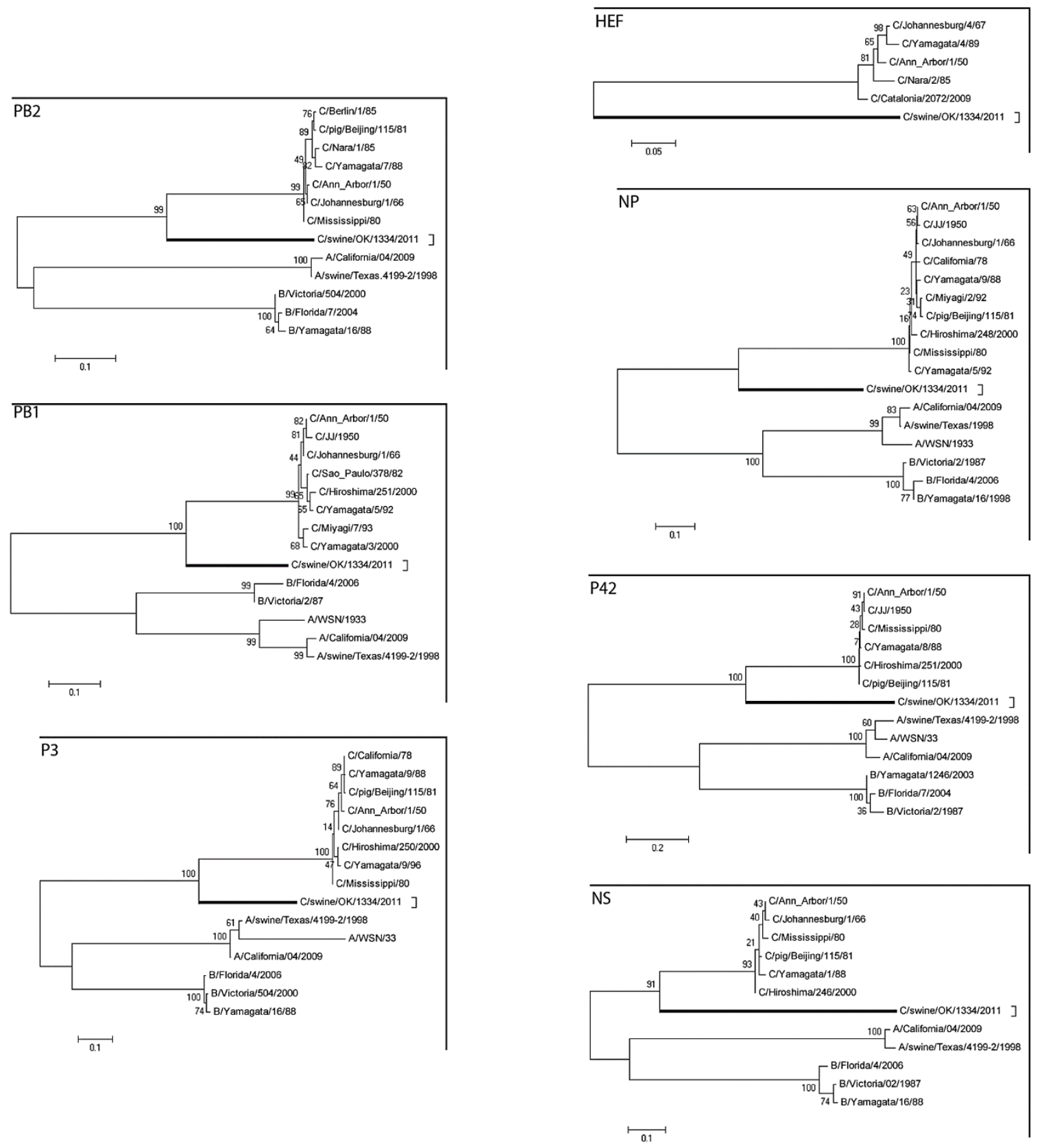

Figure 1-4. The phylogenetic relationship of C/OK with human ICV.

Reprinted with permission and under the terms of the Creative Commons Attribution Non-Commercial License. Hause BM, Ducatez M, Collin EA, Ran Z, Liu R, Sheng Z, et al. (2013) Isolation of a Novel Swine Influenza Virus from Oklahoma in 2011 Which Is Distantly Related to Human Influenza C Viruses. PLoS Pathog 9(2): e1003176. doi:10.1371/journal.ppat.1003176 
used for comparison of amino acid sequences. The maximum sequence identity of C/OK p42 and NP polypeptides to homologous ICV proteins were $38 \%$ and $39 \%$, respectively; both demonstrating similar intergenic divergence as seen between ICV and IAV. Furthermore, analysis of the most conserved influenza protein, PB1, determined that the $\mathrm{C} / \mathrm{OK}$ protein shared a maximum of $72 \%$ identity with the ICV PB1, higher than the $61 \%$ intergenic homology of IAV and IBV PB1 but lower than the $90 \%$ intragenic homology of IAV strains.

Despite the low overall sequence similarity of $\mathrm{C} / \mathrm{OK}$ to ICV, the 3' and 5' noncoding regions of the vRNA segments differ by only one nucleotide each. Previous mutagenesis studies whose results suggest that influenza type compatibility is largely determined by noncoding region length and formation of secondary structures for association with NP would predict that a single nucleotide difference would not lend to segment incompatibility. Even so, ICV failed to produce reassortant progeny with either of two ICV strains after co-infection in cell culture suggesting type incompatibility of the two viruses.

$\mathrm{C} / \mathrm{OK}$ demonstrates the extent of phylogenic and antigenic differences seen between IAV, IBV, and ICV genera and noncoding RNA incompatibility with ICV. It has been proposed that $\mathrm{C} / \mathrm{OK}$, and related influenza strains, should be classified as a novel genus titled influenza D virus (IDV) $(43,45)$. We will refer to C/OK, heretofore, as $\mathrm{D} / \mathrm{OK}$.

\section{Surveillance and Pathogenicity}

Sero-surveillance of American swine and cattle identified antibodies reacting with D/OK in approximately $9.5 \%$ of pigs and up to $90 \%$ of cattle $(43,45,46)$, with detection of D/OK vRNA in $18 \%$ of cattle by reverse transcription-realtime PCR analysis. However, only $1.3 \%$ seroprevalence was identified in a human cohort of 316 individuals (43) Domestic sheep and goats have been identified as possible hosts as well (47). Cattle are now believed to be the major reservoir for this virus due to high seroprevalence in the United States and the evolution of two phylogenetically and antigenically distinct clades represented by, provisionally named, D/OK and D/bovine/Oklahoma/660/2013 (45,48,49). Evidence of D/OK-like bovine viruses have been reported in China, France, and Italy, as well (50-52).

Initial characterization of the pathogenicity of IDV found that it was transmissible by direct contact but not aerosol droplet contact in experimentally infected pigs, ferrets, and guinea pigs $(43,53)$. All inoculated pigs, ferrets and guinea pigs seroconverted. All direct contact ferrets and guinea pigs and some direct contact swine seroconverted. No animals exhibited clinical signs. A unique observation of the guinea pig model was evidence of IDV replication in upper and lower respiratory tracts, as opposed to only upper respiratory tract of pigs and ferrets. Last, the agricultural impact of $\mathrm{D} / \mathrm{OK}$ was demonstrated by findings of direct contact transmission in cattle with mild respiratory signs and some disease pathology (54). 


\section{Research Aims}

A novel influenza virus was isolated in 2011 from swine exhibiting clinical respiratory symptoms and was later determined to represent a novel genus of swine and bovine influenza viruses, IDV. Although low seroprevalence was found in a small cohort of 316 individuals, IDV can cross species barriers. However, current literature has primarily focused on prevalence in cattle and the agricultural impact of IDV and lacks investigation of zoonotic potential in order to address potential impact on public health as well.

In this study, we proposed a range of experimental approaches to assess the potential public health risk posed by IDV. We investigated prevalence of D/OK-related viruses in cattle and humans in the United States and provide evidence of zoonotic and reassortment potential. Further, we examined multiple mechanisms which could impact IDV host species restrictions and confer altered host range compared to human ICV.

\section{Hypothesis}

IDV is widespread in cattle in the US and may infect humans based upon serosurveillance in a small human cohort and a ferret transmission study. We hypothesize that IDV, although distinct from ICV in many properties, represents a newly identified source of zoonotic infection.

To build upon preliminary research, we propose the following specific aims.

\section{Specific Aims}

Part 1. Investigate zoonotic potential of D/swine/Oklahoma/1334/2011 including prevalence in cattle and evidence of human infections.

Part 2. Evaluate the host range and receptor tropism of D/swine/Oklahoma/1334/2011 and a human-adapted influenza C virus. 


\section{CHAPTER 2. SEROLOGICAL SURVEILLANCE OF D/OK AND ASSESSMENT OF ZOONOTIC AND REASSORTMENT POTENTIAL}

\section{Introduction}

Current data concerning D/OK strongly supports a model where IDV is a virus of ruminants with high prevalence in cattle in the United States as well as France, Italy, and China (50-52). Transmission by direct contact of IDV in cattle and seroprevalence in adolescent cattle in Mississippi feedlots demonstrates a clear agricultural impact of IDV in that species (54). Furthermore, IDV can cross species barriers into swine and the potential for agricultural impact in swine and other agricultural animal species exists.

The primary focus of $\mathrm{D} / \mathrm{OK}$ studies have been concerned with the agricultural relevance of the virus and, despite widespread prevalence in American cattle and evidence of transmission between animal species, the potential for zoonotic infection is unclear. Supporting a zoonotic potential of IDV were previously published data from a seroprevalence study amongst a small number of individuals from the general population in Canada and the United States (44). In this study an IDV seroprevalence of $1.3 \%$ was detected. This level of seroprevalence in members of the general population suggests that IDV infection is not uncommon which is difficult to reconcile with the virus never being identified in humans. It is also unclear, despite lack of cross reactivity with post-infection ferret antiserum, whether prior repeated exposure to ICV could result in antibodies able to cross react with IDV. With these caveats and lack of data present, we sought to provide a more robust determination of the serologic and biologic evidence for a zoonotic threat from IDV, specifically D/OK.

We approached this task by providing a more robust temporal and spatial evaluation of IDV serology in bovine populations and by examining evidence for IDV exposure in a cohort of individuals with elevated contact with dairy cattle. We hypothesized that, should IDV infect humans, this population would have elevated seroprevalence levels. In order to better interpret these data we also utilized multiple assays and sought to determine true levels of ICV and IDV cross reactivity in human sera. We also investigated IDV replication in models that have been used to assess pandemic risk in IAV, namely, ferret transmission and in vitro replication in human respiratory epithelial cells. Lastly, as reassortment between IAV viruses has been associated with phenotypic changes and host shifts, we investigated the compatibility of IDV and ICV gene segments in reverse genetics based reassortment studies. We find that while evidence for human infection with IDV is limited, the virus has a number of traits consistent with that of a virus with an inherent zoonotic risk. 


\section{Materials and Methods}

\section{Cell Culture}

Swine testicle (ST), human embryonic kidney 293T (293T), and Madin-Darby Canine Kidney (MDCK) cells were obtained from the American Type Culture Collection (Manassas, VA). ST and 293T cells were maintained in Dulbecco modified Eagle's medium (DMEM; Invitrogen Corporation, Grand Island, NY) and minimum essential medium (MEM; Corning, Manassas, VA) respectively, supplemented with 5\% fetal bovine serum (FBS; HyClone, Logan, UT) and antibiotics-antimycotic (Sigma, St. Louis, $\mathrm{MO} ; 100 \mathrm{U} / \mathrm{ml}$ penicillin, $100 \mu \mathrm{g}$ streptomycin, and $0.25 \mu \mathrm{g}$ amphomycin per $\mathrm{ml}$ ). MDCK cells were maintained in MEM supplemented with 5\% FBS, 1x MEM vitamin solution (Invitrogen Corporation, Grand Island, NY), 200mM L-Glutamine (Invitrogen Corporation, Grand Island, NY) and antibiotics-antimycotics. Normal human bronchial epithelial (NHBE) cells were purchased from MatTek Corporation (EpiAirway AIR-100; Bratislava, Slovak Republic) in 6 well, trans-well tissue culture plates which had been differentiated for 28 days at the air-liquid interface. Upon arrival, cells were maintained for three days prior to virus infection with AIR 100 complete growth media (MatTek, Bratislava, Slovak Republic) according to manufacturer's instructions. All cell culture was incubated at $37^{\circ} \mathrm{C}$ and $5 \% \mathrm{CO}_{2}$.

\section{Viruses}

Viruses used in this study D/swine/Oklahoma/1334/2011 (D/OK), C/Victoria/1/2011 (C/Victoria), C/Kowloon/V09-2204956/2009 (C/Kowloon), and reverse genetics rescue virus C/JJ/1950 (rg-C/JJ) were provided by: Newport Laboratory (Worthington, MN), Ian Barr (World Health Organization Collaborating Centre for Reference and Research on Influenza, Melbourne, Australia), Janice Lo (Department of Health, Hong Kong Special Administrative Region, China), and Reinhard Vlasak (University of Salzburg, Salzburg, Austria), respectively. D/OK virus stocks were clarified from supernatant of infected ST cells replicated in the presence of $0.1 \mu \mathrm{g} / \mathrm{ml}$ of L-1-(tosyl-amido-2-phenyl)ethyl chloromethyl ketone (TPCK)-treated trypsin (TPCK; Worthington Diagnostics) after five days and at $37^{\circ} \mathrm{C}$. C/Victoria and C/Kowloon stocks were propagated after approximately 5 serial passages in the amniotic cavity (each passage virus diluted 1:1 with sterile allantoic fluid) of 7-10 day old embryonated eggs at $33^{\circ} \mathrm{C}$ for 5 days followed by an additional 5 passages of undiluted virus in allantoic cavities. rg-C/JJ stocks were rescued by reverse genetics (see below) and propagated in allantoic fluid of $7-10$ day old embryonated eggs at $33^{\circ} \mathrm{C}$ for 5 days. A/Brisbane/59/07 (A/Brisbane) was propagated in allantoic fluid of 7-10 day old embryonated eggs at $37^{\circ} \mathrm{C}$ for 3 days. 


\section{Human Subjects}

To assess prior bovine influenza virus exposure, banked sera collected from adults aged $\geq 50$ years previously enrolled in an influenza vaccine immune response study at Marshfield Clinic Research Foundation (WI) were evaluated. Participants of the study were residents of a community with a high probability of dairy farm exposure. A total of 741 pre- and post- vaccination samples from participants were available from four separate seasons between 2008-2009 and 2012-2013 for testing. The pre- and postvaccination titers per participant were not determined due to de-identification of samples.

\section{Bovine Sampling}

Banked bovine sera from Ronald Schultz (University of Wisconsin-Madison, Madison, WI), collected from 837 animals between 1977 and 2014 were tested for D/OK antibody titers.

\section{Virus Quantitation}

Hemagglutination Assay (HA). HA titers were determined by incubation of 2fold, serially diluted virus with $0.5 \%$ chicken red blood cells (cRBC) for 30 minutes at room temperature. HA titers were determined as the highest dilution to fully agglutinate red blood cells (RBC).

50\% Tissue Culture Infectious Dose (TCID50). TCID 50 was performed by infection of MDCK cells, washed twice with phosphate buffered saline (PBS), for $1 \mathrm{hr}$. with virus serially diluted in cell culture media (55). Virus was then removed and replaced with infection media containing $0.1 \mathrm{ug} / \mathrm{ml}$ TPCK. C/Victoria, C/ Kowloon, and $\mathrm{rg}-\mathrm{C} / \mathrm{JJ}$ were incubated at $33^{\circ} \mathrm{C}$ and $\mathrm{D} / \mathrm{OK}$ at $37^{\circ} \mathrm{C}$ for 5 days. Wells were read for agglutination following the addition of $0.5 \% \mathrm{cRBCs}$ and incubation at room temperature and TCID 50 titers were determined according to the Reed and Muench method (56).

\section{Sera Treatment}

RDE Treatment. Bovine and human sera were treated with receptor destroying enzyme (RDE; Denka Seiken Co., Ltd., United Kingdom) at $37^{\circ} \mathrm{C}$ for 18 hours, inactivated for 1 hour at $56^{\circ} \mathrm{C}$, and used at 1:10 dilution.

RBC Preadsorption. RBC preadsorption of bovine sera was performed to remove factors which might contribute to non-specific agglutination of $\mathrm{RBC}$ in a hemagglutination inhibition assay, described below, contributing a "false negative" result for antibody titers. Treatment was performed by dilution of RDE treated sera at 1:20 with packed cRBCs and incubated for one hour at $4^{\circ} \mathrm{C}$. Samples were then centrifuged at $447 \mathrm{x}$ $\mathrm{g}$ for five minutes and sera collected for subsequent analysis. 
Trypsin Periodate Treatment. Trypsin periodate treatment was performed according to World Health Organization Manual on Animal Influenza Diagnosis and Surveillance (57). Briefly, sera were inactivated with trypsin solution at $56^{\circ} \mathrm{C}$ for $30 \mathrm{~min}$. This was followed by addition of $0.011 \mathrm{M}$ metapotassium periodate and then $1 \%$ glycerol saline for 15 minutes at room temperature, each, before final dilution of sera of 1:10 with 1x PBS.

Virus Preadsoprtion. Virus preadsorption of human sera was performed to assess cross-reactivity of human ICV derived antibodies to D/OK. Enzyme immunoassay (EIA)/radioimmunoassay (RIA) plates (Costar, Corning, NY) were plated with 50ul antigen (normalized to $32 \mathrm{HA}$ titer) or uninfected egg allantoic fluid overnight at $4^{\circ} \mathrm{C}$. Plates were then washed with PBS with $0.05 \%$ Tween (PBST) and blocked with PBS with $5 \%$ bovine serum albumin (BSA) for 2 hours at room temperature before addition of sera and incubated overnight at $4^{\circ} \mathrm{C}$. Preadsorbed sera was removed and used for subsequent analysis.

\section{Serology}

Hemagglutination Inhibition. Hemagglutination inhibition (HI) assay was performed using $0.5 \% \mathrm{cRBCs}$ and RDE treated sera (57). Sera were serially diluted in PBS and incubated with a concentration of virus equal to four agglutinating doses for $1 \mathrm{hr}$ at room temperature. Next, $0.5 \% \mathrm{cRBCs}$ were added to each well and incubated for 30 min. at room temperature and read. Titers were determined as the reciprocal of the highest agglutination inhibiting dose (HIU). Only HAI titers $\geq 40$ were considered positive.

Microneutralization Assay. Microneutralization (MN) assays were performed by incubation of 2-fold serially diluted, RDE-treated sera with $2 \times 10^{3} \mathrm{TCID}_{50} / \mathrm{ml}$ virus for 30 minutes at room temperature prior to addition to MDCK cells washed twice with $1 \mathrm{x}$ PBS. Titers were determined as the reciprocal of the highest TCID $_{50}$ virus titer.

ELISA. Virus stock was inactivated for use in ELISA by addition of 1:2000 $\beta$ propiolactone (BPL) and incubated for 72 hours at $4^{\circ} \mathrm{C}$. Virus inactivation was verified by a $\mathrm{HA}$ titer of 0 after passaging twice in five eggs with 100ul each of undiluted BPLtreated virus and incubated for 5 days at $33^{\circ} \mathrm{C}$.

ELISA was performed with 1:16 dilution of BPL-treated virus (normalized to 32 HA titer) or allantoic/uninfected cell supernatant control in coating buffer. EIA/RIA plates (Costar, Corning, NY) were plated with 50ul antigen overnight at $4^{\circ} \mathrm{C}$. Plates were then washed with PBST and blocked with PBS with 5\% BSA for 2 hours at room temperature before addition of serially diluted sera and incubated overnight at $4^{\circ} \mathrm{C}$. Plates were again washed with PBST and incubated for 2 hours at room temperature with 1:1000 anti-human IgG -Alkaline Phosphatase (Jackson Immuno Research 109055-008). Plates were washed once more and developed for 45 minutes in dark room with alkaline phosphatase substrate (pNPP Microwell Substrate System: KPL \#50-80- 
00). The reaction was stopped with $0.5 \%$ EDTA and plates were read at 410nm on microplate reader.

\section{Ferret Transmission}

Ferret transmission experiments were performed by infection of three ferrets each with D/OK, C/Victoria, and C/Kowloon. Ferrets were anesthetized with $200 \mathrm{~cm}^{3} / \mathrm{min}$ of oxygen isoflurane inhalation followed by intranasal instillation of $10^{6} \mathrm{TCID}_{50}$ virus. Twenty-four hours post infection, naïve contact ferrets were introduced. Nasal wash was collected on days $2,4,6,8,10$, and 12 post infection with $1 \mathrm{ml}$ PBS after intramuscular administration of ketamine. Post-infection serum was collected on day 14 post infection. Euthanasia was performed by intravenous administration of barbiturate overdose. Euthanasia of the animals for tissues was performed according to the recommendations of the Panel of Euthanasia of the American Veterinary Association.

\section{Normal Human Bronchial Epithelial Replication Kinetics}

Virus replication kinetics was performed in NHBE cells which serve as an in vitro model for influenza virus replication in the human respiratory system. (58). NHBE cells in 6-well plate inserts were infected with $\mathrm{D} / \mathrm{OK}, \mathrm{C} /$ Victoria, $\mathrm{C} / \mathrm{Kowloon}$, or $\mathrm{rg}-\mathrm{C} / \mathrm{JJ}$ at a multiplicity of infection (moi) of 0.01 for 1 hour at $33^{\circ} \mathrm{C}$ after washing cells 10 times with 1x PBS to remove mucus. After 1 hour absorption, apical media was removed and cells exposed at the liquid-air interface. At each time point, the basal media was replaced with $1 \mathrm{ml}$ complete media, supplemented with $0.2 \%$ BSA and $300 \mathrm{ul}$ were added to the insert. Cells were incubated with apical and basal media and both were collected after 30 minutes and stored at $-80^{\circ} \mathrm{C}$ until titrated. Finally, the basal media was replaced with $1 \mathrm{ml}$ complete media so that cells were always exposed to the basal liquid-apical air interface. Samples were collected at 1, 24, 48, 72, 96, and 120 hours post infection and viral titers were determined as $\mathrm{TCID}_{50} / \mathrm{ml}$. The experiment was performed twice with triplicate wells of each virus infection.

\section{Reverse Genetics Plasmid Construction}

The bi-directional cloning plasmid, pPMV, and seven bi-directional C/JJ/1950 gene pPMV plasmids for the rescue of reverse genetics virus were kindly provided by Reinhard Vlasak, University of Salzburg. To prepare the D/OK reverse genetics plasmid system, D/OK viral RNA was extracted and purified by RNeasy Viral RNA extraction kit (Qiagen, CA). Reverse transcription and amplification of each D/OK gene was performed by SuperScript ${ }^{\circledR}$ III One-Step RT-PCR System with Platinum ${ }^{\circledR}$ Taq High Fidelity (Invitrogen ${ }^{\mathrm{TM}}$ ) with gene specific primers. Gene specific primer design was executed using the Primer Design tool for In-Fusion ${ }^{\circledR}$ HD Cloning Kit (www.clonetech.com) for HEF, P3, PB1, and PB2 genes. Cloning primers for NS, NP, and $\mathrm{M}$ genes were designed to include the terminal 25 nucleotides of each gene and the 
restriction site sequence. Each gene was then ligated into the bi-directional pPMV cloning vector using the In-Fusion HD Cloning Kits (Clontech, Mountain View, CA) according to manufacturer's instructions or T4 DNA Ligase (NEB, Ipswich, MA). The pPMV plasmid and NP, NS, and M amplified genes were cut using the Bsmb1 restriction enzyme (NEB, Ipswich, MA).

\section{Virus Rescue}

Reverse genetics virus rescue was performed with modifications as previously described for the assessment of virus reassortment compatibility (59). First, a 1:4 coculture of MDCK:293T cells were plated in 6-well plates at $37^{\circ} \mathrm{C}$ overnight. The following day, one microgram of each of the seven gene plasmids was equilibrated with 16ul TransIT-LT1 Transfection Reagent (Mirus, Madison, WI) in 200ul of optimized MEM (Opti-MEM) (Invitrogen Corporation, Grand Island, NY) for 45 minutes at room temperature. The transfection mixture was then brought to $1 \mathrm{ml}$ total volume and transferred to the MDCK:293T co-culture and incubated at $33^{\circ} \mathrm{C}$ overnight. On day 1 post-transfection; the inoculation media was replaced with $1 \mathrm{ml}$ Opti-MEM supplemented with 200mM GlutaMAX supplement (Thermofisher Scientific, Carlsbad, CA) and antibiotics-antimycotics. On day 2 post-transfection an additional $1 \mathrm{ml}$ transfection media with $1 \mathrm{ug} / \mathrm{ml}$ TPCK was added to each transfection well at $33^{\circ} \mathrm{C}$. On day 4 posttransfection; the culture supernatant was collected and HA titers of rescue virus were determined with $0.5 \%$ cRBCs. Transfection supernatant was passaged twice in MDCK cells to obtain a virus stock.

\section{Statistical Analysis}

HI, MN, and ELISA antibody titers were compared by Spearman nonparametric correlation in Graphpad Prism 5 (GraphPad Software, Inc., CA).

\section{Results}

\section{Serology of Historic Bovine Samples}

In consideration of the mounting evidence of $\mathrm{D} / \mathrm{OK}$ prevalence in cattle, which suggests this species may serve as the host reservoir for IDV, we wished to establish a relative timeline of IDV introduction and prevalence in US cattle to better assess IDV exposure to humans. Specifically, we wished to determine IDV introduction and prevalence in cattle within a similar region of our subsequent human cohort. First, we used archived bovine sera to look for evidence of prior circulation of the virus in this host. Both objectives were addressed by determining D/OK HI titers in banked bovine sera. D/OK HI antibodies were undetectable in all bovine sera collected prior to 2003 but were present in 53\% of sera collected after 2003 (geometric mean titer (GMT) 131.7, 
95\% CI [118.7, 146.1]) from various geographic regions in the United States (Figure 2-1). Positive HI titers ranged from 40 to 1280 and similar results were obtained by $\mathrm{MN}$ assay $(\mathrm{R}=0.8398, \mathrm{P}<0.0001)$ (Figure 2-2). These results suggested that individuals in the United States were likely exposed to IDV since at least 2003.

\section{Geographic Distribution of IDV Seroprevalence}

Bovine sera used for surveillance was collected from across the United States. The majority of sera collected prior to 2003 originated from WI, TN, and AL (Table 2-1). However, the origin of the rest of the historic sera was not provided. Sera collected after 2003 was collected from WI, NE, ND, SD, TX, and MS (Table 2-2). Although the geographic distribution of sera collected prior to 2003 was different from that of sera collected after 2003, a number of sera from both groups were collected from WI. The observation that no D/OK sera was identified in WI prior to 2003 but almost $60 \%$ were positive after 2003 supports conclusions that the virus emerged in American cattle some time before 2003 and that individuals living in WI have been exposed to IDV for at least 13 years. Furthermore, a small cohort of 23 sera collected from Chilean cattle in 2014 had $9(23.1 \%)$ seropositive samples demonstrating a geographic distribution of IDV spanning North and South America. This is the first report of IDV in South America.

As non-specific inhibitors of hemagglutination are not uncommon in some animal species we re-ran the D/OK HI-positive, and a selection of D/OK HI-negative samples using alternative serum preparation strategies. Specifically, cRBC preadsorption, to remove any serum components able to bind to $\mathrm{RBC}$, and trypsin periodate treatment of sera was conducted to address the possibility of non-specific interactions and confirmed the specificity of the HI results with no change in positive titers due to treatment or assay. RDE HI titers significantly correlated HI titers obtained after $\mathrm{CRBC}$ preadsorption $(\mathrm{R}=$ $0.9559, \mathrm{P}<0.0001)$ and $\mathrm{HI}$ titers after trypsin periodate treatment $(\mathrm{R}=0.4470, \mathrm{P}=0.0251)$ (Figures 2-3 and 2-4). These results confirmed the widespread nature of IDV infection in US cattle and also showed that the virus was in this population at least as far back as 2003 providing ample opportunity for exposure of humans to infected animals.

\section{D/OK Serological Surveillance in Likely Highly Exposed Individuals}

Having determined that seroprevalence of D/OK-like viruses was temporally and spatially widespread in US cattle we next sought to determine if the same was true in human exposed to these animals. To assess D/OK seroprevalence in a high-risk human population, sera from older residents of a community with high probability of dairy farm exposure, and by inference, to IDV were used (Table 2-3). Sera were assessed for the presence of D/OK-reactive antibodies by $\mathrm{HI}$ and only 8 individuals were weakly seropositive (resulting in 1\% seroprevalence) with a GMT of 46.57, 95\% CI [39.07, $55.50]$. 


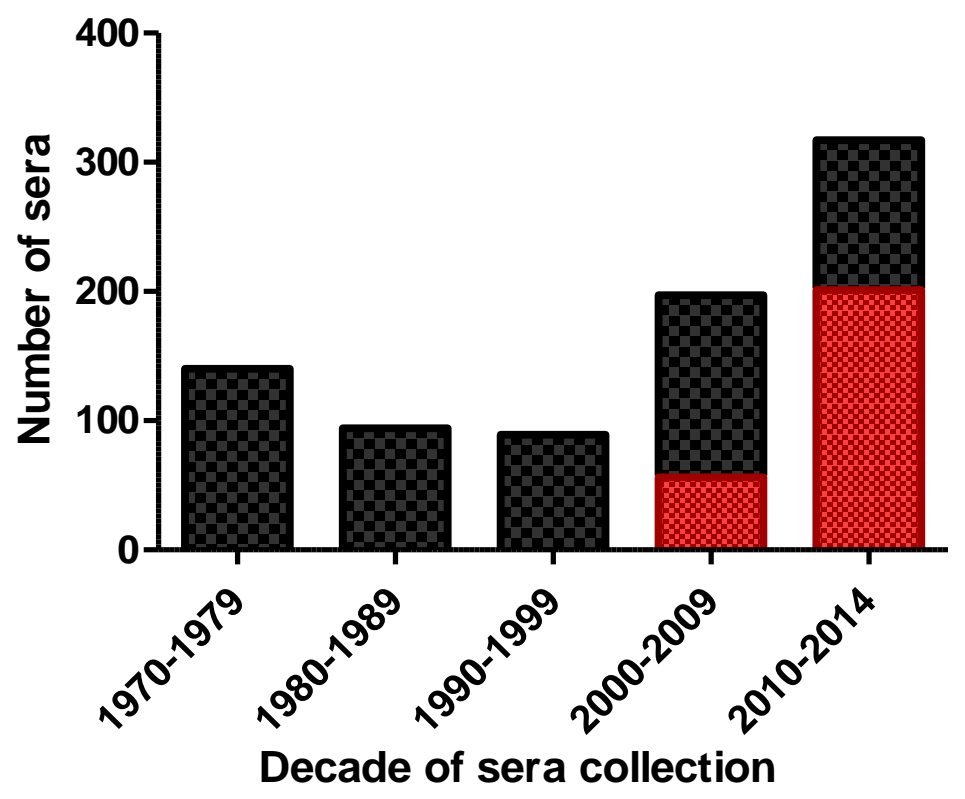

Figure 2-1. D/OK-reactive antibodies as assessed by $\mathrm{HI}$ are undetected in bovine sera collected prior to 2003 .

The total number of D/OK HI positive sera is represented by the red bars and total number of negative sera is represented by the black bars.

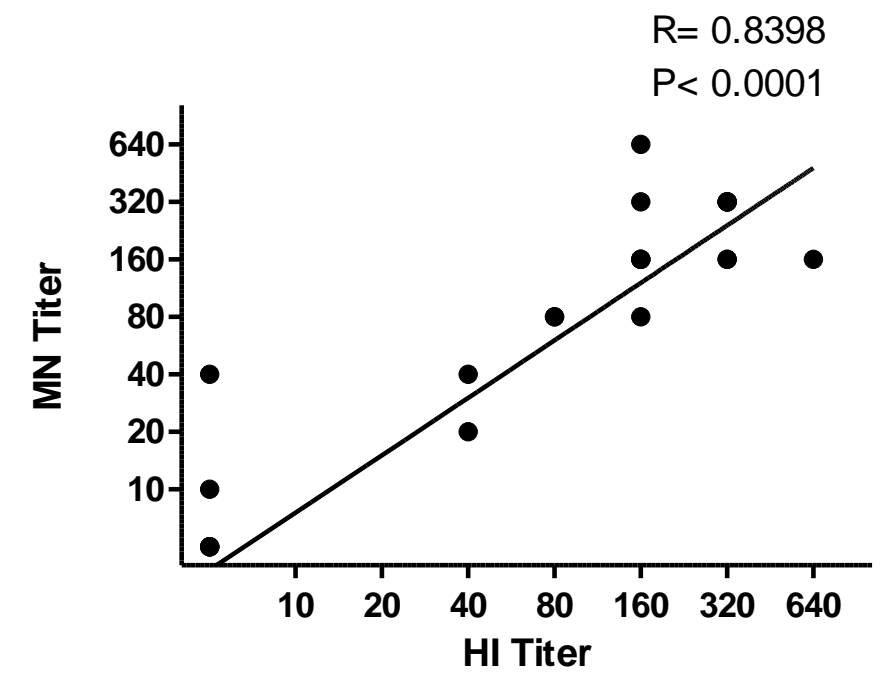

Figure 2-2. D/OK MN titers statistically correlate to HI titers in bovine sera. 
Table 2-1. Total bovine sera collected prior to 2003 by state.

\begin{tabular}{|c|c|}
\hline State & Total Sera Tested \\
\hline WI & 42 \\
\hline $\mathrm{TN}$ & 13 \\
\hline $\mathrm{AL}$ & 136 \\
\hline Unknown & 119 \\
\hline
\end{tabular}

Table 2-2. Seroprevalence of IDV, per state, collected after 2003.

\begin{tabular}{lccccccc}
\hline \multirow{2}{*}{$\begin{array}{l}\text { Data } \\
\text { Representation }\end{array}$} & WI & NE & ND & SD & TX & MS & Total \\
\cline { 2 - 7 } & & & & & & \\
\hline $\begin{array}{l}\text { Positive/ } \\
\text { total sera }\end{array}$ & $108 / 181$ & $0 / 12$ & $8 / 26$ & $15 / 67$ & $101 / 134$ & $12 / 33$ & $244 / 453$ \\
& & & & & & & \\
Percent positive & $59.7 \%$ & $0.0 \%$ & $30.8 \%$ & $22.4 \%$ & $75.4 \%$ & $36.4 \%$ & $53.9 \%$ \\
\hline
\end{tabular}

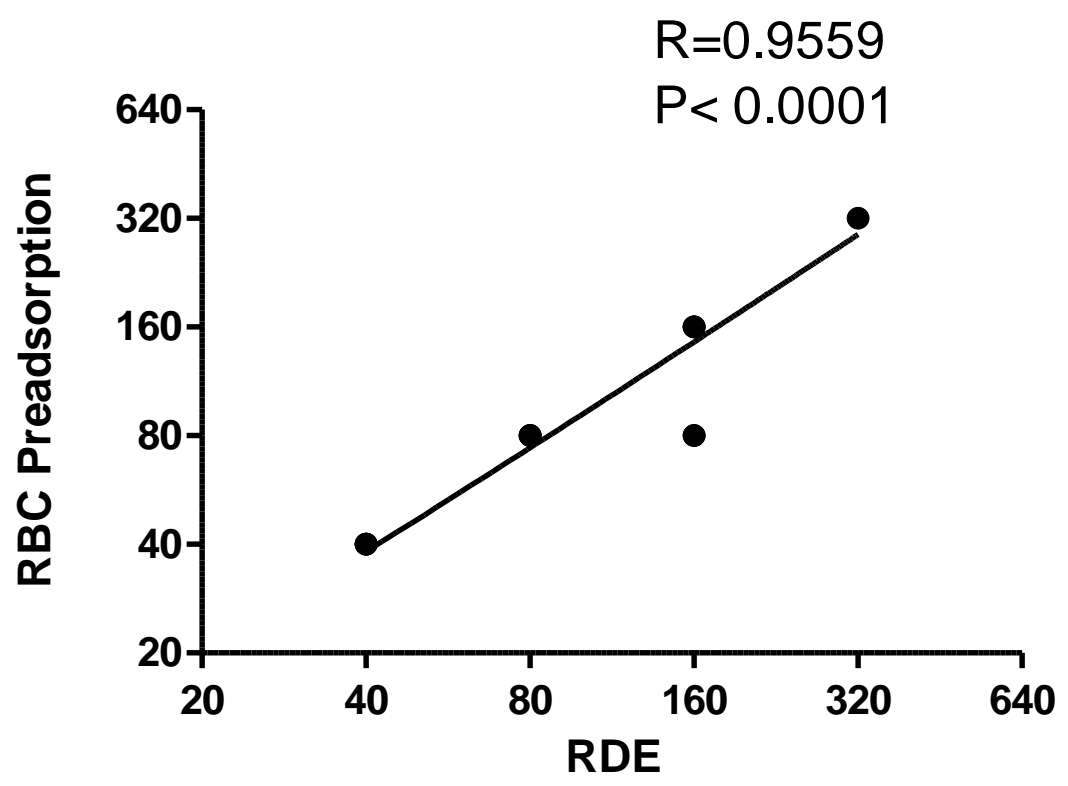

Figure 2-3. D/OK HI titers of bovine sera using RDE treated sera are not significantly different than $\mathrm{RDE}+\mathrm{RBC}$ preadsorption treated sera. 


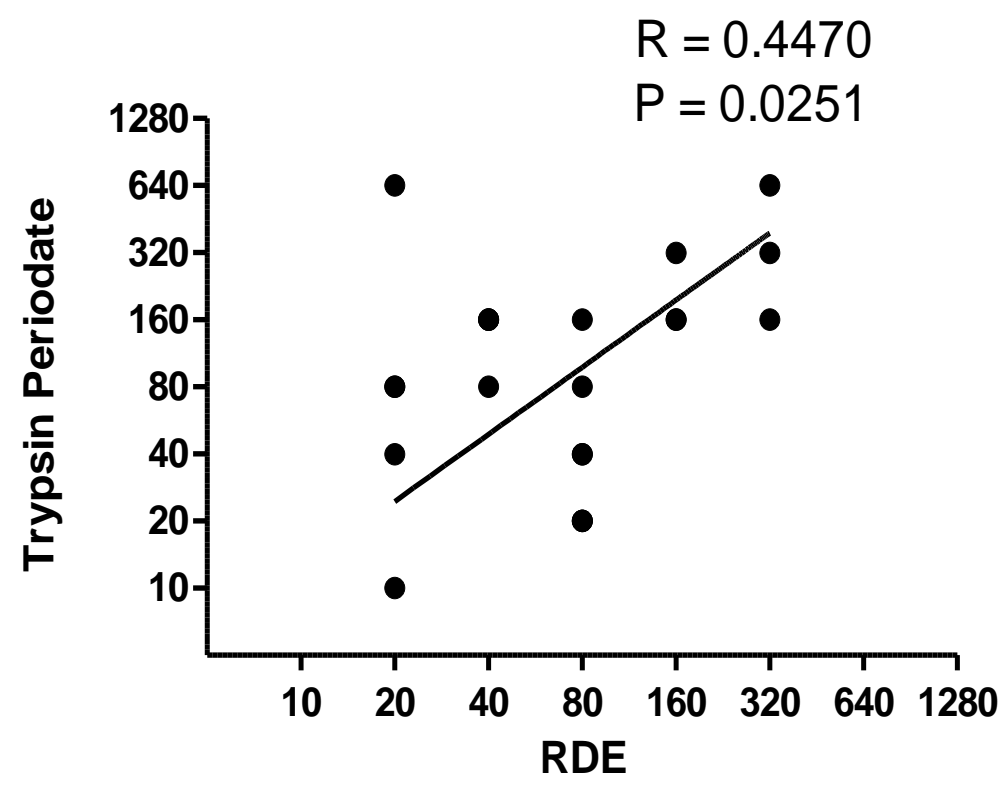

Figure 2-4. D/OK HI titers of bovine sera using RDE treated sera are not significantly different than trypsin periodate treated sera.

Table 2-3. The number of sera from individuals likely exposed to cattle which were tested for IDV antibodies by $\mathrm{HI}$ is listed by season.

\begin{tabular}{lc}
\hline Season & Total Sera Tested \\
\hline $2008-2009$ & 205 \\
$2009-2010$ & 251 \\
$2011-2012$ & 150 \\
$2012-2013$ & 135 \\
Total & 741 \\
\hline
\end{tabular}


Although it was previously shown that there was no serologic cross reactivity in $\mathrm{HI}$ between D/OK and ICV (which we confirmed below) using post infection ferret antiserum it was not clear if the same was true in human serum $(43,45)$. Thus, we further tested the 8 HI-positive and 6 randomly selected HI-negative sera by HI, ELISA and MN assay (Figures 2-5, 2-6, and 2-7) for reactive antibodies to D/OK and a human ICV, $\mathrm{C} /$ Victoria. There was no statistical correlation between D/OK and C/Victoria positive/ negative titers or between D/OK titers determined by HI, MN, and ELISA assays (Table 2-4 and 2-5).

There were two possible explanations for the positive D/OK serum samples we tested. The first is that they represented true D/OK-like virus infection with the second being that the titers were simply due to cross reactivity due to repeated exposure to ICV. To determine if the titers we observed to $\mathrm{D} / \mathrm{OK}$ were due to specific response or ICV cross reactive responses we preabsorbed positive samples with concentrated C/Victoria. We hypothesized that if the $\mathrm{D} / \mathrm{OK}$ titers were specific then $\mathrm{C} /$ Victoria preadsorption would have minimal impact on D/OK titers. Conversely, if the D/OK titers were due to cross reactive responses then $\mathrm{C} / \mathrm{Victoria}$ preadsorption would remove any $\mathrm{D} / \mathrm{OK}$ reactivity. The latter was the case and $\mathrm{C} / \mathrm{Victoria}$ preadsorption resulted in removal of all D/OK HI titers in previously positive samples. The one exception was sample 7 where preadsorption failed to even reduce $\mathrm{C} / \mathrm{Victoria}$ titers (Table 2-6). In order to validate the specificity of the assay, we assessed antibody titers specific for an H1N1 IAV strain, $\mathrm{A} /$ Brisbane, after $\mathrm{C} /$ Victoria preadsorption as well. While the A/Brisbane titers were too low in the D/OK HI positive samples to determine specificity, several D/OK HI negative sera, which had higher (up to $80 \mathrm{HIU}$ ) A/Brisbane specific titers, were similarly treated. As expected, C/Victoria preadsorption had minimal impact on A/Brisbane titers and a maximum of two-fold reduction was observed.

We further investigated the cross reactivity of IDV and ICV using post-infection ferret antiserum generated in the ferret transmission study described later in this chapter. Such reagents are known to be more specific than human serum in regards IAV serology. We compared HI, MN, and ELISA titers of ferret polyclonal antibodies generated to $\mathrm{D} / \mathrm{OK}$ and $\mathrm{C} / \mathrm{Victoria}$ for cross-reactivity. As was seen in previous studies, there was no cross-reactivity detected by HI but MN and ELISA assays were able to pick up cross reactive antibodies with (Table 2-7) $(43,45)$. Further examination of potential cross reactivity between IDV and historical ICV isolates appears warranted, although our data clearly show these two groups of viruses share common epitopes.

Taken together, these data support, or at the least we cannot exclude, that the D/OK HI antibodies in the described human cohort were non-specific and instead due to cross reactivity with antibodies generated through prior, and perhaps repeated, ICV infection.

\section{Influenza C/D Virus Replication Kinetics in NHBE Cells}

To determine the relative ability of IDV to replicate in human cells we assayed the replication of D/OK, C/Victoria, C/Kowloon, and a classical human ICV derived 


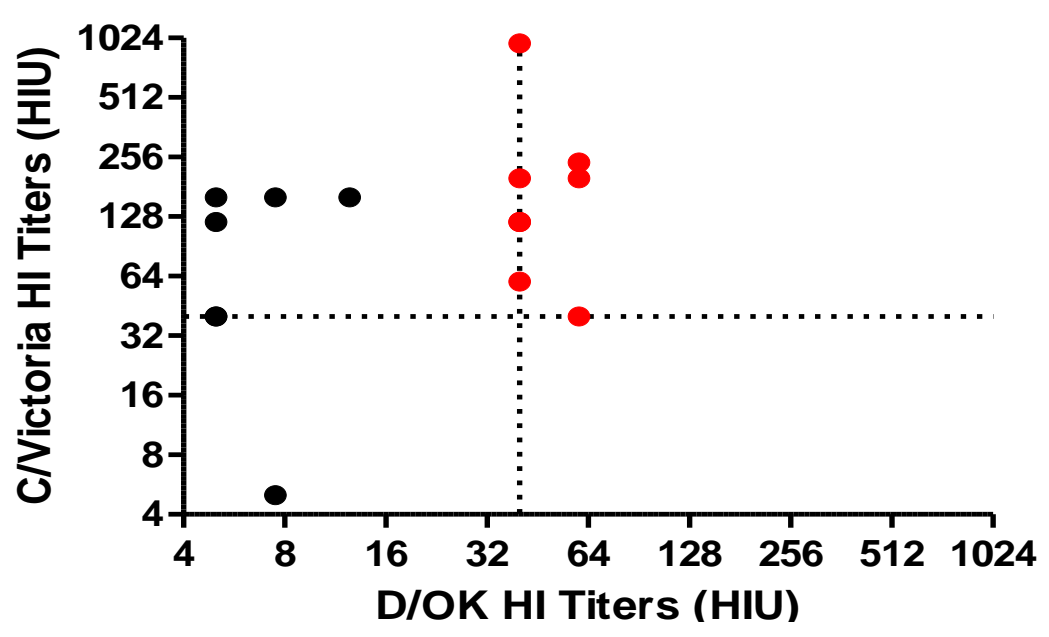

Figure 2-5. There is no statistical correlation between $\mathrm{HI} \mathrm{D} / \mathrm{OK}$ - and C/Victoriareactive antibodies from individuals from a rural farm community.

The HI titers for D/OK and C/Victoria antibodies were compared for eight D/OK HIpositive and six randomly selected D/OK HI-negative sera. D/OK HI positive sera are represented by red circles and negative sera are represented by black circles. The dotted lines denote the lowest HI titer to be considered positive.

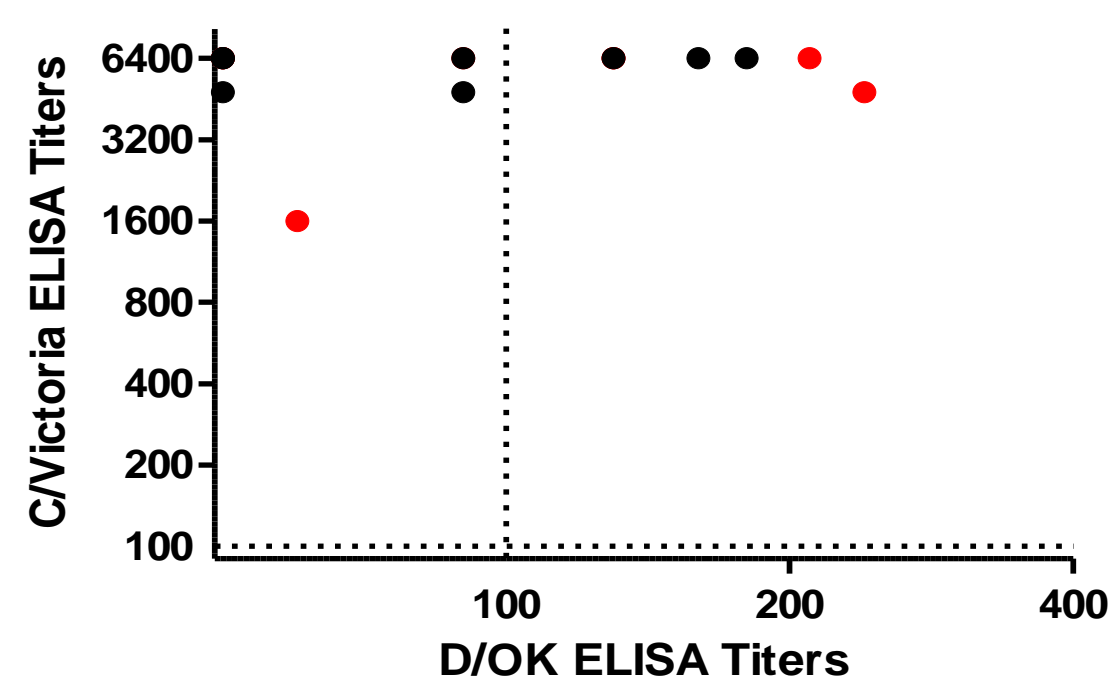

Figure 2-6. There is no statistical correlation of ELISA titers between D/OK- and $\mathrm{C} /$ Victoria-reactive antibodies of individuals which were $\mathrm{D} / \mathrm{OK} \mathrm{HI}$ positive. The ELISA titers for D/OK and C/Victoria antibodies were compared for eight D/OK HIpositive and six randomly selected D/OK HI-negative sera. D/OK HI positive sera are represented by red circles and negative sera are represented by black circles. The dotted lines denote the lowest HI titer to be considered positive. 


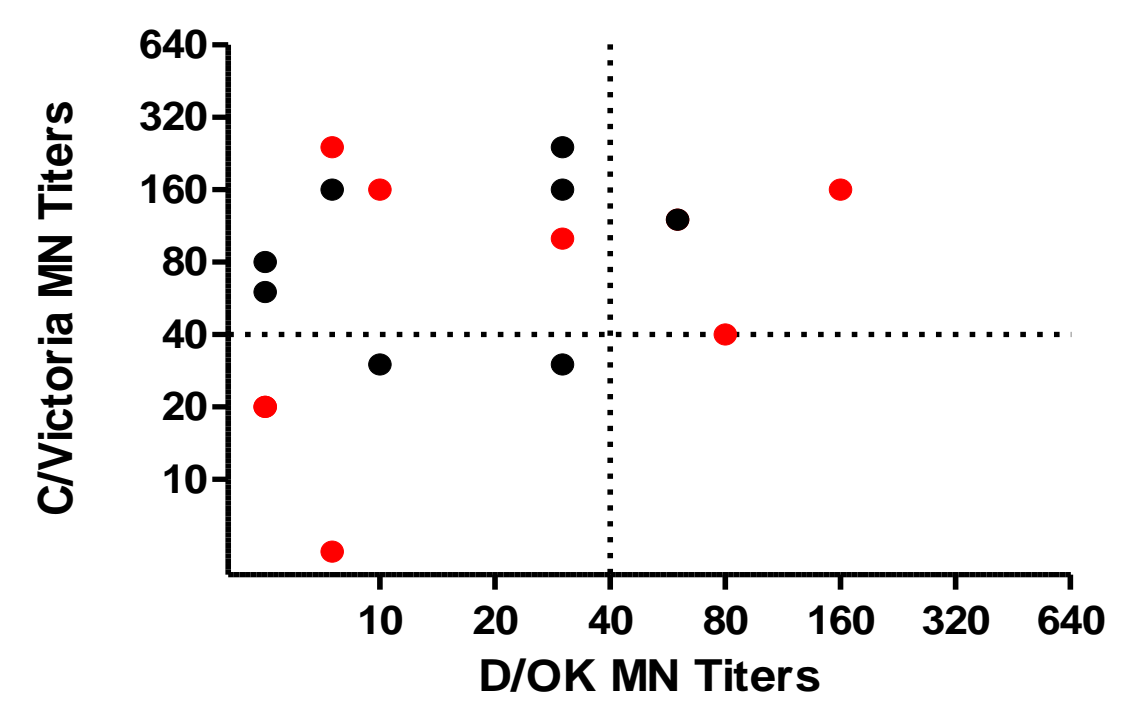

Figure 2-7. There is no statistical correlation of $\mathrm{MN}$ titers between $\mathrm{D} / \mathrm{OK}$ - and $\mathrm{C} /$ Victoria-reactive antibodies of individuals which were $\mathrm{D} / \mathrm{OK} \mathrm{HI}$ positive.

The MN titers for D/OK and C/Victoria antibodies were compared for eight D/OK HIpositive and six randomly selected D/OK HI-negative sera. D/OK HI positive sera are represented by red circles and negative sera are represented by black circles. The dotted lines denote the lowest HI titer to be considered positive.

Table 2-4. There is no statistical correlation between $\mathrm{D} / \mathrm{OK}$ and $\mathrm{C} /$ Victoria antibody titers as assessed by HI, ELISA, or MN.

\begin{tabular}{lccc}
\hline \multicolumn{1}{c}{ Statistical Value } & HI & ELISA & MN \\
\hline Spearman $r$ & 0.3633 & 0.1602 & 0.4425 \\
$\begin{array}{l}\text { P value (two-tailed) } \\
\begin{array}{l}\text { Significant? } \\
\text { (alpha=0.05) }\end{array}\end{array}$ & 0.1518 & 0.5392 & 0.0753 \\
\hline
\end{tabular}


Table 2-5. There is no statistical correlation between $\mathrm{HI}$ and $\mathrm{MN}$ titers for $\mathrm{D} / \mathrm{OK}$ or C/Victoria.

\begin{tabular}{lcc}
\hline \multicolumn{1}{c}{ Statistical Value } & D/OK & C/Victoria \\
\hline Spearman $\mathrm{r}$ & 0.006432 & 0.1965 \\
$\begin{array}{l}\text { P value (two-tailed) } \\
\begin{array}{l}\text { Significant? } \\
\text { (alpha=0.05) }\end{array}\end{array}$ & 0.9805 & 0.4498 \\
\hline
\end{tabular}

Table 2-6. C/Victoria cRBC pre-adsorption of eight D/OK HI-positive sera removed previous $\mathrm{D} / \mathrm{OK} \mathrm{HI}$ antibody titers but $\mathrm{A} / \mathrm{Brisbane} \mathrm{HI}$ antibody titers were only reduced by 2 -fold in another set of eight sera.

\begin{tabular}{|c|c|c|c|c|c|c|c|}
\hline \multirow[b]{2}{*}{ Sample } & \multicolumn{2}{|c|}{ C/Victoria (HIU) } & \multicolumn{2}{|c|}{ D/OK (HIU) } & \multirow[t]{2}{*}{ Sample } & \multicolumn{2}{|c|}{ A/Brisbane (HIU) } \\
\hline & $\begin{array}{c}\text { Non- } \\
\text { treated }\end{array}$ & $\begin{array}{c}\text { Pre- } \\
\text { adsorbed }\end{array}$ & $\begin{array}{c}\text { Non- } \\
\text { treated }\end{array}$ & $\begin{array}{c}\text { Pre- } \\
\text { adsorbed }\end{array}$ & & $\begin{array}{l}\text { Non- } \\
\text { treated }\end{array}$ & $\begin{array}{c}\text { Pre- } \\
\text { adsorbed }\end{array}$ \\
\hline 1 & 160 & 20 & 40 & 0 & 9 & 0 & 0 \\
\hline 2 & 320 & 80 & 40 & 0 & 10 & 0 & 0 \\
\hline 3 & 80 & 0 & 40 & 0 & 11 & 80 & 40 \\
\hline 4 & 40 & 0 & 60 & 0 & 12 & 40 & 20 \\
\hline 5 & 320 & 0 & 60 & 0 & 13 & 0 & 0 \\
\hline 6 & 320 & 0 & 60 & 0 & 14 & 20 & 10 \\
\hline 7 & 160 & 160 & 40 & 20 & 15 & 10 & 0 \\
\hline 8 & 1280 & 160 & 40 & 0 & 16 & 20 & 10 \\
\hline
\end{tabular}

Table 2-7. HI cross-reactivity is not observed between IDV and ICV with polyclonal ferret sera as assessed by HI but is cross-reactive as assessed by MN and ELISA.

\begin{tabular}{lccccccc}
\hline \multirow{2}{*}{ Ferret Sera } & \multicolumn{3}{c}{ D/OK Antigen } & & \multicolumn{3}{c}{ C/Victoria Antigen } \\
\cline { 2 - 4 } \cline { 3 - 4 } & HI & ELISA & MN & & HI & ELISA & MN \\
\hline C/Victoria & 0 & 260 & 0 & & 320 & 6400 & 480 \\
D/OK & 0 & 1120 & 5 & & 0 & 6400 & 20 \\
\hline
\end{tabular}


from reverse genetics for use in our reassortment assay described later, $\mathrm{rg}-\mathrm{C} / \mathrm{JJ}$ in $\mathrm{NHBE}$ cells (Figure 2-8). All viruses replicated with titers of D/OK significantly higher than the human ICV at 48 and 120 hours post infection. When the area under the curve was calculated for each virus, D/OK demonstrated the most robust replication of all tested viruses: D/OK (515.2) C/Victoria (339.9), C/Kowloon (277.0), and rg-C/JJ (302.7). While there is no confirmed predictive value between growth in NHBE cells and successful infection of the human host, these data clearly demonstrate that there is no barrier to replication of IDV in human epithelial cells.

\section{Influenza C/D Virus Transmission in Ferrets}

Our in vitro assessment of $\mathrm{D} / \mathrm{OK}$ replication in human cells supported a previously published in vivo assessment of zoonotic transmission in a ferret transmission model (43). Ferrets are used as a surrogate model of IAV infection due to similar disease pathology and transmissibility as that of human seasonal influenza viruses. However, as no animal model has been established for the study of human ICV, we also explored the suitability of this model for classical human ICV transmission for comparison of D/OK.

To determine the relative fitness of IDV to infect and transmit in ferrets we assessed the replication, transmission, and seroconversion potential of D/OK and compared these profiles to infection with, $\mathrm{C} /$ Victoria, and $\mathrm{C} /$ Kowloon. Maximum virus shedding was achieved by day 4 post infection and all infections were cleared by day 6 post infection as assessed by TCID $_{50}$ of ferret nasal wash (Figure 2-9). Two of three ferrets infected with $\mathrm{D} / \mathrm{OK}$ and one of three ferrets infected with $\mathrm{C} /$ Kowloon shed an average of $\log 1.5 \mathrm{TCID}_{50} / \mathrm{ml}$ virus on day 4 post infection. No viral shedding was detected from ferrets exposed to $\mathrm{C} /$ Kowloon by direct contact but all three ferrets exposed to $\mathrm{D} / \mathrm{OK}$ by direct contact shed an average $\log 2.5 \mathrm{TCID} 50 / \mathrm{ml}$ virus titer. Viral shedding was not detected in any $\mathrm{C} / \mathrm{Victoria}$ infected or direct contact ferrets. No clinical signs or symptoms were reported for any ferrets. HI was performed to determine seroconversion in ferrets 14 days post infection (Table 2-8). HI detectable antibodies reactive to $\mathrm{D} / \mathrm{OK}$ were not identified in any donor or direct contact ferrets despite detection of viral shedding. Ferret seroconversion was detected in $\mathrm{C} /$ Kowloon donor and direct contact ferrets and $\mathrm{C} / \mathrm{Victoria}$ donor ferrets indicating the ferrets are susceptible to $\mathrm{C} / \mathrm{Victoria}$ despite lack of viral shedding from donor ferrets. Overall, data from virologic assays and serology were not robust and titers of viral shedding were low. Poor robustness of replication and the incongruence of serology and virus shedding in ferrets were confirmed in a repeat experiment.

\section{Influenza C and D Virus Reassortment}

Reassortment between animal and human IAV is a documented route for genesis of pandemic viruses. If IDV and ICV viruses were able to reassort, it is possible that viruses with enhanced zoonotic infection could be similarly generated. While classical reassortment studies have failed to detect IDV and ICV reassortants, we sought to 


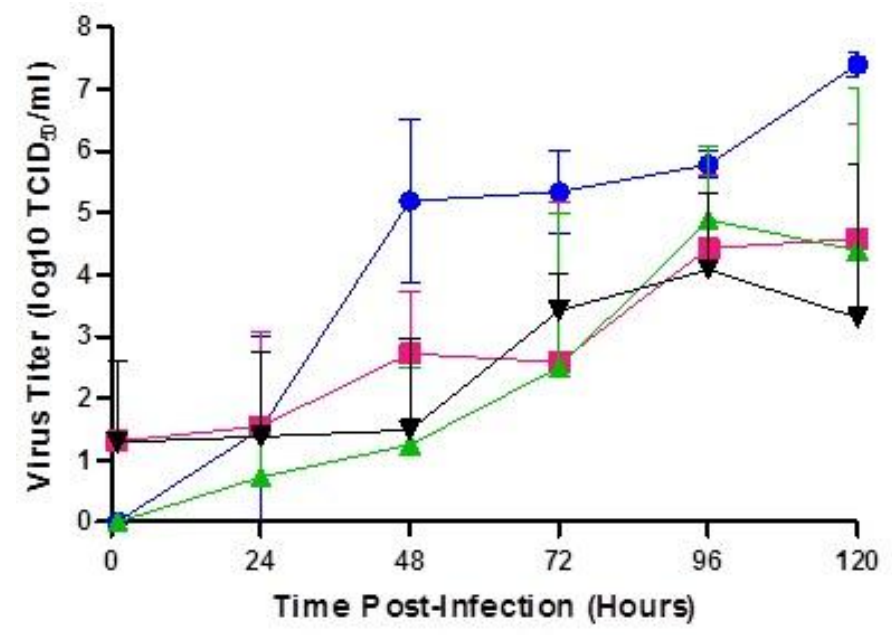

Figure 2-8. D/OK replicates to higher titers than human ICV in normal human bronchial epithelial cells.

NHBE cells were infected at moi of 0.01 with D/OK (blue circles), C/Victoria (pink squares), C/Kowloon (green triangles), and $\mathrm{rg}-\mathrm{C} / \mathrm{JJ}$ (black inverted triangles) and titers measured by $\operatorname{TCID}_{50}$ at $1,24,48,72,96$, and 120 hours post-infection. The area under the curve for each virus was: D/OK (515.2), C/Victoria (339.9), C/Kowloon (277.0), and rg$\mathrm{C} / \mathrm{JJ}(302.7)$. 


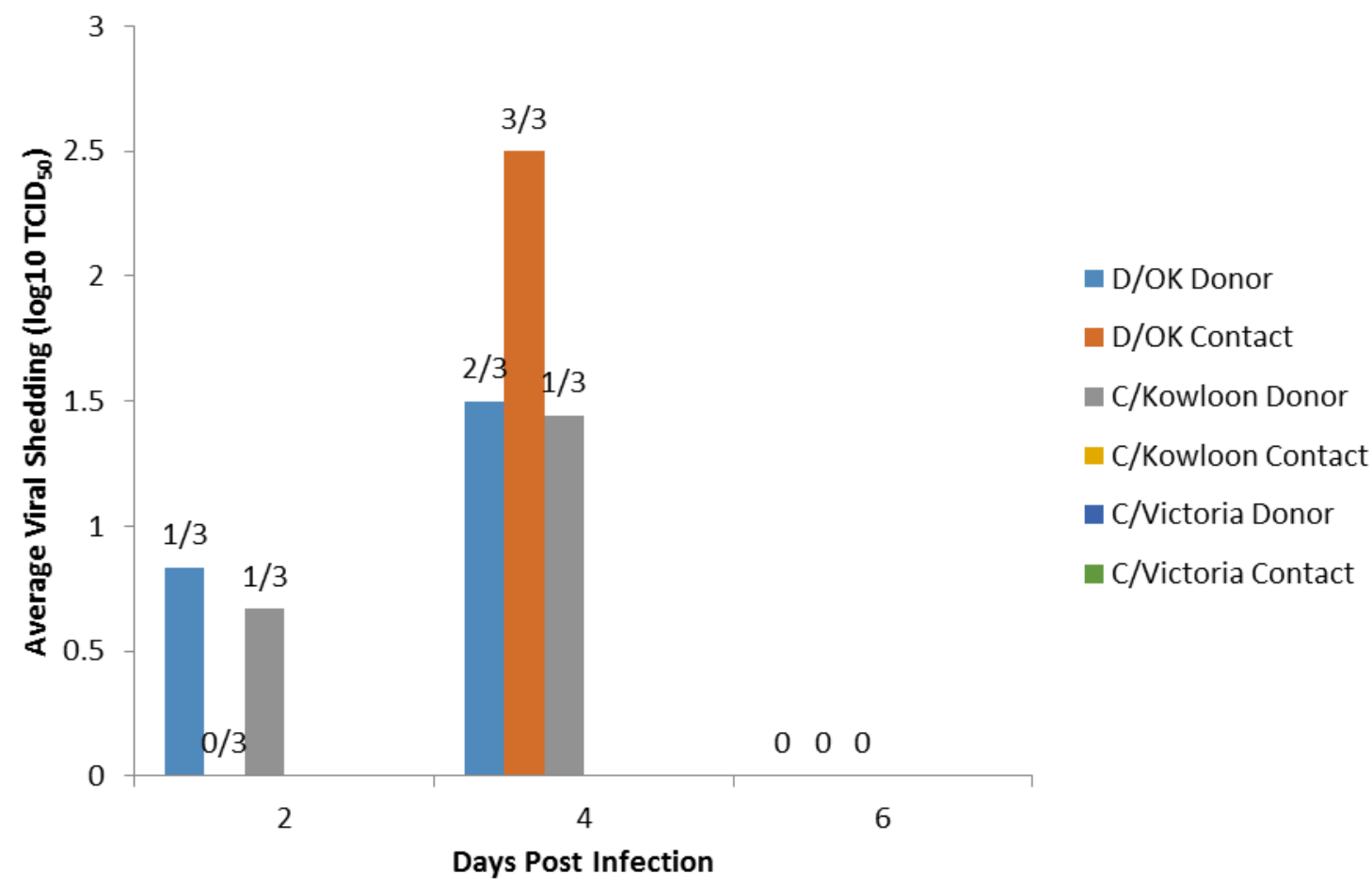

Figure 2-9. D/OK and C/Kowloon are shed by inoculated ferrets but only $\mathrm{D} / \mathrm{OK}$ is shed by direct contact ferrets.

Viral shedding is reported as $\log 10 \mathrm{TCID}_{50}$ and the number of ferrets which shed detectable virus levels is reported above each bar.

Table 2-8. ICV but not D/OK inoculated ferrets seroconverted.

\begin{tabular}{lllll}
\hline \multirow{2}{*}{ Virus } & Exposure & \multicolumn{2}{c}{ Test Antigen } \\
\cline { 3 - 5 } & Group & D/OK & C/Kowloon & C/Victoria \\
\hline D/OK & Donor & 0 & & \\
& Contact & 0 & & \\
C/Kowloon & Donor & & 640 & \\
& Contact & & 160 & 160 \\
C/Victoria & Donor & & & 0 \\
& Contact & & & 0 \\
\hline
\end{tabular}

Titers are represented as HIU. 
force reassortment through a reverse genetics approach (45). Reverse genetics systems have been previously generated for IAV, IBV, and ICV and enable rescue of infectious virus from cell culture after transfection with the complete influenza genome encoded in multiple plasmids, each containing a different virus gene. This system can also be used for generation of reassortant viruses. Correspondingly, we generated a seven plasmid $\mathrm{D} / \mathrm{OK}$ reverse genetics system using the pPMV cloning vector and protocol for $\mathrm{rg}-\mathrm{C} / \mathrm{JJ}$ (59). Effective rescue of wild-type reverse genetics D/OK virus ( $\mathrm{rg}-\mathrm{D} / \mathrm{OK}$ ) was followed by rescue of each $\mathrm{rg}-\mathrm{D} / \mathrm{OK}$ in context of a classical ICV virus, rg-C/JJ. In each case, $\mathrm{D} / \mathrm{OK}$ genes were complementary to those of the classical ICV and reassortant viruses were recovered with comparable $\mathrm{HA}$ titers to that of $\mathrm{rg}-\mathrm{C} / \mathrm{JJ}$ at 7 days post transfection (Table 2-9). The composition of the rescued reassortant viruses was confirmed by Sanger sequencing demonstrating that, despite the minimal protein homologies, there are no general incompatibility issues interfering with successful IDV/ICV reassortment.

The finding that IDV and ICV gene segments can reassort in an in vitro system has implications for the proposed classification of a novel genus. Indeed, reassortment of influenza viruses is dependent upon terminal noncoding regions of each RNA gene segment and compatibilities of protein functions and we demonstrate the ability to generate reassortant viruses containing IDV and ICV genes in vitro $(19,32,60)$. However, this conflicts with a previously published study which failed to identify reassortants between IDV and ICV after co-infection (43). These discrepancies may be a consequence of the experimental method used and does not necessarily, in light of the antigenic and phylogenetic divergence between IDV and ICV discussed earlier, reflect compatibility of these two influenza types to reassort under natural conditions.

It is important to note that the rescue of reassortant viruses discussed here were performed prior to implementation of the US Government moratorium on gain-offunction influenza viruses, which will be discussed further in Chapter 3, and thus does not violate the moratorium.

\section{Discussion}

ICV are human respiratory pathogens which occasionally cross species barriers to infect swine $(3,16)$. Unlike IAV, ICV lack an animal host reservoir and thus have never been considered to have pandemic potential. Therefore, the identification of a new subtype of ICV (or alternatively a new virus genus) antigenically distinct from circulating human strains with an altered host range (swine and cattle) is of particular public health interest.

Since isolation in 2011, bovine IDV have been reported in the United States, France, and China and two phylogenetic clades have been identified suggesting extended circulation in the bovine population $(43,45,48-52)$. Indeed, an estimated $88 \%$

seroprevalence of $\mathrm{D} / \mathrm{OK}$ in surveyed cattle herds in the United States suggests that bovine IDV is well established (45). This estimate is supported by the $94 \%$ seroprevalence identified in neonatal calves in Mississippi (46). This seroprevalence, along with our 
Table 2-9. Average HA titer of rescued wild type and reassortant reverse genetics virus.

\begin{tabular}{|c|c|c|c|c|c|c|c|c|}
\hline \multirow{2}{*}{ Virus } & \multicolumn{7}{|c|}{ Virus Origin of Contributing Gene } & \multirow{2}{*}{$\begin{array}{c}\text { Rescue } \\
\text { Titer }\end{array}$} \\
\hline & PB2 & PB1 & P3 & HEF & NP & $\mathbf{M}$ & NS & \\
\hline $\mathrm{C} / \mathrm{JJ}$ & $\mathrm{C} / \mathrm{JJ}$ & $\mathrm{C} / \mathrm{JJ}$ & $\mathrm{C} / \mathrm{JJ}$ & $\mathrm{C} / \mathrm{JJ}$ & $\mathrm{C} / \mathrm{JJ}$ & $\mathrm{C} / \mathrm{JJ}$ & $\mathrm{C} / \mathrm{JJ}$ & 6 \\
\hline $\mathrm{D} / \mathrm{OK}$ & $\mathrm{D} / \mathrm{OK}$ & $\mathrm{D} / \mathrm{OK}$ & $\mathrm{D} / \mathrm{OK}$ & $\mathrm{D} / \mathrm{OK}$ & $\mathrm{D} / \mathrm{OK}$ & $\mathrm{D} / \mathrm{OK}$ & $\mathrm{D} / \mathrm{OK}$ & 64 \\
\hline PB2 & $\mathrm{D} / \mathrm{OK}$ & $\mathrm{C} / \mathrm{JJ}$ & $\mathrm{C} / \mathrm{JJ}$ & $\mathrm{C} / \mathrm{JJ}$ & $\mathrm{C} / \mathrm{JJ}$ & $\mathrm{C} / \mathrm{JJ}$ & $\mathrm{C} / \mathrm{JJ}$ & 5 \\
\hline PB1 & $\mathrm{C} / \mathrm{JJ}$ & $\mathrm{D} / \mathrm{OK}$ & $\mathrm{C} / \mathrm{JJ}$ & $\mathrm{C} / \mathrm{JJ}$ & $\mathrm{C} / \mathrm{JJ}$ & $\mathrm{C} / \mathrm{JJ}$ & $\mathrm{C} / \mathrm{JJ}$ & 4 \\
\hline P3 & $\mathrm{C} / \mathrm{JJ}$ & $\mathrm{C} / \mathrm{JJ}$ & $\mathrm{D} / \mathrm{OK}$ & $\mathrm{C} / \mathrm{JJ}$ & $\mathrm{C} / \mathrm{JJ}$ & $\mathrm{C} / \mathrm{JJ}$ & $\mathrm{C} / \mathrm{JJ}$ & 10 \\
\hline HEF & $\mathrm{C} / \mathrm{JJ}$ & $\mathrm{C} / \mathrm{JJ}$ & $\mathrm{C} / \mathrm{JJ}$ & $\mathrm{D} / \mathrm{OK}$ & $\mathrm{C} / \mathrm{JJ}$ & $\mathrm{C} / \mathrm{JJ}$ & $\mathrm{C} / \mathrm{JJ}$ & 16 \\
\hline NP & $\mathrm{C} / \mathrm{JJ}$ & $\mathrm{C} / \mathrm{JJ}$ & $\mathrm{C} / \mathrm{JJ}$ & $\mathrm{C} / \mathrm{JJ}$ & $\mathrm{D} / \mathrm{OK}$ & $\mathrm{C} / \mathrm{JJ}$ & $\mathrm{C} / \mathrm{JJ}$ & 8 \\
\hline M & $\mathrm{C} / \mathrm{JJ}$ & $\mathrm{C} / \mathrm{JJ}$ & $\mathrm{C} / \mathrm{JJ}$ & $\mathrm{C} / \mathrm{JJ}$ & $\mathrm{C} / \mathrm{JJ}$ & $\mathrm{D} / \mathrm{OK}$ & $\mathrm{C} / \mathrm{JJ}$ & 6 \\
\hline NS & $\mathrm{C} / \mathrm{JJ}$ & $\mathrm{C} / \mathrm{JJ}$ & $\mathrm{C} / \mathrm{JJ}$ & $\mathrm{C} / \mathrm{JJ}$ & $\mathrm{C} / \mathrm{JJ}$ & $\mathrm{C} / \mathrm{JJ}$ & $\mathrm{D} / \mathrm{OK}$ & 6 \\
\hline
\end{tabular}


data showing that D/OK-like viruses have been in United States cattle since at least 2003, would strongly suggest that humans have been exposed to infected cattle providing a suitable environment for zoonotic transmission. There have, however, been no reported human cases of IDV and a previous surveillance study in a small cohort of individuals from Vancouver, Canada and Connecticut, United States identified only 1.3\% seroprevalence in that general population. It is possible that, since surveillance has not targeted cattle in those geographic regions, that IDV does not circulate or has not circulated for sufficient time for evidence of infection to be found in the general population. We hypothesized that individuals with higher likely exposure might exhibit increased seroprevalence to IDV but our human serologic study only identified $1 \%$ of a cohort of individuals enriched (the study cohort was from a rural community in Wisconsin where many families were involved in dairy cattle enterprises) for cattle exposure with $\mathrm{HI}$ titers $\geq 40$ to $\mathrm{D} / \mathrm{OK}$ despite our finding of approximately $60 \%$ seropositivity of the cattle we surveyed in that state since 2003 . We also consider it most likely that these individuals with seroreactivity to D/OK were not actually infected with the virus but rather had cross reactive antibodies likely generated by ICV infection. In the United States, $96 \%$ of adults, 20-30 years of age, possess antibody titers against human ICV (36). Supporting this conjecture, we carried out depletion studies where removal of ICV antibodies led to loss of the IDV HI titers in positive individuals. Results from earlier studies showed similar seropositivity rates of $1.3 \%$ in the general population (43). If IDV does indeed cause frequent zoonotic infection we would have expected an elevated seroprevalence in our study population.

Despite the lack of direct evidence for zoonotic infection, D/OK does possess properties that are consistent with an ability to infect humans. This includes the ability of $\mathrm{D} / \mathrm{OK}$ to replicate in NHBE cells to a level that exceeds that of a set of human-adapted ICV and transmission by direct contact in ferrets, similar to that of a contemporary ICV. NHBE cells are commonly used as an in vitro model of the human upper respiratory tract and assessment of IAV infection $(58,61,62)$. Further, ferrets are the in vivo model for assessment of transmission of IAV in humans (63-65). Neither NHBE cell replication nor the ferret transmission model have been validated for assessment of zoonotic potential of ICV but a previous study verified D/OK direct contact transmission in ferrets (43). In this study, we showed ferret transmission by direct contact, similar to a contemporary human ICV, although the titers of viral shedding were modest. However, the lack of robustness of the data from ferret serology and modest titers of ferret viral shedding would suggest that ferrets may not represent an adequate model for assessment of IDV or ICV transmission potential. Although directly inferring zoonotic infection potential from NHBE cell replication and ferret transmission might not be applicable, the fact that IDV can replicate in human primary epithelial cells argues that the possibility might exist.

Avian influenza viruses replicate poorly in the human host yet have a documented ability to cause pandemics. The process by which avian viruses adapt to humans is enhanced by two properties of the virus, mutation caused by the error prone polymerase and by the ability for viruses to exchange genetic material through reassortment. Indeed, the 1957 and 1968 IAV pandemics were caused by reassortant viruses and if reassortment 
between ICV and IDV were possible a similar route to IDV adaptation to humans could be considered. Reassortment of influenza viruses is determined by compatibilities of protein functions and terminal noncoding regions of each RNA gene segment and despite the $50 \%$ overall genome similarity of D/OK to that of human adapted ICV, the terminal noncoding regions differ by only a single nucleotide $(11-13,15,43)$. Correspondingly, we were able to show robust generation of reassortant viruses when a reverse genetics approach was used to force reassortment. These data conflict somewhat with those of Hause and colleagues who were unable to generate natural reassortants after IDV/ICV coinfections (45). Differences in experimental approaches and ICV viruses used could underlie the different results but it is clear that IDV gene segments can readily complement those of ICV. Whether such reassortants impact zoonotic potential is unresolved.

Taken together, our results provide further evidence for the widespread nature of IDV in cattle in the United States and, while there is no substantive evidence for human infection, IDV should be considered in workups of undiagnosed respiratory disease in individuals with exposure to cattle and other ruminants. 


\section{CHAPTER 3. RECEPTOR TROPISM AND ESTERASE STABILITY OF IDV HEF RECEPTOR}

\section{Introduction}

In Chapter 2 we assessed the zoonotic potential of a novel influenza virus, $\mathrm{D} / \mathrm{OK}$, the representative virus of a novel influenza genus that infects pigs, cattle, sheep, and goats. We showed that seroprevalence to $\mathrm{D} / \mathrm{OK}$ in a cohort of individuals likely highly exposed to bovine pathogens was due to cross-reactive antibodies. While these data suggest that human infection with this virus is likely not high, D/OK does possess many of the characteristics commonly attributed to zoonotic potential of IAVs and may represent a zoonotic risk to public health. These two conflicting data sets suggest that if IDV were to become a common human pathogen-which it does not currently appear to be- it would likely need to undergo molecular adaptations similar to what is seen when avian IAV adapt to mammalian hosts. Based on the wealth of supporting literature from IAV, we hypothesized that a change in host range for IDV might be associated with changes in receptor preferences and perhaps biophysical characteristics. We therefore sought to examine IDV and ICV receptor usage and acid stability and, for the former, the underlying molecular determinants.

The mechanisms which confer zoonotic potential, or, maintain host species barriers, are complex and not well understood. Studies have focused on IAV proteins, particularly HA and NA and host restriction of IBV and ICV has not been as readily addressed. This is of significance as ICV is the closest evolutionarily related genus to that of IDV, with $50 \%$ sequence homology across their whole genome and 53\% or less homology in their HEF genes, similar to the sequence identity shared between IAV serotypes. We thus based our comparison of IDV and ICV host restriction upon mechanisms elucidated for IAV.

The surface glycoproteins of influenza viruses contribute multiple functions in the virus infectious cycle including host cell receptor recognition/binding, viral and host cell membrane fusion for entry into the host cell, and receptor destroying function for budding of progeny virions. Each of these functions is essential for virus infection and correspondingly likely exhibits a role in host species restrictions (66-68). First, in order to facilitate binding of host cell receptors, the HA must first be activated by host enzyme proteolytic cleavage. This step can also contribute to host species restrictions based upon the compatibility of host proteolytic enzymes to the HA. Specifically, those IAV HA which contain a multi-basic cleavage site or lack an additional carbohydrate side chain near the cleavage site, are less restricted as to the specificity of proteolytic enzymes $(66,69,70)$. The avian IAV strains possessing these characteristics, then, have demonstrated increased pathogenicity in human hosts. The proteolytic enzyme necessary for activation of ICV and IDV HEF is not known although the HEF polypeptide of both genera does exhibit a conserved monobasic cleavage site and crystal structure of both activated proteins confirms proteolytic cleavage (71). 
The second mechanism of glycoprotein host restriction involves the recognition and binding of host cell sialic acids. The recognition and binding to host cell receptors by IAV HA is highly specific, differentiating between alpha 2,3- and alpha 2,6- linkages of sialic acids to galactose on the host cell which are expressed in a tissue and host species specific manner (65,72-76). Those IAV which specifically recognize and bind alpha 2,3linked sialic acids, which are the predominant sialic acid species on the intestinal epithelia of avian hosts, predominately infect wild and domestic birds. Conversely, those viruses specific for alpha2,6-linked sialic acids, highly expressed on tracheal epithelia of the human respiratory tract, are associated with human-adaptation. Evolutionary adaptation which enables conversion of IAV receptor specificity from alpha 2,3- to alpha 2,6- linked sialic acids is attributed to increased transmissibility of avian originating viruses in human hosts.

The ICV glycoprotein utilizes O-type acetylated sialic acids to facilitate host cell binding and entry $(28,30,77)$. Sialic acids can undergo O-type acetylation on either the 4 or 9 carbon and ICV receptor recognition is highly specific to the position of the acetylated carbon atom. ICV HEF specifically binds 9-O-acetylated, but not 4-Oacetylated, sialic acids and the crystal structure of ICV HEF was solved bound to 9-Oacetylated sialic acid $(30,78,79)$. Glycan arrays comparing IDV and ICV HEF receptor specificity have revealed higher binding affinity of IDV HEF than ICV HEF to 9-Oacetylated sialic acids (71). Further, IDV HEF exhibits broader receptor tropism through binding of 9-O-acetylated sialic acid derivatives which ICV HEF does not bind. Comparison of the crystal structure of both proteins showed highly homologous overall structure but slightly altered conformation of the IDV HEF receptor binding moiety, in part due to an open channel formed by the absence of a salt bridge interaction between amino acid residues T239 and A273 (71). Slight conformational shifts seen in the IDV HEF binding cavity compared to ICV HEF may explain the altered receptor binding specificity and affinity of IDV $\operatorname{HEF}(43,71)$.

The many orthomyxoviruses and coronaviruses which express acetylated sialic acid-binding surface glycoproteins, including ICV, IDV, mouse hepatitis virus, porcine torovirus, and human respiratory coronavirus OC43 and its proposed zoonotic ancestor bovine coronavirus, suggests widespread species distribution of acetylated sialic acids $(43,80-82)$. However, the species and tissue distribution of acetylated sialic acids in mammals are largely unknown except for two studies only one of which included respiratory tissue $(71,83)$. Using ICV and IDV esterase-null HEF probes for staining paraffinized sections, ICV and IDV receptors were detected on the apical surface of human, swine, and bovine trachea, although swine and bovine trachea had much brighter staining, suggesting the presence of 9-O-acetylated sialic acids (71). No publications were found concerning the species and tissue distribution of other acetylated 4-Oacetylated sialic acids.

The third mechanism of host restriction, once the influenza virion has undergone proteolytic cleavage and bound the host cell receptor, is to facilitate fusion of viral and host cell membranes. For IAV, the bound virion is endocytosed and a conformational change of the HA is triggered by decreasing $\mathrm{pH}$ of the maturing endosome. The 
conformational alteration of the this protein is $\mathrm{pH}$ specific and this varies in different cell types and host species, which may confer host restrictions $(69,84,85)$. Human-adapted IAV generally exhibit lower optimal $\mathrm{pH}$ of activation specificity than do avian IAV, as shown previously in a panel of human and avian IAV. In this study, human IAVs exhibited lower $\mathrm{pHs}$ of activation overall compared to avian IAVs (69). Adaptation leading to lowered $\mathrm{pH}$ of activation may be a contributing attribute to IAV pandemic potential.

Extensive characterization of the ICV HEF protein has been performed in in vitro assays that assessed how membrane fusion and enzyme activity was affected by $\mathrm{pH}$. Optimal esterase activity occurred between $\mathrm{pH} 7$ and 8 , with $50 \%$ enzyme activity retained when exposed to conditions as low as $\mathrm{pH}$ 5. Similarly, maximum fusion of liposomes in vitro occurs at $\mathrm{pH} 5.5$, but the physiologic relevance is unknown (86). $\mathrm{pH}$ of activation may represent a mechanism of the HEF protein in host species restriction.

The fourth mechanism of host restriction requires the enzyme specificity and activity of NA to correlate sufficiently with HA binding specificity $(66,68)$. The NA exhibits a receptor destroying function necessary to allow progeny virions to properly bud from the host cell. If the NA receptor binding specificity and enzyme activity does not correlate to HA receptor specificity and affinity, the infectious cycle is impeded or delayed due to improper virion budding and may also contribute to host species restrictions.

The HEF protein of ICV and IDV also exhibits receptor destroying activity via an acetylesterase domain. The ICV esterase specifically cleaves O-linked acetyl groups as assessed by its ability to hydrolyze only O-linked acetyl group containing compounds. The acetylesterase moiety of IDV HEF is highly structurally and functionally conserved to ICV HEF including homologous active site structure $(43,71)$. Both ICV and IDV HEF utilize the esterase catalytic triad including amino acid residues S57, D356, and H359. Both enzymes exhibit receptor destroying activity even at $4^{\circ} \mathrm{C}$.

Last, a more general mechanism of viral host restriction involves temperature of viral replication. Avian IAV replication is adapted for replication at $40^{\circ} \mathrm{C}$ which corresponds to the temperature of avian intestinal tracts but replication in cell culture can also be observed at $37^{\circ} \mathrm{C}$ which corresponds to the lower human respiratory tract (87). However, $32^{\circ} \mathrm{C}$, the temperature of the proximal human respiratory system is restrictive, possibly serving as a barrier to infection by avian IAV in humans. Conversely, ICV, which is widespread in humans, replicates optimally in cell culture at $33^{\circ} \mathrm{C}$ but is restricted at $37^{\circ} \mathrm{C}$ corresponding to higher expression of the HEF protein (88). IDV replication is not restricted at either temperature in cell culture (43).

In this chapter, IDV receptor binding specificity, effect of temperature on replication kinetics, and $\mathrm{pH}$ of activation as compared to ICV is investigated as possible mechanisms of host species restrictions and barrier to zoonotic transmission of IDV. 


\section{Materials and Methods}

\section{Cell Culture}

Swine testicle (ST), human rectal tumor 18G (HRT-18G), and human embryonic kidney 293T (293T) cells were obtained from the American Type Culture Collection (Manassas, VA). ST and HRT-18G cells were maintained in Dulbecco modified Eagle's medium (DMEM; Invitrogen Corporation, Grand Island, NY) and 293T cells were maintained in minimum essential medium (MEM; Corning, Manassas, VA), all media was supplemented with 5\% fetal bovine serum (FBS; HyClone, Logan, UT) and antibiotics-antimycotic (Sigma, St. Louis, MO; $100 \mathrm{U} / \mathrm{ml}$ penicillin, $100 \mu \mathrm{g}$ streptomycin, and $0.25 \mu \mathrm{g}$ amphomycin per $\mathrm{ml}$ ). All cell culture was incubated at $37^{\circ} \mathrm{C}$ and $5 \% \mathrm{CO}_{2}$.

\section{Viruses}

In addition to the viruses listed in Materials and Methods of Chapter 2, the $\mathrm{pH}$ of activation assay used A/Tennessee/1-560/2009 (A/TN/09) stock supplied by Marion Russier and Charles Russell (St. Jude Children's Research Hospital, Memphis, Tennessee).

\section{Virus Quantitation: Hemagglutination Assay}

Hemagglutination (HA) titers were determined by incubation of 2-fold, serially diluted virus with packed red blood cells (RBC) from various species at room temperature or $4^{\circ} \mathrm{C}$. HA was performed using $0.5 \%$ chicken RBCs for 30 minutes and $1 \%$ horse, rat, sheep, pig, bovine, rabbit, guinea pig, and goat RBCs (Rockland Antibodies and Assays, Limerick, PA) for 60 minutes. HA titers were determined as the highest dilution to fully agglutinate the RBC.

\section{Virus Replication Kinetics}

Virus replication kinetics was performed in ST and HRT-18G cells. Cells in 6well plates were infected with D/OK at a multiplicity of infection (moi) of 0.01 for 1 hour at $33^{\circ} \mathrm{C}$ or $37^{\circ} \mathrm{C}$ after which virus was replaced with infection media. Samples were collected at 72,120 , and 168 hours post infection and stored at $-80^{\circ} \mathrm{C}$ until titrated. Viral titers were reported as TCID $50 / \mathrm{ml}$. The experiment was performed twice.

\section{Mutagenesis}

Single, double, and triple mutants of D/OK and C/JJ HEF proteins were prepared using the QuikChange ${ }^{\circledR}$ Site-Directed Mutagenesis Kit (Catalog \#200518; 
ThermoScientific, La Jolla, CA) according to manufacturer's instructions. Briefly, the pPMV vector containing either D/OK or C/JJ HEF gene was used as the DNA template for standard protocol PCR using mutant specific primers and the subsequent PCR product was subjected to Dpn1 digestion prior to transformation to ensure transformation of mutant only clones.

\section{Viral-like Particle Expression}

$293 \mathrm{~T}$ cells were plated in 6-well plates at $37^{\circ} \mathrm{C}$ overnight. The following day, one microgram of each gene plasmid to be used was equilibrated with 16ul TransIT-LT1 Transfection Reagent (Mirus, Madison, WI) in 200ul of Opti-MEM (Invitrogen Corporation, Grand Island, NY) for 45 minutes at room temperature. The transfection mixture was then brought to $1 \mathrm{ml}$ total volume and transferred to the $293 \mathrm{~T}$ culture overnight at $33^{\circ} \mathrm{C}$. On day 1 post-transfection; the inoculation media was replaced with $1 \mathrm{ml}$ Opti-MEM supplemented with 200mM GlutaMAX supplement (Thermofisher Scientific, Carlsbad, CA) and antibiotics-antimycotics. On day 2 post-transfection; an additional $1 \mathrm{ml}$ transfection media with $1 \mathrm{ug} / \mathrm{ml}$ TPCK was added to each transfection well at $33^{\circ} \mathrm{C}$. On day 4 post-transfection; the culture supernatant was collected and HA titers of viral-like particles (VLPs) were determined with $0.5 \%$ chicken red blood cells.

\section{pH Inactivation Assay}

The $\mathrm{pH}$ inactivation assay was used to investigate $\mathrm{pH}$ stability of the influenza virion. $\mathrm{pH}$ inactivation was assessed by exposure of each virus, standardized to equivalent $\mathrm{HA}$ titers based on the titer of the virus with lowest titer, to $\mathrm{pH} 3.0,3.5,4.5$, $5.0,5.25,5.5,5.8,6.0,6.2,6.5$, or 7.0 at $37^{\circ} \mathrm{C}$ for 1 hour. Virus infectivity was then assessed by $\mathrm{TCID}_{50}$ in MDCKs. The assay was performed twice in replicate.

\section{Results}

\section{D/OK Receptor Tropism}

Hemagglutination Specificity Assay. A hemagglutination assay using a panel of species specific $\mathrm{RBC}$ was used to determine if $\mathrm{D} / \mathrm{OK}$ exhibited altered receptor specificity from ICV (Table 3-1). To compensate for varying concentrations of virus, the $\mathrm{HA}$ titers using RBC of the various species were normalized to the cRBC HA values, typically used in HA with ICV, and represented as a ratio to cRBC HA, where cRBC HA was represented as 1 . No viruses agglutinated RBCs from guinea pig, goat, pig, bovine, or sheep at a detectable titer. Absence of detectable HA titer in sheep RBC was not surprising due to the absence of acetylated sialic acids on sheep RBCs. All three ICV agglutinated rat $\mathrm{RBC}$ to higher titers than $\mathrm{cRBC}$ as expected since a slightly higher percent of total rat RBC sialic acids are acetylated than cRBC. Conversely, D/OK 
Table 3-1. IDV hemagglutination specificity differs from ICV.

\begin{tabular}{lccccccc}
\hline \multirow{2}{*}{ RBC Species } & \multicolumn{4}{c}{ Virus } & \multicolumn{2}{c}{ Acetylated Sialic Acid } \\
\cline { 2 - 4 } Chicken & D/OK & C/Victoria & C/Kowloon & rg-C/JJ & & Percent & Position \\
Rat & 1 & 1 & 1 & 1 & $20 \%$ & C-9 \\
Horse & 0.75 & 3 & 6 & 3 & $25 \%$ & C-9 \\
Guinea Pig & 2 & 1.5 & 2.5 & 1.5 & $20 \%$ & C-4 \\
Goat & 0 & 0 & 0 & 0 & NK & NK \\
Pig & 0 & 0 & 0 & 0 & NK & NK \\
Bovine & 0 & 0 & 0 & 0 & NK & NK \\
Sheep & 0 & 0 & 0 & 0 & NK & NK \\
& 0 & 0 & 0 & 0 & $0 \%$ & C-4 and \\
\hline
\end{tabular}

Values represent HA titer fold-change as compared to cRBC HA titer for each virus. NK indicates that percent or position of acetylated sialic acid is not known. 
agglutinated rat $\mathrm{RBC}$ poorly compared to $\mathrm{cRBC}$ but agglutinated horse $\mathrm{RBC}$, which expresses 4-O-acetylated sialic acids as the primary acetylated sialic acid species, to higher titer than cRBC. In summary, all ICV demonstrated preference to agglutinate 9-Oacetylated expressing RBCs and D/OK preferentially agglutinated 4-O-acetylated expressing RBCs.

Fold-change Analysis. The HA assay was optimized for comparison of viral receptor specificity by comparison of horse $\mathrm{RBC}$ and rat $\mathrm{RBC} H \mathrm{HA}$ titers by normalizing total titers to rat RBC titers for each virus (Table 3-2). Rat RBC HA titers of each ICV was higher than horse RBC indicating preference for 9-O-acetylated sialic acids but the $\mathrm{HA}$ titer of IDV with rat RBC was lower than horse RBC indicating preference for 4-Oacetylated sialic acids.

Use of VLP Instead of Virus. Several factors attribute to limitations of studying IDV and ICV receptor specificity. First, the most precise assay for studying influenza virus receptor binding specificity is through the use of a glycan array, which consists of a membrane coated with various species of sialic acid. This assay was not possible here as acetylated sialic acids were not commercially available and the core facilities at St. Jude Children's Research Hospital were not equipped to produce them. Therefore, alternative methods for assessment of receptor tropism were needed. Second, the US Government moratorium on gain-of-function studies in all influenza viruses imposed a halt to any work which could be reasonably expected to increase transmission or pathogenicity of any influenza virus in mammals. The mutants we proposed to create for the study of receptor binding specificity would either alter receptor specificity of human-adapted ICVs to potentially increase specificity for bovine-like receptors or IDV to increase specificity for human-like receptors. The consequence of the resulting change in receptor specificity could be reasonably expected to increase transmission or pathogenicity of human-adapted viruses in cattle or bovine-adapted viruses in humans. In order to study receptor specificity of influenza viruses within the limitations of the moratorium, we attempted to create mutant virus-like particles (VLPs) expressing six of the seven total IDV or ICV genes. As VLPs are not replication competent, they do not violate the moratorium. VLPs were created by co-transfection of six of the seven reverse genetics plasmids for D/OK and C/JJ (the NS plasmid was omitted) and receptor binding specificity of the VLPs were compared to D/OK virus and $\mathrm{rg}-\mathrm{C} / \mathrm{JJ}$. C/JJ VLP agglutinated rat $\mathrm{RBC}$ s to higher titers than horse RBCs, similar to rg-C/JJ virus. D/OK VLPs demonstrated different agglutination specificity from $\mathrm{D} / \mathrm{OK}$, which agglutinated horse $\mathrm{RBC}$ to higher titers than rat RBCs, and agglutinated RBCs in a pattern similar to rgC/JJ (Table 3-3).

Optimization of Hemagglutination Assay. Differential binding of D/OK VLP and D/OK virus required optimization of the VLP HA assay. The assay was performed at $4^{\circ} \mathrm{C}$ and at room temperature for $1 \mathrm{hr}$ with both rat RBCs and horse RBCs to assess possible differences in esterase activity between D/OK VLP and D/OK virus. D/OK VLP HA titers were higher with horse RBCs than rat RBCs, similar to D/OK virus, at $4^{\circ} \mathrm{C}$ but not room temperature, suggesting that the different HA titer ratio between D/OK VLP and $\mathrm{D} / \mathrm{OK}$ virus at room temperature was due to a difference in esterase activities. 
Table 3-2. D/OK exhibits preference for horse RBC agglutination.

\begin{tabular}{lccccccc}
\hline \multirow{2}{*}{ RBC Species } & \multicolumn{4}{c}{ Virus } & & \multicolumn{2}{c}{ Acetylated Sialic Acid } \\
\cline { 2 - 4 } & D/OK & C/Victoria & C/Kowloon & rg-C/JJ & & Percent & Position \\
\hline Rat & 1 & 1 & 1 & 1 & & $25 \%$ & C-9 \\
Horse & 4 & 0.5 & 0.125 & 0.5 & & $20 \%$ & C-4 \\
\hline
\end{tabular}

Values represent HA titers for each virus as normalized to rat RBCs.

Table 3-3. D/OK VLP do not exhibit the same HA specificity as D/OK virus.

\begin{tabular}{lcccc}
\hline \multirow{2}{*}{$\begin{array}{c}\text { RBC Species } \\
\text { (Position of Acetylated Carbon) }\end{array}$} & C/JJ VLP & $\begin{array}{c}\text { rg-C/JJ } \\
\text { Virus }\end{array}$ & \multicolumn{1}{c}{ D/OK VLP D/OK Virus } \\
\hline Rat (C-9) & 1 & 1 & 1 & 1 \\
Horse (C-4) & 0.1875 & 0.125 & 0.3125 & 8 \\
\hline
\end{tabular}

Values represent HA titer fold-change as compared to rat RBC HA titer for each virus or VLP. 
HEF Mutant Strategy. Computer modeling predicted three non-homologous amino acid residues in IDV HEF which may be contribute to altered receptor binding and esterase affinity of IDV compared to ICV (43). The IDV HEF amino acid residues proposed included 143, 201, and 256, which correspond to 141, 198, and 250 in ICV HEF (Figures 3-1 and 3-2). The 143 residue is located in the esterase domain and the 201 and 256 residues are located in the receptor binding domain. We hypothesized that changes in these residues of IDV HEF could affect esterase and receptor specificity, contributing to the altered host range of IDV as compared to ICV. We mutated each of the three residues of an IDV representative virus, D/OK, alone or in combination, to the homologous residue in an ICV representative virus, C/JJ, and vice versa. Each single, double, and triple mutant was then expressed as a VLP along with wild type (WT) VLP and WT-reverse genetics virus (WT-rg virus) (Table 3-4). WT VLP was used as control for the mutant VLPs and WT-rg virus was used as control for the absence of the NS protein in the VLP.

Expression and Quantitation of Mutant HEF VLP. Once optimized, rat RBC and horse RBC HA titers, as an indirect assessment of 9-O-acetylated and 4-O-acetylated sialic acids, respectively, of D/OK and C/JJ receptor binding mutant VLPs were determined compared to WT VLP, WT virus, and WT-rg virus (Tables 3-5 and 3-6). Due to concerns over using hemagglutination values to normalize virus amounts- we anticipated that mutants would have different avidities for RBC- ELISA was performed on all samples with polyclonal ferret anti-D/OK or anti-C/JJ antibodies and total virus normalized according to concentration. Mutant VLP F143Y and W201L decreased horse RBC titers but all three mutants increased rat RBC titers. C/JJ VLP mutants L198W and $\mathrm{R} 250 \mathrm{~F}$ increased horse RBC but decreased rat RBC titers whereas Y141F had no effect.

Effect of Receptor Mutations on Hemagglutination Specificity. All D/OK VLP double mutants and the D/OK-Triple mutant completely ablated horse RBC HA titers but increased rat RBC HA titers over WT VLP and WT virus. For the C/JJ VLP mutants, Y141F/L198W increased rat RBC agglutination over WT VLP but Y141F/R250F and L198W/R250F decreased rat RBC agglutination (Figure 3-3a and b). Further, L198W/R250F increased horse RBC agglutination. However, the C/JJ-Triple mutant ablated agglutination of both horse RBC and rat RBC. Possible explanations of this lack of agglutination could be explained by altered tropism imposed by the specific mutations or may be due to a reduction in overall conformational integrity of the receptor binding epitope of the C/JJ HEF or because the HEF protein was not incorporated, or insufficiently incorporated into the VLP.

\section{D/OK Replication Kinetics}

To assess preferential replication conditions of $\mathrm{D} / \mathrm{OK}$, we assessed replication in ST and HRT-18G cells. These cell lines were used to assess effect of temperature on replication in a cell line developed from the animal species D/OK was isolated from and a cell line developed from humans. We compared replication in both cell lines at $33^{\circ} \mathrm{C}$ and $37^{\circ} \mathrm{C}$ (Figure 3-4). D/OK replicated to highest titers in ST cells at $37^{\circ} \mathrm{C}$ and titers were significantly higher at 120 and 168 hours post infection at this condition. When the 

$\mathrm{D} / \mathrm{OK}$
1 MFLLLATITAITACQAERELICIVQRVNESFSLHSGEGGNVYSMKTEPMTGETNVTKGAS
1 MFESLLLMLGLT--EAEKIKICLQKQVNSSESLHNGFGGNLYATEEKRMFELVKPKAGAS
1 MFESLLLVLGLT--EAEKIKICLQKQVNSSFSLHNGFGGNLYATEEKRMFELVKPKAGAS
$c / J J$
1 MFFSLLLMLGLT--EAEKIKICLQKQVNSSFSLHNGEGGNLYATEEKRMFELVKPKAGAS
$\frac{\mathrm{D} / \mathrm{OK}}{\mathrm{C} / \mathrm{A} \mathrm{A}}$
C/ JHB
61 VINQKDWIGFGDSRTDLTNDQFPASSDVPLAVAKKFRSLSGASLMLSAFGPPGKVDYLYQ
59 VLNQSTWIGFGDSRTDKSNSAFPRSADVSAKTADKFRSLSGGSLMLSMFGPRGKVDYLYQ
59 VLNQSTWIGEGDSRTDKSNSAFPRSADVSAKTADKFRSLSGGSLMLSMFGPPGKVDYLYQ
c. $J J$
59 VLNQSAWIGFGDSRTDKSNSAFPRSADVSAKTADKFRSLSGGSLMLSMFGPPGKVDYLYQ
D/OK 121 GCGKEKVFYEGVNWSPEAGIDCFGSNWTQTKKDFYSRIYEAARSSTCMTLVNSLDTKISS
C/AA 119 GCGKHKVFYEGVNWSPHAAINCYRKNWTDIKLNEQKNIYELASQSHCMSLVNALDKTIP-
C/JHB 119 GCGKHKVFYEGVNWSPHAAINCYRINWTDIKLNEQKNIYELASQSHCMSLVNALDKTIR-
C/JJ 119 GCGKHKVEYEGVNWSPHAAINCYRKNWTDIKLNEQKNIYELASQSHCMSLVNALDKTIP-
D/OK $181 \frac{198 / 201}{}$
C/AA 178 LQATAGVAKNCNNSFLKNPALYTQ-EVNPSV--EKCGKENLAFFTLPTQFGTYECKLHLV
C/JHB 178 LQVTAGTAGNCNNSFLKNPALYTQ-EVKPSE--NKCGKENLAFFTLPTQFGTYECKLHLV
C/JJ 178 LQATAGVAKNCNNSFLKNPALYTQ-EVNPSE--RKCGKENLAFFTLPTQFGTYECKLHLV
$250 / 256$
D/OK 241 QLCYFVYENKAKFNTFGCGDYYQNYYDGNGNLIGGMDNRVAAYRGIANAGVKIECPSKII
C/AA 235 ASCYEIYDSKEVYNKRGCDNYFQVIYDSSGKVVGGLDNRVSPYTGNSGDTPTMQCDMLQI
C/JHB 235 ASCYFIYDSKEVYNKRGCDNYFQVIYDSSGKVVGGLDNRVSPYTGNSGDTPTMQCDMLQL
C/JJ 235 ASCYFIYDSKEVYNKRGCDDYFQVIYDSYGKVVGGLDNRVSPYTGNSGDIRTMQCDMLQL

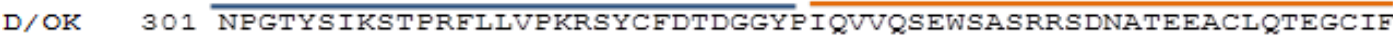
C/AA 295 KPGRYSVRSSPRELLMPERSYCFDMKEKGPVTAVQSIWGKGRESDHAVDQACLSTPGCMI
C/JHB 295 KPGRYSVRSSPRELLMPERSYCFDMKEKGPVTAVQSIWGKGRESDYAVDQACLSTPGCML
C/JJ 295 KPGRYSVRSSPRELLMPERSYCFDMKEKGPVTAVQSIWGKGRESDHAVDQACLSTPGCML
D/OK 361 IKKTTPYVGEADDNHGDIEMRQLLSGLGNNDTVCVSQSGYTKGETPFVKDYLSPPKYGRC
C/AA 355 IQKQKPYIGEADDHHGDQEMRELLSGLD-YEARCISQSGWVNETSPFTEEYLLPPKFGRC
C/JHB 355 IQKQKRYIGEADDHHGDQEMRELLSGLD-YEARCISQSGWVNETSPETEKYLLPPKFGRC
C/JJ 355 IQKQKPYIGEADDHHGDQEMRELLSGLD-YEARCISQSGWVNETSPFTEEYLLPPKEGRC
D/OK 421 QLKTDSGRIPTLPSGLIIPQAGTDSLMRTLTPATRIFGIDDLIFGLLFVGFVAGGVAGGY
C/AA 414 PLAAREESIPKIPDGLIIPTSGTDTTV--TKPKSRIFGIDDIIIGLIFVAIVEAGI-GGY
C/JHB 414 PLAAKEESIPKIPDGLIIPTSGTDTTV--TKPKSRIFGIDDLIIGLLFVAIVETGI-GGY
C/JJ 414 PLAAKEESIPKIPDGLIIPTSGTDTTV--TKPKSRIFGIDDLIIGLFFVSIVEAGI-GGY
D/OK 481 FWGRSNGGGGGASVSSTQAGFDKIGKDIQQLRNDTNAAIEGFNGRIAHDEQAIKNLAKEI
C/AA 471 LLGSRKVSGGGVTKESAEKGFEKIGNDIQILRSSTNIAIEKLNDRISHDEQAIRDITLEI
C/JHB 471 LLGSRKESGGGVTKESAEKGFEKIGNDIQILKSSINIAIEKLNDRISHDEQAIRDITLEI
C/JJ 471 LLGSRKQSGGGVTKESAEKGFEKIGNDIQILRSSTNIAIEKLNDRISHDEQAIRDITLEI
D/OK 541 EDARAEALVGELGIIRSIIVANI SMNLKESLYELANQITKRGGGIAQEAGPGCWYVDSEN
C/AA 531 ENARSEALLGELGIIRALLVGNISIGLQESLWELASEITNRAGDLAVEVSPGCWVIDNNI
C/JHB 531 ENARSEALLGELGIIRALLVGNISIGLQESLWELASEITNRAGDLAVEVSPGCWI IDNNI
C/JJ 531 ENARSEALIGELGIIRALLVGNISIGLQESLWELASEITNRAGDLAVEVSPGCWVIDNNI
D/OK GO1 CDASCKEYIFNFNGSATVPTLRPVDTKVVITSDPYYLGTIALCLLGLVAIAASV-GVIT
C/AA 591 CDQSCQNFIFKFNETAPVPTIPPLDTKIDLQSDPFYWGSSLGLAITAAISLAALVISGIA
C/JHB 591 CDQSCQNFIFKFNETAPVPTIPPIDTKIDLQSDPFYWGSIGLAITATIBLAAIVISGIA
C/JJ 591 CDQSCQNFIFKFNETAPVPTIPPLDTKIDLQSDLFYWGSSIGLVITAAIBLAALVIBGIA
$D / O K \quad 660 \quad \overline{I C C K K}$
C/AA 651 ICRTK
$C / J H B \quad 651$ ICRTK

\section{Esterase domain}
Receptor binding domain
Transmembrane domain
HEF substrate interacting resiches

Figure 3-1. The non-homologous amino acid residues proposed to affect receptor binding specificity of D/OK HEF reside in the receptor binding and esterase domains.

Viruses included in alignment: D/OK, C/Ann Arbor/50 (C/AA), C/Johannesburg/1/66 $(\mathrm{C} / \mathrm{JHB})$, and $\mathrm{C} / \mathrm{JJ}$. 
A

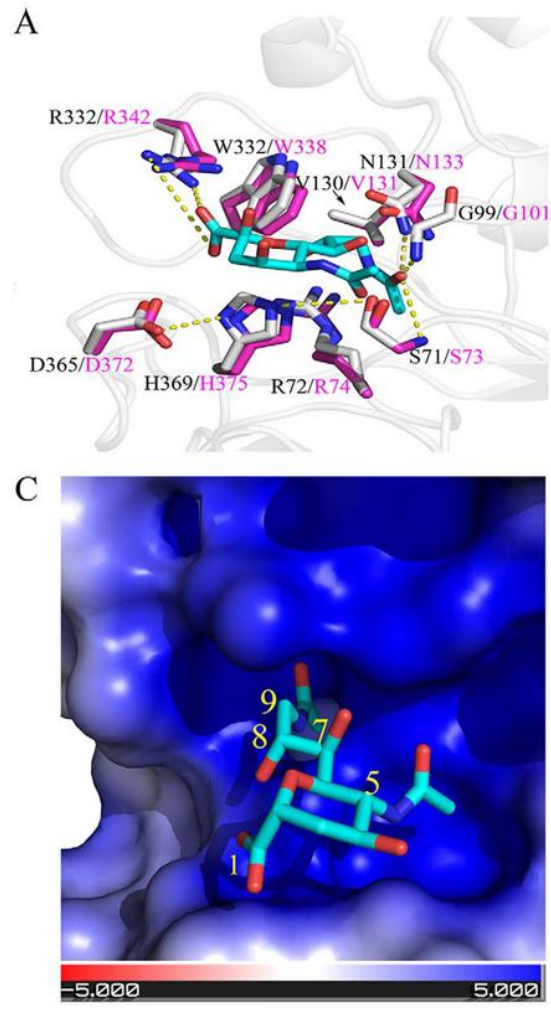

B
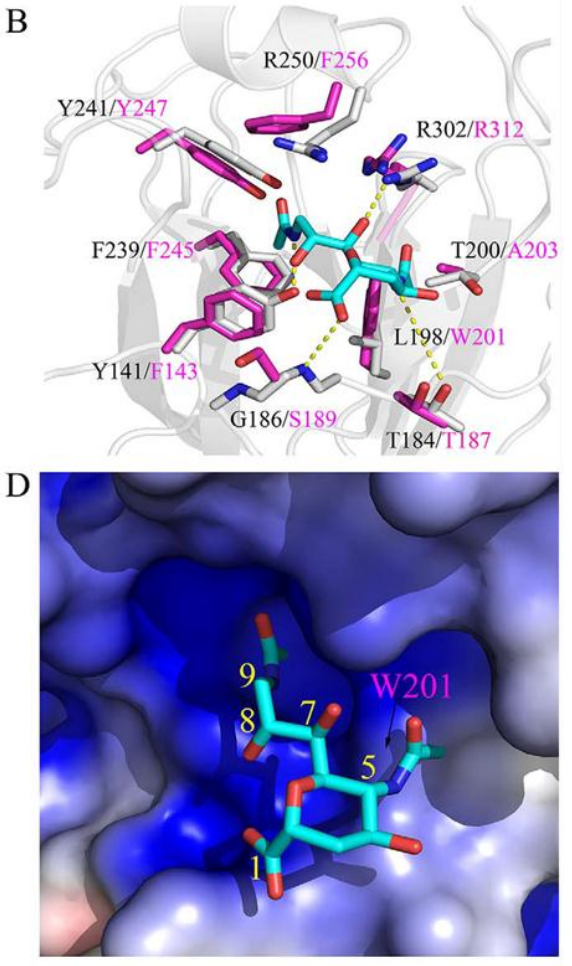

Figure 3-2. Altered ligand orientation in the D/OK receptor binding site as predicted by computer modeling may contribute to altered receptor specificity. A) Superposition of D/OK (pink sticks) and C/JHB (gray sticks) esterase active site. The blue sticks represent the modeled orientation of a 9-O-acetylated sialic acid analog. B) Superposition of the receptor binding site of both viruses. C) Electrostatic model of surface of C/JHB receptor binding pocket with 9-O-acetylated sialic acid. D) Electrostatic model of the D/OK receptor binding pocket with 9-O-acetylated sialic acid. Reprinted with permission and under the terms of the Creative Commons Attribution Non-Commercial License. Hause BM, Ducatez M, Collin EA, Ran Z, Liu R, Sheng Z, et al. (2013) Isolation of a Novel Swine Influenza Virus from Oklahoma in 2011 Which Is Distantly Related to Human Influenza C Viruses. PLoS Pathog 9(2): e1003176. doi:10.1371/journal.ppat.1003176 
Table 3-4. Strategy of receptor binding mutations.

\begin{tabular}{cccc}
\hline Virus & Abbreviation & Residue & Mutation \\
\hline D/OK & F143Y & 143 & F143 to Y \\
& W201L & 201 & W201 to L \\
& F256 R & 256 & F256 to R \\
& F143Y/ W201L & 143 and 201 & F143 to Y and W201 to L \\
F143Y/ F256R & 143 and 256 & F143 to Y and F256 to R \\
W201L/ F256R & 201 and 256 & W201 to L and F256 to R \\
& D/OK-Triple & 143,201 , and & F143 to Y, W201 to L, and F256 to R \\
C/JJ & Y141F & 256 & Y141 to F \\
& L198W & 141 & L198 to W \\
R250F & 258 & R250 to F \\
& Y141F/ L198W & 141 and 198 & Y141 to F and L198 to W \\
& Y141F/ R250F & 141 and 250 & Y141 to F and R250 to F \\
& L198W/ R250F & 198 and 250 & L198 to W and R250 to F \\
& C/JJ-Triple & 143,201, and & Y141 to F, L198 to W, and R250 to F \\
& & 250 &
\end{tabular}

Note that the virus, representative of ICV, used here has been referred to as $\mathrm{rg}-\mathrm{C} / \mathrm{JJ}$ in this dissertation since it was originally rescued from reverse genetics and subsequently passaged in egg allantoic fluid to obtain sufficient stock. For clarity, in chapter 3, rg-C/JJ will be referred to as simply C/JJ virus and WT-rg C/JJ virus will be used to refer to rescued reverse genetics virus which was not subsequently passaged in egg allantoic fluid. 
Table 3-5. Mutant receptor binding VLPs alter HA specificity of D/OK as compared to WT VLP and WT virus.

\begin{tabular}{lcc}
\hline \multirow{2}{*}{ Sample } & \multicolumn{2}{c}{$\begin{array}{c}\text { RBC Species } \\
\text { (Position of Acetylated Carbon) }\end{array}$} \\
\cline { 2 - 3 } & $\begin{array}{c}\text { Horse } \\
(\mathbf{C - 4})\end{array}$ & $\begin{array}{c}\text { Rat } \\
(\mathbf{C}-9)\end{array}$ \\
\hline D/OK WT VLP & 4 & 0 \\
F143Y & 2 & 16 \\
W201L & 2 & 16 \\
F256R & 4 & 8 \\
D/OK WT-rg & 4 & 2 \\
Virus & 16 & 1 \\
D/OK Virus & & \\
\hline
\end{tabular}

VLP particle concentration was normalized according to quantitation of total viral protein by ELISA with polyclonal antibodies. Total HA titers are reported.

Table 3-6. Mutant receptor binding VLPs alter HA specificity of C/JJ as compared to WT VLP and WT virus.

\begin{tabular}{lcc}
\hline \multirow{2}{*}{ Sample } & \multicolumn{2}{c}{ RBC Species } \\
& (Position of Acetylated Carbon) \\
\cline { 2 - 3 } & $\begin{array}{c}\text { Horse } \\
(\mathbf{C - 4})\end{array}$ & $\begin{array}{c}\text { Rat } \\
(\mathbf{C}-9)\end{array}$ \\
\hline C/JJ WT VLP & 0 & 1 \\
Y141F & 0 & 1 \\
L198W & 4 & 8 \\
R250F & 2 & 4 \\
C/JJ WT-rg Virus & 4 & 16 \\
C/JJ Virus & 0 & 4 \\
\hline
\end{tabular}

VLP particle concentration was normalized according to quantitation of total viral protein by ELISA with polyclonal antibodies. Total HA titers are reported. 


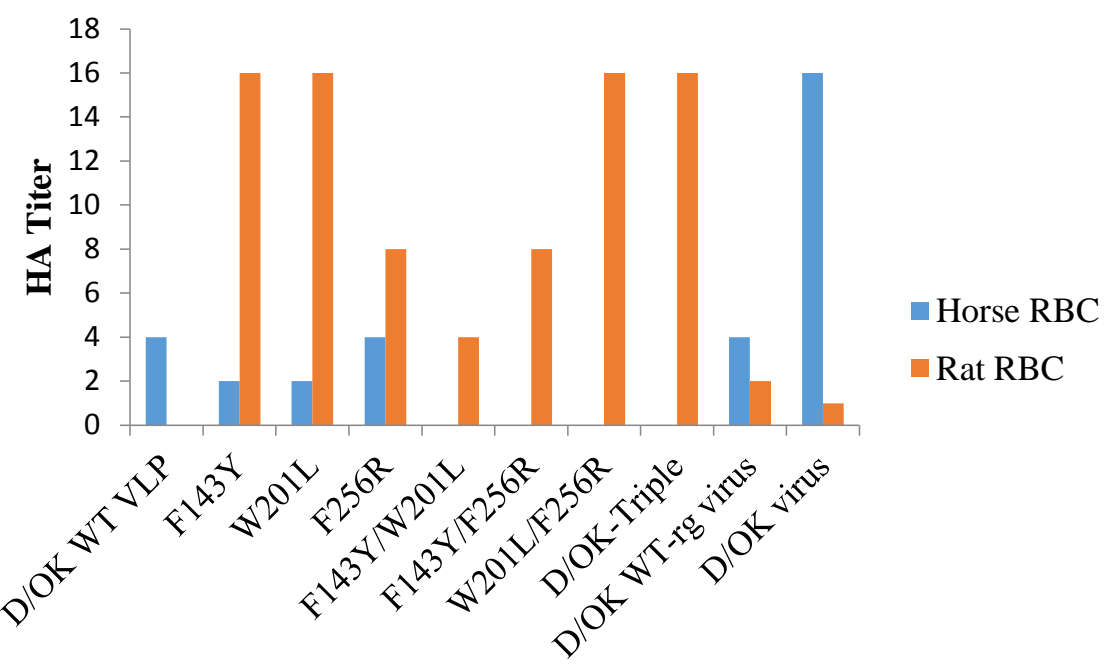

b

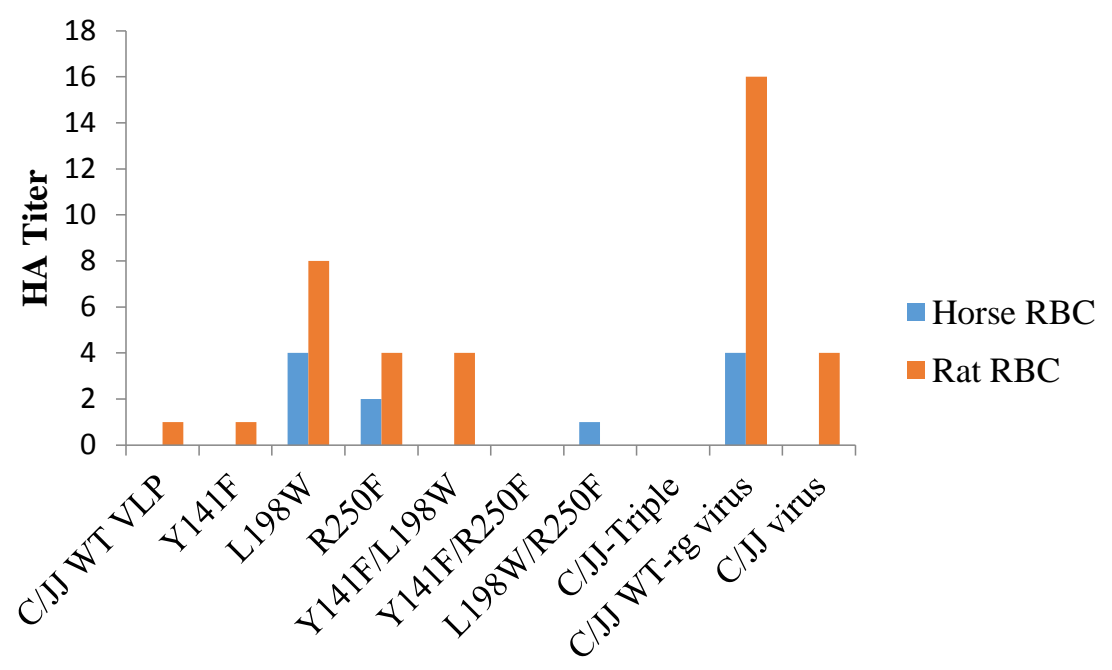

Figure 3-3. Double and triple receptor binding mutants have increased effect on HA specificity compared to single mutants.

VLP concentration was normalized according to quantitation for total viral protein by ELISA with polyclonal antibodies. Total HA titers are reported. Horse RBCs expressed 4-O-acetylated sialic acids and rat RBCs expressed 9-O-acetylated sialic acids. a) Results for D/OK VLP and mutants. b) Results for C/JJ VLP and mutants. 


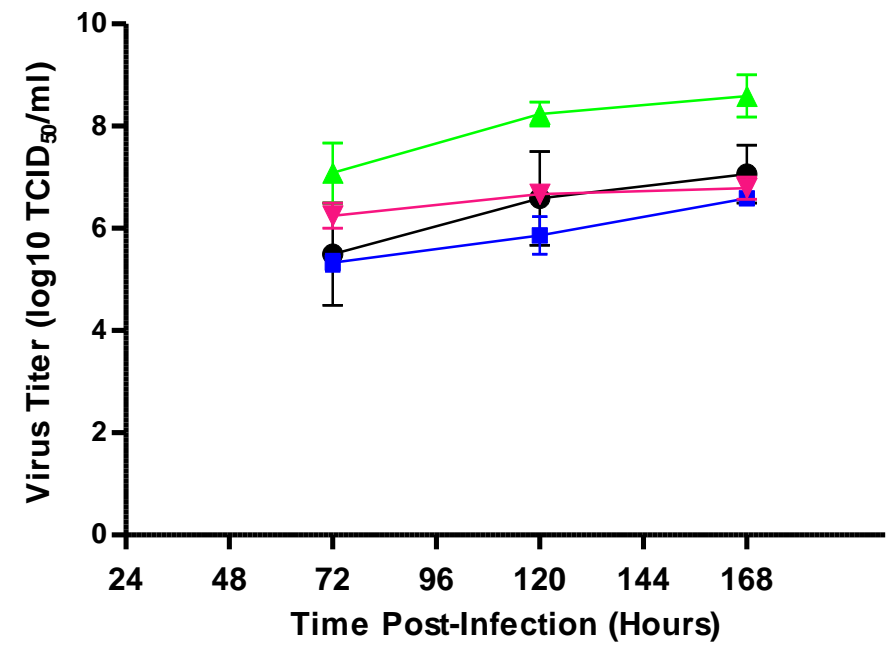

Figure 3-4. D/OK replication replicates to highest titers in $\mathrm{ST}$ cells at $37^{\circ} \mathrm{C}$.

ST and HRT-18G cells were infected at moi of 0.01 with D/OK and titers measured by $\mathrm{TCID}_{50}$ at 72, 120, and 168 hours post-infection. Replication kinetics was assessed in ST at $33^{\circ} \mathrm{C}$ (black line), HRT- $18 \mathrm{G}$ at $33^{\circ} \mathrm{C}$ (blue line), ST at $37^{\circ} \mathrm{C}$ (green line), and HRT-18G at $37^{\circ} \mathrm{C}$ (pink line). The area under the curve for each condition was: ST at $33^{\circ} \mathrm{C}(617.5)$, HRT- $18 \mathrm{G}$ at $33^{\circ} \mathrm{C}(567.5)$, ST at $37^{\circ} \mathrm{C}(771.6)$, and $\mathrm{HRT}-18 \mathrm{G}$ at $37^{\circ} \mathrm{C}(632.8)$. 
area under the curve was calculated for each condition, ST at 37oC was the condition which supported the most robust replication of D/OK: ST at 33oC (617.5), HRT-18G at 33oC (567.5), ST at 37oC (771.6), and HRT-18G at 37oC (632.8).

\section{D/OK pH Sensitivity}

$\mathrm{pH}$ of $\mathrm{D} / \mathrm{OK}$ inactivation and infectivity were assessed by comparison to an IAV, A/TN/09, in a pH inactivation assay (Figure 3-5). At pH 5.5 and below, infectivity of IAV was inhibited. D/OK infectivity did not decrease due to low $\mathrm{pH}$ treatment, suggesting that low $\mathrm{pH}$ may not trigger HEF fusion.

\section{Discussion}

The identification of a novel influenza genus, IDV, which shares at most $50 \%$ overall identity to ICV and exhibits an altered host range including an animal host reservoir reveals a zoonotic potential of the viruses classified in this genus. Further, IDV exhibits many of the characteristics generally attributed to zoonotic potential in IAV. The lack of direct evidence of IDV infection in humans presents the opportunity to investigate possible mechanism contributing to host species restrictions in IDV and impede zoonotic transmission. Several mechanisms of host species restriction have been attributed to the HA surface glycoprotein of IAV, which confers ability of zoonotic transmission from its numerous animal host species, and shares several similar functions to the HEF of IDV and ICV. Those zoonotic restrictions of IAV HA that may apply to IDV HEF include host receptor specificity, compatibility to host specific proteases, and optimal $\mathrm{pH}$ of virus activation which is compatible with specific host species. In this study, we investigated the possible role of host receptor specificity and $\mathrm{pH}$ of activation in the altered host range between IDV and ICV.

To first determine receptor specificity of IDV in comparison to ICV, the hemagglutination specificity of D/OK and several ICVs were assessed using a panel of RBC from different species. In this assay, IDV and ICV agglutinated chicken, rat, and horse RBCs, as was expected based upon previously published data of acetylated sialic acid content for chicken, rat, and horse RBCs. Our analysis further compared agglutination of rat RBC and horse RBC by IDV and ICV. The preference of IDV to agglutinate horse $\mathrm{RBC}$ to greater titers than rat $\mathrm{RBC}$ indicates 4-O-acetylated sialic acids as the primary receptor of IDV, as compared to ICV which preferentially binds 9-Oacetylated sialic acids.

Based upon computer model predictions, three amino acid residue differences were identified which may contribute to the altered receptor specificity of IDV HEF compared to ICV and mutational analysis of those residues was proposed. Although expression of mutant viruses to assess these mutations were impeded due to the federally imposed gain-of-function moratorium, VLPs expressing those proposed residue mutations were created via a reverse genetics system in which six of the seven IDV and 


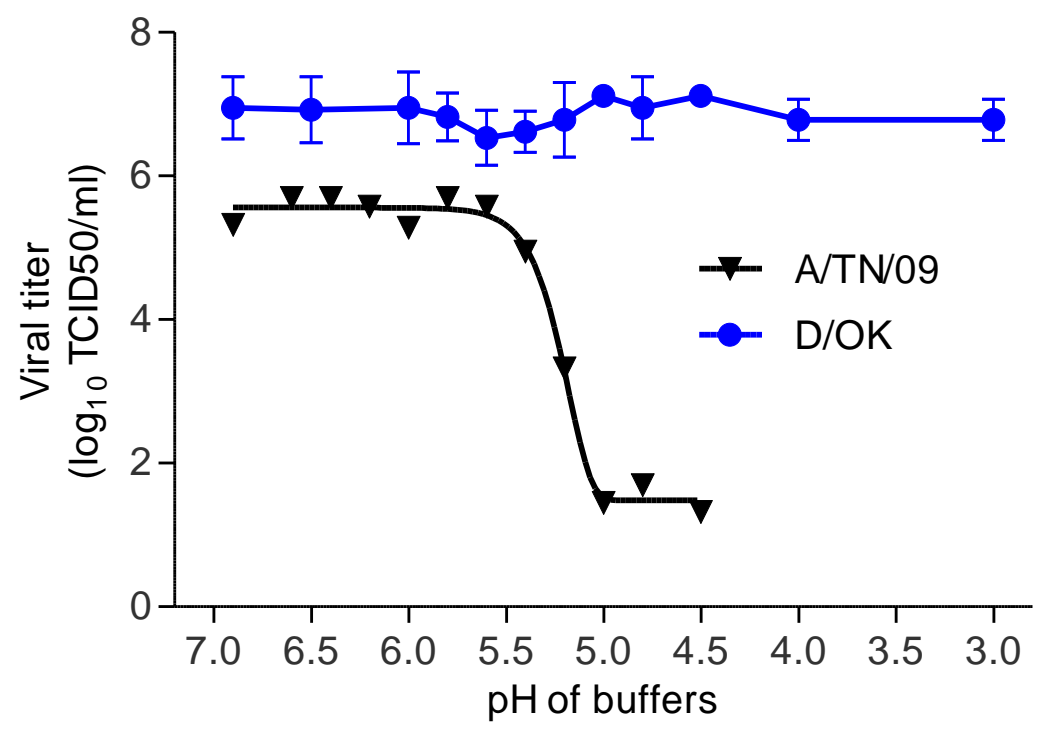

Figure 3-5. D/OK infectivity is not affected by $\mathrm{pH}$ inactivation.

Infectivity of each virus was determined as $\log 10 \mathrm{TCID} \mathrm{D}_{50} / \mathrm{ml}$ of virus after 5 days incubation at $33^{\circ} \mathrm{C}$ after inactivation at various $\mathrm{pH}$. 
ICV gene segments were co-expressed producing non-infectious VLPs. Expression of mutants as VLPs instead of infectious reverse genetics virus required optimization of the HA assay since the VLP agglutination profile of D/OK differed from the D/OK virus but this was remedied by incubation of the assay at $4^{\circ} \mathrm{C}$. The optimized HA assay of mutant VLPs revealed a role for each of the proposed amino acid residues in viral receptor tropism. Indeed, each single mutation expressing VLP reduced agglutination of the VLP preferred acetylated sialic acid expressing RBC, save for C/JJ Y141F, which did not alter agglutination from the WT VLP. The combination of double or triple mutations in D/OK VLP further increased agglutination of the non-preferred acetylated sialic acid expressing RBC. The C/JJ L198W/R250F VLP mutant followed this trend but C/JJ Y141F/L198W, Y141F/R250F, and triple mutant VLPs did not suggesting a more complex role of Y141F mutation in receptor specificity. These results suggest altered receptor binding specificity of IDV from ICV which may contribute to the altered host range of IDV. However, the contribution of this altered tropism is difficult to assess as the host and tissue distribution of acetylated sialic acids is largely unknown, save for a single study of 9-O-acetylated sialic acid immunohistochemistry in rat tissues, which did not include respiratory tissues.

Another possible mechanism of host restriction which is relevant to IDV and ICV is temperature of the host respiratory system. The temperature of the human upper and lower respiratory tract is $32^{\circ} \mathrm{C}$ and $37^{\circ} \mathrm{C}$, respectively, and ICV infection and diseases is generally restricted to the upper respiratory tract. This corresponds to optimal replication kinetics of ICV at $33^{\circ} \mathrm{C}$ in cell culture. Here, we demonstrate that $33^{\circ} \mathrm{C}$, while not restrictive, is suboptimal to $\mathrm{D} / \mathrm{OK}$ replication in certain cell lines and that replication in ST cells at $37^{\circ} \mathrm{C}$ was significantly higher at 120 and 168 hours post infection compared to other treatment groups. It may be that, if observation of in vitro replication kinetics corresponds to in vivo replication, IDV could effectively establish lower respiratory tract infections in humans once other zoonotic adaptations are acquired.

In addition to the role of $\mathrm{HEF}$ receptor specificity the HEF $\mathrm{pH}$ of activation may also impose host species restrictions. Results in this study show that D/OK infectivity is not decreased by pre-exposure to $\mathrm{pH}$ values from 3.0 to 7.0 , unlike a strain of IAV which is inactivated by exposure to $\mathrm{pH} 5.5$ and lower. Despite the preliminary nature of the results, the experiment was repeated twice in triplicate adding strength to this observation. These results raise the unexpected finding that IDV infectivity is not affected by $\mathrm{pH}$ and that it may utilize a $\mathrm{pH}$-independent pathway for host cell entry. This would be a unique trait for orthomyxoviruses and would be strong support for inclusion of this virus in a separate genus. This result should, however, be treated as preliminary and needs additional assays employed to confirm this observation.

Taken together, the results presented here suggest that the HEF protein of IDV exhibits altered receptor binding specificity from the HEF of ICV and optimal replication temperature and may contribute to a novel, $\mathrm{pH}$-independent mechanism for host cell entry. Both unique features of this protein may contribute to the altered host range and zoonotic potential of IDV and should be further investigated in the interest of public health. 


\section{CHAPTER 4. CONCLUSIONS AND FUTURE DIRECTIONS}

\section{Conclusions}

A novel virus was isolated in 2011 from a swine exhibiting clinical respiratory symptoms in Oklahoma (43). Initial characterizations led to a classification as an ICV because it contains seven, negative-sense, single stranded RNA gene segments including a HEF gene segment. The novel virus displayed $50 \%$ overall homology to that of human ICV and was antigenically distinct, which lead to the proposed classification as a new genus, IDV, and naming the representative virus $\mathrm{D} / \mathrm{OK}$, although this is a provisional designation $(43,45)$.

In addition to phylogenetic and antigenic divergence, $\mathrm{D} / \mathrm{OK}$ also has an altered host range from ICV. Human ICV infects $60 \%$ of children by 4 years of age and exhibits only sporadic transmission across species barriers into swine populations $(38,89)$, whereas $\mathrm{D} / \mathrm{OK}$ has been isolated from swine and cattle but only $1.3 \%$ seroprevalence was identified in a human cohort of 316 individuals $(38,43,45,89)$. Furthermore, serosurveillance has suggested that domestic sheep and goats are also hosts (47). Cattle are now believed to be the major reservoir for this virus due to high seroprevalence in the United States and the evolution of two phylogenetically and antigenically distinct clades represented by $\mathrm{D} / \mathrm{OK}$ and, provisionally named, D/660 $(45,46,48,49)$. Evidence of bovine IDV has also been reported in China, France, and Italy (50-52).

\section{Bovine Influenza Viruses Should Be Classified as IDV}

The antigenic and phylogenetic evidence supporting the classification of bovine influenza viruses as a novel genus is, as discussed in Chapter 1, consistent with the qualifications considered previously for influenza virus classification. IDV is

antigenically diverged, as the predicted $\mathrm{M}$ (p42) and NP proteins of IDV exhibit less than $40 \%$ amino acid identity to ICV proteins, and the PB1 protein of IDV, which is the most highly conserved of influenza proteins, shares only $72 \%$ identity with the closest related ICV. Although we present the observation of reassortment between recombinant IDV and ICV in this dissertation, this may not necessarily reflect compatibility of the two viruses to reassort in the event of a natural co-infection. In addition to terminal noncoding region compatibility, reassortment of two influenza viruses is also affected by the host-virus dynamic in which virus fitness and timing of infection in a specific host impacts reassortment (90-95). Though not permissible under the current US moratorium on influenza viruses, reassortant virus replication kinetics could provide additional insight into the functional compatibility of IDV and ICV proteins and fitness of reassortant viruses and the International Committee on Taxonomy of Viruses Orthomyxoviridae Study Group requested our in vitro reassortment data for consideration of IDV classification. Taken in consideration of these experimental limitations, while IDV and ICV noncoding regions support production of recombinant reassorant progeny, the 
antigenic and genetic distances observed between IDV and other influenza genera is compelling and we propose official designation of a new orthomyxovirus genus, IDV.

In practice, whether this virus is a new genus or not is really an academic question. We have provided evidence in this dissertation, and in published studies with collaborators, that it is clearly widespread in cattle and there is mounting evidence that it could well be associated with disease in this host $(46,54)$. We can categorically state that IDV is a pathogen of multiple ruminants and other animals although much work is to be done to understand its impact in these hosts. Whether IDV represents a zoonotic threat is less clear although the data that we have generated and detailed below suggests that if it is human cases are rare but plausible.

\section{D/OK Is Widespread in Cattle with at Least Ten Years of Exposure Evident in the United States Population}

The widespread prevalence of $\mathrm{D} / \mathrm{OK}$ in cattle for at least ten years provides evidence of probable human exposure to D/OK, particularly in those with frequent contact with cattle. Previously, a seroprevalence of $1.3 \%$ to D/OK was reported in a small cohort of 400 individuals with no reporting of prior exposure to cattle, prompting the hypothesis that individuals with higher exposure to bovine pathogens exhibit higher seroprevalence (43). We tested this hypothesis using a cohort consisting of over 700 individuals greater than 50 years of age living in communities which would increase the likelihood of higher exposure to bovine pathogens. The age of the cohort was particularly relevant as the likelihood of seroconversion increases with increasing exposure.

However, the serosurvey of this cohort did not reveal a seroprevalence greater than $1 \%$ prompting further serological analysis of the positive samples. HI titer of D/OK positive samples did not statistically correlate to HI titers of a contemporarily circulating ICV, but tended to be higher in the samples with higher ICV titers. Further, preadsorption of the sera with ICV prior to HI analysis of the samples abrogated the positive HI result to $\mathrm{D} / \mathrm{OK}$. These results suggest that seropositivity to $\mathrm{D} / \mathrm{OK}$ is actually caused by crossreactive antibodies that were generated by a previous exposure to human ICV.

Taken together, these results demonstrate that IDV is not highly infectious in humans, although work should be done to continue surveillance in highly exposed populations. Previous surveillance in feedlot cattle suggest younger cattle are highly susceptible to IDV infection and a cohort of individuals that work in feedlots or in the veterinary field may exhibit greater evidence of seroconversion (46). Further, seroprevalence is primarily assessed by inhibition of receptor binding by HA for IAV or HEF for IDV and ICV; however, in the case of IDV and ICV, the HEF protein exhibits both receptor binding and receptor destroying functions. Increasing evidence shows that antibodies reactive to NA of IAV may play a role in immune protection and future work should address the possibility that protective antibodies generated to IDV specifically target esterase and not receptor binding function (96-98). Last, it cannot be ruled out, due to existence of two antigenically distinct clades of IDV, that the population included in this study had been previously exposed to the antigenic clade not tested or that the cattle 
those individuals had been exposed to were never infected by IDV. Future work should address both questions.

\section{D/OK Possesses Characteristics Generally Attributed to Zoonotic Potential and Can Reassort with ICV}

Lack of direct evidence of D/OK infection in humans with likely exposure to bovine pathogens led us to question the zoonotic potential of IDVs. Addressing this question was somewhat problematic as the most similarly influenza genus, ICV, is primarily a human virus and no laboratory models exist for assessment of ICV zoonotic transmission. Thus, laboratory methods generally used to assess zoonotic potential of IAV were employed to assess IDV zoonotic potential and were simultaneously validated for use in the evaluation of ICV zoonotic potential. First, IDV and ICV replication kinetics were compared in NHBE cells, an in vitro model of the human upper respiratory tract used commonly in studies of IAVs. All ICVs assessed replicated in NHBE cells and $\mathrm{D} / \mathrm{OK}$ replicated to statistically higher titers than the ICV at two time points. Therefore, $\mathrm{D} / \mathrm{OK}$ could infect and replicate in human epithelial cells.

Second, we compared the transmissibility of D/OK and ICVs in ferrets. Hause, et al. 2013 previously showed that $\mathrm{D} / \mathrm{OK}$ does transmit via direct contact in ferrets and induce seroconversion in infected animals but it was impossible to determine the significance of these results since the ferret transmission model had never been assessed for ICV (43). In this study, shedding of C/Kowloon was detected in inoculated ferrets and direct contact ferrets seroconverted, which suggests transmission via direct contact, although viral shedding from direct contact ferrets was not detected. D/OK transmitted to direct contact ferrets, as seen previously, but no evidence of seroconversion was detected. The absence of ferret seroconversion after D/OK infection compared to C/Kowloon may have been due to the reduced titer of $\mathrm{D} / \mathrm{OK}$ used for ferret inoculation compared to $\mathrm{C} /$ Kowloon. The protocol used to determine the titers of the $\mathrm{C} / \mathrm{Kowloon}$ and D/OK stock viruses involved extending the incubation time by 48 hours before determining TCID 50 titers. Shorter incubation time in the previous study may have underestimated the D/OK titer, leading to a greater dilution of $\mathrm{D} / \mathrm{OK}$ in our study to obtain the same infectious dose. If true, the $\mathrm{D} / \mathrm{OK}$ ferret inoculum was of a lower titer compared to the $\mathrm{C} / \mathrm{Kowloon}$ inoculum, and may have been sub-immunogenic. Indeed, although D/OK shedding was detected in inoculated and direct contact ferrets, the titers were lower than seen previously. Regardless the inconsistencies seen between the previously published study and the ferret transmission experiment discussed here, D/OK virus shedding was detected in direct contact ferrets for both studies. We also show that one of two human ICV likely transmitted by direct contact, as evidenced by seroconversion indicating that ferrets may be a useful model for IDV/ICV zoonotic transmission.

The NHBE replication kinetics and ferret transmission studies presented here demonstrate IDV replication and transmission characteristics equal to or higher than the assessed ICV. However, the implications of these results do not necessarily indicate increased zoonotic potential of IDV since little is known about ICV pathogenicity and 
transmission and validated models for such assessment do not exist. The results do demonstrate that $\mathrm{D} / \mathrm{OK}$ does exhibit some of the characteristics generally attributed to zoonotic potential for IAV.

In light of possible IDV zoonotic potential, further consideration for the possibility of IDV reassortment with ICV was addressed. Reassortment of IDV and ICV was attempted in a previous study by another research group using an in vitro coinfection model but this study failed to identify reassortant progeny. This was surprising as compatibility of influenza gene reassorment is largely determined by the complementarity of the terminal, noncoding ends and, for IDV and ICV, there is only a single nucleotide difference in these regions. Here, reassortment potential is addressed by rescue of reassortant viruses using a reverse genetics system. This study demonstrated that each of the seven $\mathrm{rg}-\mathrm{D} / \mathrm{OK}$ genes could be rescued in the context of a $\mathrm{rg}-\mathrm{C} / \mathrm{JJ}$ virus indicating that, if zoonotic transmission of IDV is achieved, co-infection by IDV and ICV could yield reassortant progeny with increased transmissibility.

\section{D/OK May Possess Altered Host Restrictions from ICV}

Lack of evidence of IDV infection in humans, despite exhibiting characteristics attributed to zoonotic potential in IAV, suggests that mechanisms exist that maintain species barriers for IDV. While the mechanisms which impose species restrictions on influenza viruses are highly relevant to public health, they are not well understood. For IAV, the surface glycoproteins have been implicated, including host receptor specificity and $\mathrm{pH}$ of activation. The possible role of these mechanisms in IDV host restriction was assessed by comparison to ICV. The surface glycoprotein of ICV and IDV, HEF, was assessed for receptor binding specificity by HA using RBCs from various animal species. These experiments revealed a preference of IDV for agglutination of 4-O-acetylated sialic acid-rich RBCs compared to ICV, which preferentially agglutinated 9-O-acetylated sialic acid-rich RBCs. Previously published computer modeling predicted that three nonhomologous amino acids in the receptor binding domain of the IDV and ICV HEFs would alter receptor binding. Ideally, the significance of these amino acids would have been assessed in mutant viruses. However, the current moratorium on gain-of-function studies precluded such an experiment. Instead, it was necessary to create non-infectious virus-like particles (VLPs) using six of the seven ICV or IDV reverse genetics plasmids containing these mutations.

Initial expression of VLP required some troubleshooting as the agglutination profile of IDV VLP differed from that of IDV virus. There are many possible explanations for this difference, including altered HEF incorporation into the VLP, altered VLP morphology, or altered HEF glycosylation due to propagation of virus in ST cells and rescue of VLP in 293T cells. These differences could result in altered receptor binding or esterase activity leading to the observed differences in agglutination profile between IDV VLP and virus. Ultimately, the altered agglutination profile was remedied by incubation of the assay at $4^{\circ} \mathrm{C}$ indicating that esterase activity was likely the cause of this difference although protein conformation may also be affected by the lowered 
temperature. The cause of altered VLP agglutination could be further addressed via use of an HEF inhibitor, diisopropyl fluorophosphate, in the agglutination assay which would be expected to restore VLP agglutination to that of the virus agglutination profile by reducing cleavage of the IDV receptor on RBCs. Alternatively, various techniques including electron microscopy, Western blotting, or coumassie staining of total viral protein would provide a comparison of virion and VLP morphology and HEF incorporation which could also contribute to the altered VLP agglutination profile.

After optimization of the VLP assay, which revealed a likely difference in esterase activities between the IDV VLP and IDV virus, we tested the impact of the aforementioned mutations in the D/OK VLPs. Individually, these mutations increased the agglutination of RBCs that were not 'preferred' previously. Introduction of two or three of these mutations further decreased agglutination of the preferred RBC species. The results of the VLP assays suggested that the predicted amino acids do influence the host receptor specificity of IDV and ICV. Indeed, conversion of combinations of the IDV amino acid residues to be homologous to ICV residues altered receptor binding to be more "ICV-like" and vice versa. A natural extrapolation of these data would suggest that a similar phenomenon applies to IDV and ICV host range as seen in IAV where receptor distribution is central to virus host partnerships. One could hypothesize that human respiratory tissues lack the 4-O-acetylated sialic acids needed for infection by IDV and, thereby, providing a mechanism for the lack of frequent human infection inferred from our serologic studies. Such a hypothesis could be readily tested by closer examination of 4-O-acetylated sialic acids lining the bovine and human respiratory tracts. It would further be of interest, though not permissible under the conditions of the current US moratorium, if the mutant HEF of both viruses would contribute to altered fitness of infectious virus in cell culture or an animal model such as ferrets or guinea pigs.

Another aspect of host restriction for IDV addressed optimal temperature conditions for replication. Avian IAV replication is adapted for replication at $40^{\circ} \mathrm{C}$ which corresponds to the temperature of avian intestinal tracts but $32^{\circ} \mathrm{C}$, the temperature of the proximal human respiratory system is restrictive, possibly serving as a barrier to infection by avian IAV in humans. We show that, in cell culture, IDV replicates to relatively high titers at both $33^{\circ} \mathrm{C}$ and $37^{\circ} \mathrm{C}$, the higher temperature associated with the human lower respiratory track suggesting that IDV infectivity would not be restricted by temperatures of the proximal human respiratory system. It is possible that the in vitro observations made in this study are not conferred to in vivo conditions; however, temperature restrictions of ICV in cell culture do correspond to the restriction of ICV to primarily upper respiratory infections caused in humans. Comparison of replication kinetics in human primary cells such as NHBEs or tissue explants from upper and lower respiratory tracts at both $33^{\circ} \mathrm{C}$ and $37^{\circ} \mathrm{C}$ would add to interpretation of these findings.

The $\mathrm{pH}$ of inactivation of IDV was also compared to IAV in a preliminary experiment to determine total virus infectivity after exposure to buffers of varying $\mathrm{pH}$. The results suggest that IDV infectivity is not decreased by exposure to $\mathrm{pH}$ ranging from 3.0 to 7.0, in contrast to IAV. This data, albeit very preliminary, raises the unexpected suggestion that IDV replication is $\mathrm{pH}$ independent. However, further experimentation 
will need to be conducted in order to confirm this $\mathrm{pH}$ independent mechanism. It is possible that exposure to low $\mathrm{pH}$ does indeed induce a conformational change of the IDV $\mathrm{HEF}$ but that it is a reversible change and returning the virion to neutral $\mathrm{pH}$ for infection reverses the $\mathrm{pH}$-induced inactivation. This possibility would be addressed experimentally with the use of pharmacological agents to raise endosomal $\mathrm{pH}$, including bafilomycin A, a vacuolar H+-ATPase, and monensin, a carboxylic ionophore (99). If IDV does utilize a $\mathrm{pH}$ independent mechanism of cell entry IDV infection would not be affected by use of these pharmacological agents. Ammonium chloride is another possible reagent for assessment of $\mathrm{pH}$ independent cell entry although it induced conformational changes to the HA of IAV during cell surface transport and packaging. Ammonium chloride could be evaluated for use with IDV and ICV. Additional assays including $\mathrm{pH}$ syncytia formation and $\mathrm{pH}$ of activation should also be optimized to confirm the observation that IDV utilizes a $\mathrm{pH}$ independent mechanism of cell entry. If this observation is confirmed, it would be a first for this family of viruses and is an area that needs to be vigorously explored. It has become clear in recent years that HA stability in IAV is an underappreciated factor contributing to host range $(69,84)$. The preliminary observation of a $\mathrm{pH}$-independent mechanism of IDV infectivity could prove very valuable to understanding IDV infectious cycle and host species restrictions.

\section{Continued IDV Assessment and Surveillance for Public Safety}

The widespread exposure of the United States population to IDV in cattle necessitates continued surveillance of IDV in America and across the globe. Particularly, expanded sero-surveillance should be conducted in the countries of South America, with respect to the single identification of $\mathrm{D} / \mathrm{OK}$ seroprevalence in Chile, to better understand worldwide exposure and risk posed to the human population. Expanded studies should also include surveillance of both identified phylogenic/antigenic lineages of bovine IDV for a more complete assessment of prevalence in cattle and risk to humans. Additionally, with respect to low seroprevalence and cross-reactivity of $\mathrm{HI}$ antibody titers in our human cohort, it may be that IDV is not immunogenic in humans or that neutralizing antibodies generated in response to IDV infection are not inhibitory to receptor binding and thus not detectable by HI or MN. Alternative assays may better detect IDV neutralizing antibodies, specifically esterase inhibition assays. Finally, the low seroprevalence seen in our human cohort could be explained by the cross-reactivity of human IDV directed antibodies. IDV may zoonotically transmit but the high seroprevalence of ICV in humans and cross-reactivity of ICV generated antibodies may provide protection against IDV established infections. Results of a ferret IDV challenge would be interesting in light of our sero-surveillance data.

The assessment of zoonotic potential of IDV in this study is based upon current laboratory models commonly used for assessment of IAV zoonotic potential. They may not represent optimal methods for assessment of zoonotic potential of ICV or IDV. Specifically, we were not able to detect direct contact transmission of one of our human ICV in our ferret study and no ferrets demonstrated clinical signs due to virus infection in that experiment. Additionally, a previous study was not able to detect IDV replication in 
laboratory inoculated ferret tissues. Validation of the ferret model for IDV and ICV zoonotic transmission, specifically viral replication competence in ferret respiratory primary cell culture and tissue, would contribute further support of the conclusions presented here. Another laboratory model for consideration, guinea pigs, has demonstrated IDV transmission by direct contact, with detection of virus in nasal turbinates and lung tissues. Guinea pigs may be a better animal model for IDV transmission studies and should be evaluated for such use in comparison to ICV transmission.

Determination of the possible receptor binding specificities of IDV that differ from ICV may be valuable concerning host range and adaptations necessary for zoonotic transmission of IDV. Additional and more precise experimentation needs to be conducted to confirm the receptor specificity of IDV, specifically, acetylated sialic acid binding arrays with IDV and ICV. Additionally, expanded assessment of acetylated sialic acid expression in bovine and human respiratory tissues, including lung tissues, by immunohistochemistry would greatly enhance the understanding of the role of receptor specificity in host barriers of IDV. If the specific evolutionary changes necessary to increase zoonotic transmission of IDV via receptor specificity are determined, this will lend to more effective surveillance efforts for the detection of zoonotic IDV.

Addressing the aspects of temperature restriction on IDV replication will add to further understanding of IDV host restriction and zoonotic potential. Exposure to ICV is widespread in humans and infections are primarily restricted to the upper respiratory track although lower respiratory tract infections and hospitalizations do occasionally occur. No studies, however, have elucidated whether specific mutations are acquired by ICV to enable replication in the human lower respiratory tract. A study of ICV-associated infections leading to hospitalization could reveal the mutations, if any, which contribute to more severe disease caused by ICV and could be used to better inform surveillance efforts for detection of zoonotic IDV.

Finally, if IDV indeed enters the host cell via a $\mathrm{pH}$ independent mechanism, the very exciting opportunity is presented to elucidate a novel mechanism for orthomyxovirus host cell entry. Further experimentation will be needed to consider the possibility that IDV utilizes receptor-mediated endocytosis followed by $\mathrm{pH}$-independent fusion, fusion at the plasma membrane and disassembly of the cell's actin cortex, or another novel mechanism $(100,101)$. Various reagents and assays are available to fully evaluate IDV mechanism of cell entry. It would seem likely that, given the general structural homology of IDV to other influenza genera including a predicted M2 polypeptide, IDV utilizes the endocytic transport pathway for virion uncoating and cell entry despite that HEF induction of membrane fusion is not $\mathrm{pH}$ dependent. Amantadine is an antiviral which acts via a mechanism of IAV M2 inhibition and, although specific to IAV M2 and not effective against IBV, could be evaluated for use with IDV and ICV ion channel proteins represented by the $\mathrm{P} 42$ polypeptide (102). Results from use of amantadine would be expected to inhibit IDV infection. Another caveat to study of $\mathrm{pH}$ independent cell entry is elucidated by filoviruses such as Ebola, which were previously believed to utilize a $\mathrm{pH}$ independent mechanism of cell entry, in part, because Ebola 
infectivity was not inactivated by low $\mathrm{pH}$. Ebola is now known to require $\mathrm{pH}$ induced conformational change prior to subsequent cleavage by endosomal cysteine proteases $(103,104)$. This may not be the case for IDV considering the crystal structure of the ligand-bound IDV HEF is in a cleaved confirmation; however, there are a myriad of specific protease inhibitors which would be expected to reduce IDV infection in an inhibitor-specific manner if this is the mechanism utilized by IDV (71). Once identified, pre-incubation with said protease, with or without previous $\mathrm{pH}$ exposure, or deletion of the protease target sequence would also inhibit IDV infection and further validate IDV $\mathrm{pH}$ independent cell entry. Last, various assays to determine if IDV enters the host cell via clathrin/caveolin-mediated endocytosis, clathrin/caveolin-independent endocytosis, or macropinocytosis/phagocytosis can be used. Inhibitors such as dynasore block clathrin/caveolin-mediated endocytosis via inhibition of dynamin activity but not clathrin/caveolin-independent pathways (105). Inhibition of IDV infection using dynasore or related inhibitor would indicate use of clathrin/caveolin mediated endocytosis. Further, cytochalasin D, which inhibits actin polymerization, inhibits phagocytosis and macropinocytosis due to inability to rearrange the actin cytoskeleton $(106,107)$. IDV infection inhibition by cytochalasin D but not dynasore would indicate possible entry by macropinocytosis or phagocytosis. Use of these and/or related inhibitors can assist to tease out the mechanism of IDV cell entry.

If IDV replication is indeed $\mathrm{pH}$ independent it would represent a remarkable evolutionary distinction from IAV. What factors led to differential entry mechanisms of IVD and IDV may provide further insight into the mechanism of host range differences between the two.

\section{Summary}

The study outlined in this dissertation reveals that IDV is widespread in cattle in the United States, with zoonotic exposure to the US population over a period of at least ten years. IDV is also present in South America. While there is no direct evidence of human infections, IDV does possess characteristics attributed to zoonotic potential of IAV. However, host receptor specificity, a characteristic believed to contribute to the host restriction of IAVs, may contribute to the species barriers of IDV. Further, IDV may utilize a $\mathrm{pH}$-independent mechanism for host cell entry, unique from other influenza viruses. IDV may present a zoonotic risk and should continue to be monitored in cattle and human populations while continued studies of the mechanisms which confer host barriers are assessed. 


\section{LIST OF REFERENCES}

1. Digard P, Tiley L, Elton D. Orthomyxovirus genome transcription and replication. In: Raney KD, Gotte M, Cameron CE, editors. Viral Genome Replication. Boston, MA: Springer US; 2009. p. 163-80.

2. Webster RG, Bean WJ, Gorman OT, Chambers TM, Kawaoka Y. Evolution and ecology of influenza A viruses. Microbiol Rev. 1992;56(1):152-79.

3. Wu Y, Wu Y, Tefsen B, Shi Y, Gao GF. Bat-derived influenza-like viruses. Trends Microbiol. 2014;22(4):183-91.

4. Tong S, Zhu X, Li Y, Shi M, Zhang J, Bourgeois M, et al. New world bats harbor diverse influenza A viruses. PLoS Pathog. 2013;9(10):e1003657. doi:10.1371/journal.ppat.1003657.

5. Oong XY, Ng KT, Lam TT, Pang YK. Epidemiological and Evolutionary Dynamics of Influenza B Viruses in Malaysia , 2012-2014. PLoS One. 2015;10(8):e0136254. doi:10.1371/journal.pone.0136254.

6. Buonagurio D a, Nakada S, Fitch WM, Palese P. Epidemiology of influenza C virus in man: multiple evolutionary lineages and low rate of change. Virology. 1986;153(1):12-21.

7. Matsuzaki Y, Mizuta K, Sugawara K, Tsuchiya E, Hongo S, Suzuki H, et al. Frequent Reassortment among Influenza C Viruses. J Virol. 2003;77(2):871-81.

8. Matsuzaki Y, Sugawara K, Mizuta K, Tsuchiya E, Muraki Y, Hongo S, et al. Antigenic and genetic characterization of influenza $\mathrm{C}$ viruses which caused two outbreaks in Yamagata City, Japan, in 1996 and 1998. J Clin Microbiol. 2002;40(2):422-9.

9. Desselberger U, Racaniello VR, Zazra JJ, Palese P. The 3' and 5'-terminal sequences of influenza A, B, and C virus RNA segments are highly conserved and show partial inverted complentarity. Gene. 1980;8:315-28.

10. Wang M, Veit M. Hemagglutinin-esterase-fusion ( $\mathrm{HEF}$ ) protein of influenza C virus. Protein Cell. 2016;7(1):28-45.

11. Fujii K, Fujii Y, Noda T, Muramoto Y, Watanabe T, Takada A, et al. Importance of both the coding and the segment-specific noncoding regions of the influenza $\mathrm{A}$ virus NS segment for its efficient incorporation into virions. J Virol. 2005;79(6):3766-74. 
12. Lee YS, Seong BL. Nucleotides in the panhandle structure of the influenza B virus virion RNA are involved in the specificity between influenza A and B viruses. J Gen Virol. 1998;79(7):673-81.

13. Crescenzo-Chaigne B, Barbezange C, Frigard V, Poulain D, van der Werf S. Chimeric NP non coding regions between type $\mathrm{A}$ and $\mathrm{C}$ influenza viruses reveal their role in translation regulation. PLoS One. 2014;9(9):e109046. doi:10.1371/journal.pone.0109046.

14. Crescenzo-Chaigne B, van der Werf S, Naffakh N. Differential Effect of Nucleotide Substitutions in the 3' Arm of the Influenza A Virus vRNA Promoter on Transcription/Replication by Avian and Human Polymerase Complexes Is Related to the Nature of PB2 Amino Acid 627. Virology. 2002;303(2):240-52.

15. Crescenzo-Chaigne B, Barbezange C, van der Werf S. The Panhandle formed by influenza $\mathrm{A}$ and $\mathrm{C}$ virus NS non-coding regions determines NS segment expression. PLoS One. 2013;8(11):e81550. doi:10.1371/journal.pone.0081550.

16. Yamashita M, Krystal M, Palese P. Comparison of the three large polymerase proteins of influenza A , B , and C viruses. Virology. 1989;171:458-66.

17. Boivin S, Cusack S, Ruigrok RWH, Hart DJ. Influenza A Virus Polymerase : Structural Insights into Replication and Host Adaptation Mechanisms. J Biol Chem. 2010;285(37):28411-7.

18. Hengrung N, Omari K El, Martin IS, Vreede FT, Cusack S, Rambo RP, et al. Crystal structure of the RNA-dependent RNA polymerase from influenza $\mathrm{C}$ virus. Nature. 2015;527(7576):114-7.

19. Crescenzo-Chaigne B, Naffakh N, van der Werf S. Comparative analysis of the ability of the polymerase complexes of influenza viruses type A, B and C to assemble into functional RNPs that allow expression and replication of heterotypic model RNA templates in vivo. Virology. 1999 Dec 20;265(2):342-53.

20. Donelan NR, Dauber B, Wang X, Basler CF, Wolff T, García-sastre A. The N-and C-terminal domains of the NS1 protein of influenza B virus can independently inhibit IRF-3 and beta interferon promoter activation. J Virol. 2004;78(21):1157482 .

21. Pachler K, Vlasak R. Influenza C virus NS1 protein counteracts RIG-I-mediated IFN signalling. Virol J. 2011;8(1):48.

22. Muraki Y, Furukawa T, Kohno Y, Matsuzaki Y, Takashita E, Sugawara K, et al. Influenza C virus NS1 protein upregulates the splicing of viral mRNAs. J Virol. 2010;84(4):1957-66. 
23. Kohno Y, Muraki Y, Matsuzaki Y, Takashita E, Sugawara K, Hongo S. Intracellular localization of influenza $C$ virus NS2 protein (NEP) in infected cells and its incorporation into virions. Arch Virol. 2009;154:235-43.

24. Muraki Y. Influenza $C$ virus : structure and function of $M$ gene and its products lipid bilayer vRNA. In: Adoga M, editor. Molecular Virology. Rijeka: InTech; 2012. p. 66-74.

25. Yamashita M, Krystal M, Palese P. Evidence that the matrix protein of influenza C virus is coded for by a spliced mRNA. J Virol. 1988;62(9):3348-55.

26. Li ZN, Hongo S, Sugawara K, Sugahara K, Tsuchiya E, Matsuzaki Y, et al. The sites for fatty acylation, phosphorylation and intermolecular disulphide bond formation of influenza C virus CM2 protein. J Gen Virol. 2001;82:1085-93.

27. Takeuchi K, Shaughnessy MA, Lamb RA. Influenza virus M2 protein ion channel activity is not required to maintain the equine-1 hemagglutinin in its native form in infected cells. Virology. 1994;202:1007-11.

28. Herrler G, Dürkop I, Becht H, Klenk HD. The glycoprotein of influenza C virus is the haemagglutinin, esterase and fusion factor. J Gen Virol. 1988;69:839-46.

29. Vlasak R, Krystal M, Nacht M, Palese P. The influenza C virus glycoprotein (HE) exhibits receptor-binding (hemagglutinin) and receptor-destroying (esterase) activities. Virology. 1987;160(2):419-25.

30. Rogers GN, Herrler G, Paulson JC, Klenk HD. Influenza C virus uses 9-O-acetyl$\mathrm{N}$-acetylneuraminic acid as a high affinity receptor determinant for attachment to cells. J Biol Chem. 1986;261(13):5947-51.

31. Suzuki Y, Nakao T, Ito T, Watanabe N, Toda Y, Guiyun X, et al. Structural determination of gangliosides that bind to influenza $\mathrm{A}, \mathrm{B}$, and $\mathrm{C}$ viruses by an improved binding assay: strain-specific receptor epitopes in sialo-sugar chains. Virology. 1992;189(1):121-31.

32. Marshall N, Priyamvada L, Ende Z, Steel J, Lowen AC. Influenza virus reassortment occurs with high frequency in the absence of segment mismatch. PLoS Pathog. 2013;9(6):e1003421. doi:10.1371/journal.ppat.1003421.

33. Osterhaus ADME, Rimmelzwaan GF, Martina BEE, Bestebroer TM, Fouchier RAM. Influenza B Virus in Seals. Science. 2000;288(5468):1051-3.

34. Kimura H, Abiko C, Peng G, Muraki Y, Sugawara K, Hongo S, et al. Interspecies transmission of influenza $\mathrm{C}$ virus betwen humans and pigs. Virus Res. 1997;48:71-9. 
35. Salez N, Mélade J, Pascalis H, Aherfi S, Dellagi K, Charrel RN, et al. Influenza C virus high seroprevalence rates observed in 3 different population groups. J Infect. 2014;69(2):182-9.

36. O'Callaghan RJ, Gohd RS, Labat DD. Human antibody to influenza C virus: its age-related distribution and distinction from receptor analogs. Infect Immun. 1980;30(2):500-5.

37. Hirsilä M, Kauppila J, Tuomaala K, Grekula B, Puhakka T, Ruuskanen O, et al. Detection by reverse transcription-polymerase chain reaction of influenza $\mathrm{C}$ in nasopharyngeal secretions of adults with a common cold. J Infect Dis. 2001;183(8):1269-72.

38. Matsuzaki Y, Katsushima N, Nagai Y, Shoji M, Itagaki T, Sakamoto M, et al. Clinical features of influenza $\mathrm{C}$ virus infection in children. J Infect Dis. 2006;193(9):1229-35.

39. Principi N, Scala A, Daleno C, Esposito S. Influenza C virus-associated community-acquired pneumonia in children. Influenza Other Respi Viruses. 2013;7(6):999-1003.

40. Calvo C, Garcia-Garcia ML, Centeno M, Perez-Brena P, Casas I. Influenza C virus infection in children, Spain. Emerg Infect Dis. 2006;12(10):1621-2.

41. Sugawara K, Nishimura H, Hongo S, Kitame F, Nakamura K. Antigenic characterization of the nucleoprotein and matrix protein of influenza $\mathrm{C}$ virus with monoclonal antibodies. J Gen Virol. 1991;72:103-9.

42. Tada Y, Hongo S, Muraki Y, Sugawara K, Kitame F, Nakamura K. Evolutionary analysis of influenza C virus M genes. Virus Genes. 1997;15(1):53-9.

43. Hause BM, Ducatez M, Collin E a, Ran Z, Liu R, Sheng Z, et al. Isolation of a novel swine influenza virus from Oklahoma in 2011 which is distantly related to human influenza C viruses. PLoS Pathog. 2013;9(2):e1003176. doi:10.1371/journal.ppat.1003176.

44. Colman PM, Hoyne PA, Lawrence MC. Sequence and structure alignment of paramyxovirus hemagglutinin-neuraminidase with influenza virus neuraminidase. J Virol. 1993;67(6):2972-80.

45. Hause BM, Collin EA, Liu R, Huang B, Sheng Z, Lu W, et al. Characterization of a novel influenza virus in cattle and swine : proposal for a new genus in the Orthomyxoviridae family. MBio. 2014;5(2):e00031-14. doi:10.1128/mBio.0003114. 
46. Ferguson L, Eckard L, Epperson WB, Long L-P, Smith D, Huston C, et al. Influenza D virus infection in Mississippi beef cattle. Virology. 2015;486:28-34.

47. Quast M, Sreenivasan C, Sexton G, Nedland H, Singrey A, Fawcett L, et al. Serological evidence for the presence of influenza D virus in small ruminants. Vet Microbiol. 2015;180:281-5.

48. Collin E a., Sheng Z, Lang Y, Ma W, Hause BM, Li F. Cocirculation of two distinct genetic and antigenic lineages of proposed influenza $D$ virus in cattle. $J$ Virol. 2015;89(2):1036-42.

49. Sheng Z, Ran Z, Wang D, Hoppe AD, Simonson R, Chakravarty S, et al. Genomic and evolutionary characterization of a novel influenza-C-like virus from swine. Arch Virol. 2014;159(2):249-55.

50. Jiang W-M, Wang S-C, Peng C, Yu J-M, Zhuang Q-Y, Hou G-Y, et al. Identification of a potential novel type of influenza virus in bovine in China. Virus Genes. 2014;49(3):493-6.

51. Ducatez MF, Pelletier C, Meyer G. Influenza D Virus in Cattle , France , 2011 2014. Emerg Infect Dis. 2015;21(2):368-71.

52. Chiapponi C, Faccini S, Mattia A de, Baioni L, Barbieri I, Rosignoli C. Detection of influenza D virus among swine and cattle, Italy [letter]. Emerg Infect Dis. 2016;22(2):352-4.

53. Sreenivasan C, Thomas M, Sheng Z, Hause BM, Collin EA, Knudsen DEB, et al. Replication and transmission of novel bovine influenza $D$ virus in guinea pig model. J Virol. 2015;89(23):11990-2001.

54. Ferguson L, Olivier A, Genova S, Epperson WB, Smith D, Schneider L, et al. Pathogenesis of Influenza D viurs in Cattle. J Virol. 2016;90(8):03122-15.

55. Ilyushina N a, Khalenkov AM, Seiler JP, Forrest HL, Bovin N V, Marjuki H, et al. Adaptation of pandemic H1N1 influenza viruses in mice. J Virol. 2010;84(17):8607-16.

56. Reed LJ, Muench H. A simple method of estimating fifty per cent endpoints. Am J Epidemiol. 1938;27(3):493-7.

57. Webster R, Cox N, Stohr K. WHO Manual on Animal Influenza Diagnosis and Surveillance. WHO Global Influenza Programme. Geneva: World Health Organization; 2002. 1-105 p. 
58. Ilyushina N a, Ikizler MR, Kawaoka Y, Rudenko LG, Treanor JJ, Subbarao K, et al. Comparative study of influenza virus replication in MDCK cells and in primary cells derived from adenoids and airway epithelium. J Virol. 2012;86(21):1172534.

59. Pachler K, Mayr J, Vlasak R. A seven plasmid-based system for the rescue of influenza C virus. J Mol Genet Med. 2010;4:239-46.

60. Baker SF, Nogales A, Finch C, Tuffy KM, Domm W, Perez DR, et al. Influenza A and $\mathrm{B}$ virus intertypic reassortment through compatible viral packaging signals. $\mathrm{J}$ Virol. 2014;88(18):10778-91.

61. Gerlach RL, Camp J V, Chu Y-K, Jonsson CB. Early host responses of seasonal and pandemic influenza A viruses in primary well-differentiated human lung epithelial cells. PLoS One. 2013;8(11):e78912. doi:10.1371/journal.pone.0078912.

62. Chan RWY, Yuen KM, Yu WCL, Ho CCC, Nicholls JM, Peiris JSM, et al. Influenza $\mathrm{H} 5 \mathrm{~N} 1$ and $\mathrm{H} 1 \mathrm{~N} 1$ virus replication and innate immune responses in bronchial epithelial cells are influenced by the state of differentiation. PLoS One. 2010;5(1):e8713. doi:10.1371/journal.pone.0008713.

63. Belser JA, Katz JM, Tumpey TM. The ferret as a model organism to study influenza A virus infection. Dis Model Mech. 2011;579:575-9.

64. Zeng H, Goldsmith CS, Maines TR, Belser J a, Gustin KM, Pekosz A, et al. Tropism and infectivity of influenza virus, including highly pathogenic avian H5N1 virus, in ferret tracheal differentiated primary epithelial cell cultures. J Virol. 2013;87(5):2597-607.

65. Jayaraman A, Chandrasekaran A, Viswanathan K, Raman R, Fox JG, Sasisekharan R. Decoding the distribution of glycan receptors for human-adapted influenza A viruses in ferret respiratory tract. PLoS One. 2012;7(2):e27517. doi:10.1371/journal.pone.0027517.

66. Neumann G, Kawaoka Y. Host range restriction and pathogenicity in the context of influenza pandemic. Emerg Infect Dis. 2006;12(6):881-6.

67. Baigent SJ, Mccauley JW. Influenza type A in humans, mammals and birds: determinants of virus virulence, host-range and interspecies transmission. BioEssays. 2003;25:657-71.

68. Kuiken T, Holmes EC, McCauley J, Rimmerlzwaan GF, Williams CS, Grenfell BT. Host species barriers to influenza virus infections. Science. 2006;312:394-7. 
69. Galloway SE, Reed ML, Russell CJ, Steinhauer DA. Influenza HA subtypes demonstrate divergent phenotypes for cleavage activation and $\mathrm{pH}$ of fusion: implications for host range and adaptation. Plos Pathog. 2013;9(2):e1003151. doi:10.1371/journal.ppat.1003151.

70. Stieneke-grober A, Vey M, Shawl E, Thomas G, Roberts C, Kienk H, et al. Influenza virus hemagglutinin with multibasic cleavage site is activated by furin, a subtilisin-like endoprotease. EMBO J. 1992;1(7):2407-14.

71. Song H, Qi J, Khedri Z, Diaz S, Yu H, Chen X, et al. An open receptor-binding cavity of hemagglutinin-esterase-fusion glycoprotein from newly-identified influenza D virus : basis for its broad cell tropism. PLoS Pathog. 2016;12(1):e1005411. doi:10.1371/journal.ppat.1005411.

72. Nicholls JM, Bourne AJ, Chen H, Guan Y, Peiris JSM. Sialic acid receptor detection in the human respiratory tract: evidence for widespread distribution of potential binding sites for human and avian influenza viruses. Respir Res. 2007;8:73-83.

73. Trebbien R, Larsen LE, Viuff BM. Distribution of sialic acid receptors and influenza A virus of avian and swine origin in experimentally infected pigs. Virol J. 2011;8(1):434.

74. Suzuki Y, Ito T, Suzuki T, Holland RE, Chambers TM, Kiso M, et al. Sialic acid species as a determinant of the host range of influenza A viruses. J Virol. 2000;74(24):11825-31.

75. Kuchipudi S V, Nelli R, White G a, Bain M, Chang KC, Dunham S. Differences in influenza virus receptors in chickens and ducks: implications for interspecies transmission. J Mol Genet Med. 2009;3(1):143-51.

76. Liao H-Y, Hsu C-H, Wang S-C, Liang C-H, Yen H-Y, Su C-Y, et al. Differential receptor binding affinities of influenza hemagglutinins on glycan arrays. J Am Chem Soc. 2010;132(42):14849-56.

77. Pleschka S, Klenk HD, Herrler G. The catalytic triad of the influenza C virus glycoprotein HEF esterase: characterization by site-directed mutagenesis and functional analysis. J Gen Virol. 1995;76:2529-37.

78. Pekosz A, Lamb RA. Cell surface expression of biologically active influenza C virus HEF glycoprotein expressed from cDNA. J Virol. 1999;73(10):8808-12.

79. Rosenthal PB, Zhang X, Formanowski F, Fitz W, Wong C-H, Meier-Ewert H, et al. Structure of the haemagglutinin-esterase fusion glycoprotein of influenza $\mathrm{C}$ virus. Nature. 1998;396:92-6. 
80. Vlasak R, Luytjes W, Spaan W, Palese P. Human and bovine coronaviruses recognize sialic acid-containing receptors similar to those of influenza $\mathrm{C}$ viruses. Proc Natl Acad Sci U S A. 1988;85(12):4526-9.

81. Klausegger A, Strobl B, Regl G, Kaser A, Luytjes W, Vlasak R. Identification of a coronavirus hemagglutinin-esterase with a substrate specificity different from those of influenza C virus and bovine coronavirus. J Virol. 1999;73(5):3737-43.

82. Schultze B, Gross HJ, Brossmer R, Herrler G. The S protein of bovine coronavirus is a hemagglutinin recognizing 9-O-acetylated sialic acid as a receptor determinant. J Virol. 1991;65(11):6232-7.

83. Zimmer G, Reuter G, Schauer R. Use of influenza C virus for detection of 9-Oacetylated sialic acids on immobilized glycoconjugates by esterase activity. Eur $\mathrm{J}$ Biochem. 1992;204(1):209-15.

84. Reed ML, Bridges OA, Seiler P, Kim J, Yen H, Salomon R, et al. The pH of activation of the hemagglutinin protein regulates H5N1 influenza virus pathogenicity and transmissibility in ducks. J Virol. 2010;84(3):1527-35.

85. Reed ML, Yen H, Dubois RM, Bridges OA, Salomon R, Webster RG, et al. Amino acid residues in the fusion peptide pocket regulate the $\mathrm{pH}$ of activation of the H5N1 influenza virus hemagglutinin protein. J Virol. 2009;83(8):3568-80.

86. Formanowski F, Wharton S a, Calder LJ, Hofbauer C, Meier-Ewert H. Fusion characteristics of influenza C viruses. J Gen Virol. 1990;71:1181-8.

87. Scull MA, Gillim-ross L, Santos C, Roberts KL, Bordonali E, Barclay WS, et al. Avian influenza virus glycoproteins restrict virus replication and spread through human airway epithelium at temperatures of the proximal airways. PLoS Pathog. 2009;5(5):e1000424. doi:10.1371/journal.ppat.1000424.

88. Takashita E, Muraki Y, Sugawara K, Asao H, Nishimura H, Suzuki K, et al. Intrinsic temperature sensitivity of influenza $\mathrm{C}$ virus hemagglutinin-esterase-fusion protein. J Virol. 2012;86(23):13108-11.

89. Guo $\mathrm{Y}$, Jin $\mathrm{F}$, Wang $\mathrm{P}$, Wang $\mathrm{M}$, Zhu J. Isolation of influenza $\mathrm{C}$ virus from pigs and experimental infection of pigs with influenza C virus. J Gen Virol. 1983;64(1983):177-82.

90. Marsh GA, Rabadan R, Levine AJ, Palese P. Highly conserved regions of influenza A virus polymerase gene segments are critical for efficient viral RNA packaging. J Virol. 2008;82(5):2295-304. 
91. Li C, Hatta M, Watanabe S, Neumann G, Kawaoka Y. Compatibility among polymerase subunit proteins is a restricting factor in reassortment between equine H7N7 and human H3N2 influenza viruses. J Virol. 2017;82(23):11880-8.

92. Downie JC. Reassortment of influenza A virus genes linked to PB1 polymerase gene. Int Congr Ser. 2004;1263:714-8.

93. Rabadan R, Levine AJ, Krasnitz M. Non-random reassortment in human influenza A viruses. Influenza Other Respi Viruses. 2008;2:9-22.

94. Xu X, Smith CB, Mungall BA, Lindstrom SE, Hall HE, Subbarao K, et al. Intercontinental circulation of human influenza A (H1N2) reassortant viruses during the 2001 - 2002 influenza season. J Infect Dis. 2002;186:1490-3.

95. Tao H, Steel J, Lowen AC. Intrahost dynamics of influenza virus reassortment. J Virol. 2014;88(13):7485-92.

96. Wei C-J, Boyington JC, McTamney PM, Kong W-P, Pearce MB, Xu L, et al. Induction of broadly neutralizing $\mathrm{H} 1 \mathrm{~N} 1$ influenza antibodies by vaccination. Science. 2010;329(5995):1060-4.

97. Eichelberger MC, Wan H. Influenza Neuraminidase as a Vaccine Antigen. Curr Top Microbiol Immunol. 2015;386:275-99.

98. Wohlbold TJ, Nachbagauer R, Xu H, Tan GS, Hirsh A, Brokstad KA, et al. Vaccination with adjuvanted recombinant neuraminidase induces broad heterologous, but not heterosubtypic , cross-protection against influenza virus infection in mice. MBio. 2015;6(2):1-13.

99. Brindley MA, Maury W. Endocytosis and a low-pH atep are required for productive entry of equine infectious anemia virus. J Virol. 2005;79(23):14482-8.

100. Dimitrov DS. Virus entry: molecular mechanisms and biomedical applications. Nat Rev Microbiol. 2004;2:109-22.

101. Cosset F-L, Lavillette D. Cell Entry of Enveloped Viruses. Advances in Genetics. Elsevier; 2011. p. 121-83.

102. Ohigashi Y, Ma C, Jing X, Balannick V, Pinto LH, Lamb RA. An amantadinesensitive chimeric BM2 ion channel of influenza B virus has implications for the mechanism of drug inhibition. PNAS. 2009;106(44):18775-9.

103. Bar S, Takada A, Kawaoka Y, Alizon M. Detection of cell-cell fusion mediated by ebola virus glycoproteins. J Virol. 2006;80(6):2815-22. 
104. Misasi J, Chandran K, Yang J, Considine B, Filone M, Côté M, et al. Filoviruses require endosomal cysteine proteases for entry but exhibit distinct protease preferences. J Virol. 2012;86:3284-92.

105. Kirchhausen T, Macia E, Pelish HE. Use of dynasore, the small molecule inhibitor of dynamin, in the regulation of endocytosis. Methods Enzymol. 2008;438(07):7793.

106. Peng GE, Wilson SR, Weiner OD. A pharmacological cocktail for arresting actin dynamics in living cells. Mol Biol Cell. 2011;22:3986-94.

107. Roberts KL, Manicassamy B, Lamb RA. Influenza A virus uses intercellular connections to spread to neighboring cells. J Virol. 2015;89(3):1537-49. 


\section{VITA}

Laura Evelyn Lasiter was born in 1984 and obtained her diploma from Cedars of Lebanon Academy, McMinnville, TN in 2002. She then matriculated at Middle Tennessee State University in Murfreesboro, TN where she participated in several research projects including the effectiveness of a novel antibiocidal delivery system, the flavonoid composition of wine produced by various yeast strains, and creation of a Raman polyphenol library. After receiving a dual Bachelor's of Science in Biology and Chemistry in 2006, she completed a summer research fellowship at Oak Ridge National Laboratory continued her education at Middle Tennessee State University as a Master's of Science candidate. In 2010, she began her doctoral education at the University of Tennessee Health Science Center in Memphis, TN and later joined laboratory of Dr. Richard Webby at St. Jude Children's Research Hospital where she conducted research on influenza $\mathrm{C}$ viruses and a novel influenza $\mathrm{C}$-like virus. Laura received a doctoral degree with a concentration in microbial pathogenesis, immunology, and inflammation after completion of her defense in 2016. 